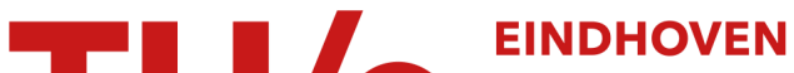 \\ UNIVERSITY OF \\ TECHNOLOGY
}

\section{Surface science approach to modeling supported catalysts}

Citation for published version (APA):

Gunter, P. L. J., Niemantsverdriet, J. W., Ribeiro, F. H., \& Somorjai, G. A. (1997). Surface science approach to modeling supported catalysts. Catalysis Reviews : Science and Engineering, 39(1-2), 77-168.

https://doi.org/10.1080/01614949708006469

DOI:

10.1080/01614949708006469

Document status and date:

Published: 01/01/1997

\section{Document Version:}

Publisher's PDF, also known as Version of Record (includes final page, issue and volume numbers)

\section{Please check the document version of this publication:}

- A submitted manuscript is the version of the article upon submission and before peer-review. There can be important differences between the submitted version and the official published version of record. People interested in the research are advised to contact the author for the final version of the publication, or visit the $\mathrm{DOI}$ to the publisher's website.

- The final author version and the galley proof are versions of the publication after peer review.

- The final published version features the final layout of the paper including the volume, issue and page numbers.

Link to publication

\section{General rights}

Copyright and moral rights for the publications made accessible in the public portal are retained by the authors and/or other copyright owners and it is a condition of accessing publications that users recognise and abide by the legal requirements associated with these rights.

- Users may download and print one copy of any publication from the public portal for the purpose of private study or research.

- You may not further distribute the material or use it for any profit-making activity or commercial gain

- You may freely distribute the URL identifying the publication in the public portal.

If the publication is distributed under the terms of Article 25fa of the Dutch Copyright Act, indicated by the "Taverne" license above, please follow below link for the End User Agreement:

www.tue.nl/taverne

Take down policy

If you believe that this document breaches copyright please contact us at:

openaccess@tue.nl

providing details and we will investigate your claim. 


\section{Surface Science Approach to Modeling Supported Catalysts}

PIETER L. J. GUNTER and J. W. (HANS) NIEMANTSVERDRIET*

Schuit Institute of Catalysis

Eindhoven University of Technology

5600 MB Eindhoven, The Netherlands

\section{FABIO H. RIBEIRO}

E. O. Lawrence Berkeley National Laboratory

Materials Sciences Division

1 Cyclotron Rd., MS 66-200

Berkeley, California 94720, USA

\section{GABOR A. SOMORJAI}

Department of Chemistry

University of California at Berkeley

Berkeley, California 94720, USA

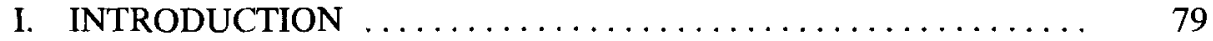

II. THE "SPECTRUM" OF MODEL CATALYSTS ........... 82

III. CHARACTERIZATION TOOLS $\ldots \ldots \ldots \ldots \ldots \ldots \ldots \ldots \ldots \ldots$

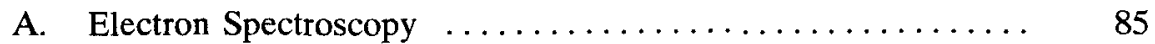

B. Electron Microscopy ................... 88

*To whom correspondence should be sent: Schuit Institute of Catalysis, Eindhoven University of Technology, PO Box 513, 5600 MB Eindhoven, The Netherlands. Fax: +3140 2455054; E-mail: tgtahn@chem.tue.nl 
C. Ion Spectroscopy $\ldots \ldots \ldots \ldots \ldots \ldots \ldots \ldots \ldots \ldots \ldots \ldots . \ldots \ldots$

D. Vibrational Spectroscopy $\ldots \ldots \ldots \ldots \ldots \ldots \ldots \ldots \ldots \ldots . \ldots 1$

E. Scanning Probe Microscopy $\ldots \ldots \ldots \ldots \ldots \ldots \ldots \ldots \ldots . \ldots \ldots$

F. Temperature-Programmed Methods $\ldots \ldots \ldots \ldots \ldots \ldots \ldots . \ldots 2$

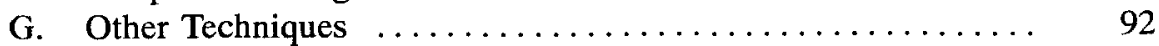

H. Reactors for Model Catalysts $\ldots \ldots \ldots \ldots \ldots \ldots \ldots \ldots \ldots . \ldots 2$

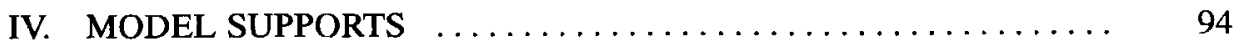

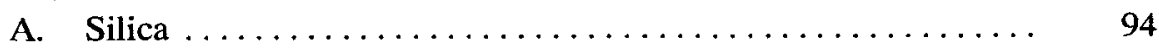

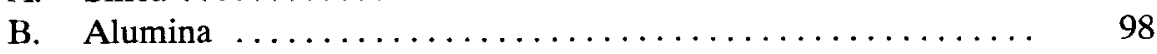

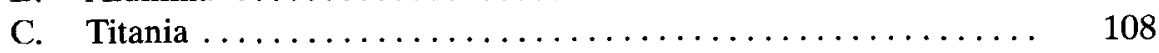

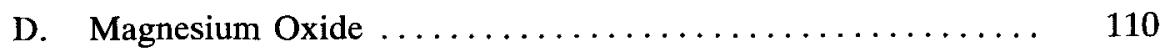

E. Zinc Oxide ............................... 111

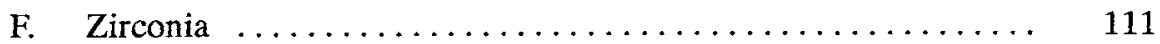

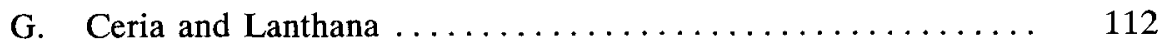

H. Mica ............................... 112

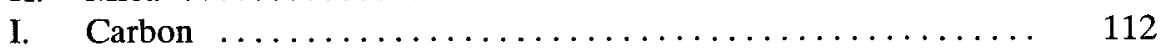

V. SYNTHESIS OF CATALYSTS ON MODEL SUPPORTS . . . . 113

A. Deposition of Metals by Evaporation ............. 114

B. Preparation of Model Catalysts by Chemical Vapor

C. Wet Chemical Impregnation of Model Supports ......... 118

D. Microfabricated Model Catalysts: Lithography .......... 122

E. Concluding Remarks on Catalyst Preparation ........... 124

VI. PARTICLES ON MODEL SUPPORTS IN CATALYSIS

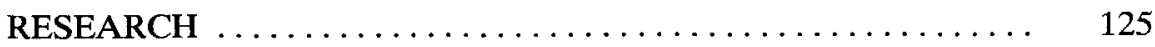

A. Structure of Supported Particles $\ldots \ldots \ldots \ldots \ldots \ldots \ldots \ldots \ldots . \ldots \ldots$

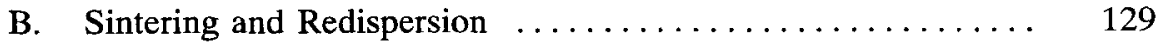

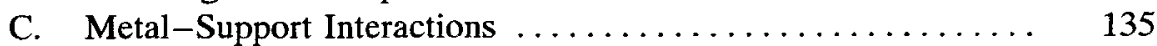

D. Studies of Catalyst Preparation Using Model Systems ...... 140

E. Adsorption and Desorption on Model Metal-Support

F. Catalytic Reactions on Model Metal-Support Systems ...... 149

VII. CONCLUDING REMARKS ................... 154

ACKNOWLEDGMENT $\ldots \ldots \ldots \ldots \ldots \ldots \ldots \ldots \ldots \ldots \ldots \ldots \ldots \ldots$

REFERENCES ............................. 156

Key Words: Catalysis; Heterogeneous catalyst; Model catalyst; Model support.

\begin{abstract}
Nanoscale structural information underlies research aimed at fabricating catalysts in a more controlled way. Surface science methods can provide that information, but the complexity of heterogeneous systems in general hinders
\end{abstract}


the application of these methods to their full potential. In the last decades, a solution to this problem has been found in the use of model systems, ranging from well-defined single crystals of the supported phase to films or particles of that phase on flat or spherical model supports. In this paper, we review the literature on the latter model systems, that is, particles on a model support. Attention is payed to both preparation and use of such model systems.

\section{INTRODUCTION}

In order to develop new generations of catalysts with superior properties, it is essential to obtain control over the bonding of particles on the support, their size, structure, composition, and spatial distribution, on the smallest possible length scale. At present, it is the lack of tools for characterizing supported catalysts on a local basis that seriously impedes research aimed at fabricating catalysts in a more controlled way.

The last decades have seen a tremendous evolution in surface-sensitive methods which provide atomic-level information on structure, composition, oxidation state, some even combined with high spatial and temporal resolution. We mention monochromatic XPS, static SIMS, ion scattering, STM/ AFM, Auger depth profiling and imaging as tools to study structure and composition of the surface; and vibrational spectroscopies (HREELS, RAIRS), UPS, and temperature-programmed desorption, reaction and SIMS for the study of adsorbed species and their reactivity [1-5] (Table 3, p. 86).

However, catalysts usually consist of small particles hidden inside the pores of a support, inhibiting the application of, for example, EELS, STM and AFM. Moreover, oxidic supports are electrically insulating, which leads to serious loss of intensity and/or resolution in techniques such as XPS, SIMS, AES and ISS, implying that much, in principle extremely relevant, information on the surface state of a catalyst cannot be obtained. Thus, one has to resort to models in order to do surface science on catalysts.

Up to now model studies in catalysis usually employed single crystals of metals, or thin films of metals or oxides grown epitaxially on other model crystal surfaces. Their success has been outstanding in identifying many of the molecular ingredients of important catalytic reactions [4,6,7]. Table 1 lists the reactions and the surfaces that were investigated in this fashion. The drawback has been that usually the catalyst support was not a part of the catalyst system, and that the extrapolation to catalyst-support systems used in most technologies has not been possible. While they were proven to be good catalysts, the large difference between their morphology and that of the industrial catalysts limited their utility to guide the improvement in the fabrication of the high surface area catalyst systems.

The solution is to employ model systems which incorporate a support but still allow the use of all those methods from surface science that have 
been so outstandingly successful in combination with single crystals. Because the expression "model catalyst" has been used in many different contexts, it is essential to clearly define the type of model system that are described in this paper: We limit ourselves to models for supported catalysts, designed

TABLE 1

Partial List of Catalytic Reactions Studied with Large Single Crystals at a High Pressure ( $>1$ torr)

\begin{tabular}{|c|c|c|}
\hline Substrate & Reactions & Promoters \\
\hline \multirow[t]{2}{*}{$\mathrm{Fe}$} & Ammonia synthesis $[287,288]$ & $\mathrm{Al}[289], \mathrm{K}[290,291], \mathrm{Al}$ and \\
\hline & CO hydrogenation [292] & $\mathrm{K}[290,291]$ \\
\hline $\mathrm{Co}$ & CO methanation $[293,294]$ & \\
\hline \multirow[t]{2}{*}{$\mathrm{Ni}$} & CO methanation [295] & S [296], C [295], K [297] \\
\hline & $\begin{array}{l}\text { Reactions with hydrocarbons and } \mathbf{H}_{2} \\
\text { [298] }\end{array}$ & \\
\hline \multirow[t]{2}{*}{$\mathrm{Cu}$} & Water-gas shift $[299,300]$ & $\begin{array}{l}\mathrm{ZnO}_{x}[299], \mathrm{S}[301] \\
\quad \mathrm{Ce}[300]\end{array}$ \\
\hline & Methanol synthesis [302] & $\mathrm{ZnO}[175]$ \\
\hline \multirow[t]{2}{*}{ Mo } & $\begin{array}{l}\text { Hydrodesulfurization of thiophene } \\
\text { [303] }\end{array}$ & $\begin{array}{l}\text { S }[304], \text { Co }[305,306] \\
\quad C[307,308]\end{array}$ \\
\hline & CO methanation [309] & \\
\hline \multirow[t]{3}{*}{ Ru } & CO methanation [295] & C [295] \\
\hline & CO oxidation $[310]$ & \\
\hline & $\begin{array}{l}\text { Reactions with hydrocarbons and } \mathrm{H}_{2} \\
\text { [311] }\end{array}$ & $S[311]$ \\
\hline \multirow[t]{3}{*}{$\mathrm{Rh}$} & CO hydrogenation [312] & \\
\hline & CO oxidation $[313]$ & \\
\hline & $\begin{array}{l}\text { Reactions with hydrocarbons and } \mathbf{H}_{2} \\
\text { [314] }\end{array}$ & \\
\hline \multirow[t]{2}{*}{ Pd } & CO oxidation $[315]$ & \\
\hline & Methanol synthesis [316] & \\
\hline $\mathrm{Ag}$ & Ethylene epoxidation [317] & $\mathrm{Cl}[318], \mathrm{Cs}[319]$ \\
\hline \multirow[t]{2}{*}{ W } & $\begin{array}{l}\text { Reactions with hydrocarbons and } \mathrm{H}_{2} \\
\text { [320] }\end{array}$ & \\
\hline & $\mathrm{CO}$ methanation $[321]$ & \\
\hline \multirow[t]{2}{*}{$\operatorname{Re}$} & $\begin{array}{l}\text { Reactions with hydrocarbons and } \mathrm{H}_{2} \\
\text { Ammonia synthesis [324] }\end{array}$ & Pt [322], Pt and S [323] \\
\hline & $\begin{array}{l}\text { Hydrodesulfurization of thiophene } \\
{[325,326]}\end{array}$ & \\
\hline \multirow[t]{2}{*}{$\mathrm{Ir}$} & $\begin{array}{l}\text { Reactions with hydrocarbons and } \mathrm{H}_{2} \\
\text { [327] }\end{array}$ & \\
\hline & $\mathrm{CO}$ oxidation $[315]$ & \\
\hline \multirow[t]{2}{*}{ Pt } & $\begin{array}{l}\text { Reactions with hydrocarbons and } \mathrm{H}_{2} \\
{[328-330]}\end{array}$ & $\begin{array}{l}\operatorname{Re}[322], \operatorname{Re} \text { and } S[323] \\
\quad K[331,332]\end{array}$ \\
\hline & $\mathrm{CO}$ oxidation $[315]$ & $\mathrm{Au}[333,334]$ \\
\hline
\end{tabular}


Surface science model

of a supported catalyst

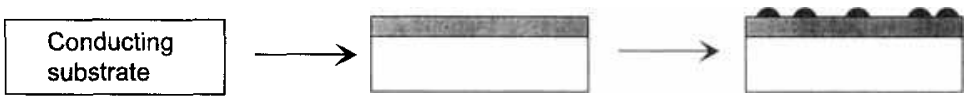

FIG. 1. Surface science model of a supported catalyst, consisting of particles supported by a thin oxide on a flat, conducting substrate so that they can be studied by almost all surface spectroscopies.

with the objective that surface science methods can be applied to study them. The strategy would be to deposit thin films of oxide or carbon on an inert, conducting substrate, such as gold or silicon. In this way serious charging is avoided, even if the thin film support is an insulator. Finally, catalyst particles are deposited on this support. A scheme of this procedure is shown in Fig. 1. These flat supports with the catalytic particles on top offer full access to surface spectroscopies and present the additional advantage that one degree of freedom, the $z$ coordinate, is resolved. Several types of these model supports can be envisaged:

- Single crystal oxides have the advantage that the surface structure of the support is defined, although the lack of electrical conductivity may still cause charging phenomena.

- Thin film oxides on conducting substrates - for example, $\mathrm{SiO}_{2}$ layers on silicon, or $\mathrm{Al}_{2} \mathrm{O}_{3}$ layers on a refractory metal substrate-offer the advantage of electrical conductivity for the ion and electron spectroscopies, such that techniques as XPS, AES, and SIMS can be used at their optimum resolution. Thin oxides can also be applied as transparent supports for HRTEM studies, when special preparation procedures are applied (described later in this review).

- Graphite also offers the advantage of electrical conductivity and is in fact the preferred substrate for STM studies of small particles.

The challenge in devising model catalysts is to develop techniques for the preparation of particles with definition with respect to size and morphology, on flat, oxidic substrates which are suitable for studying fundamental issues from catalysis (such as structure-activity relationships, particle size effects) as well as addressing practical questions from the field of catalyst preparation. Both applications ask for information on the smallest conceivable detail, that is, on the subnanometer scale.

Several ways exist to apply particles onto these model supports. By far the most popular way has been to deposit metals by evaporation. Loading and particle size can to some extent be controlled by means of the exposure time and the substrate temperature. The disadvantage is that particle size distributions tend to be rather broad. Soft landing of mass selected metal clusters from a beam of particles may be a way around this, but this has only 
incidentally been employed so far. A second method is to deposit the active phase by chemical vapor deposition, as has been done with organorhodium, osmium, and rhenium compounds. The third method is to apply the catalyst precursor via wet chemical techniques, followed by drying and reduction steps. This procedure comes very close to the industrial practice of catalyst preparation and offers additional opportunities to study catalyst preparation on the model scale.

Particles on model supports have successfully been applied to study effects of particle size on the adsorption and desorption of gases, and on the catalytic activity and selectivity, and also to investigate possible roles of the support in adsorption and catalysis. Only a few review papers exist on supported model catalysts. We mention those of Poppa on particle growth phenomena [8], of Kroeker and Hansma on the use of inelastic tunneling spectroscopy [9], and of Bartholomew on catalyst deactivation [10]. Raupp et al. [11] and Goodman [12] presented reviews with a wider scope. The purpose of this paper is to review the literature on model catalysts and to identify their unique properties for studies in fundamental catalysis. As said before, we limit ourselves to models for supported catalysts, that is, particles on oxide or carbon substrates.

\section{THE "SPECTRUM" OF MODEL CATALYSTS}

The term "modeling" usually implies that a realistic, often complex catalyst is imitated by means of a simplified system. Indeed, several possibilities can be envisaged between the industrially applied catalyst in all its complexity and the well-defined single crystal surface where we know where every atom is supposed to be. Figure 2 shows two intermediate cases along with the extremes. Table 2 contains a list of models for a supported catalyst and indicates some unique opportunities for characterization studies.

On the complex end of the spectrum is the industrially applied supported catalyst, often consisting of a high surface area carrier, one or more catalytically active materials, and chemical and structural promoters. Examples are
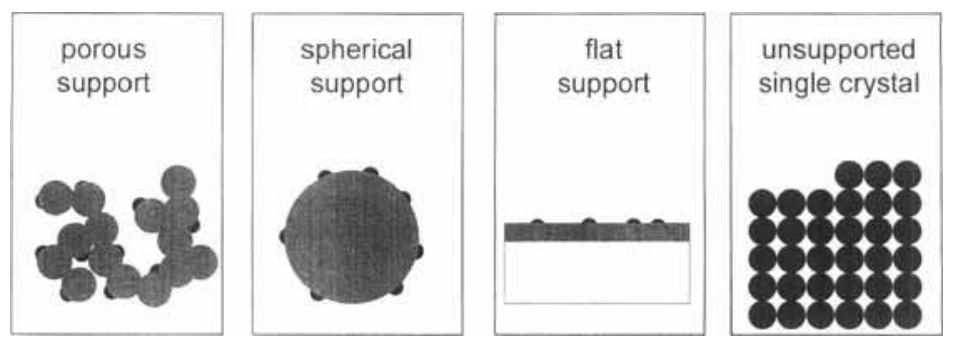

FIG. 2. Several possibilities for modeling catalysts exist between the industrial system with a high surface area, porous support (left) and the surface of a single crystal (right). 
TABLE 2

Model Systems Between the High Surface Area Supported Catalyst As Used in Industry, an Surface Science

\begin{tabular}{|c|c|c|}
\hline System & Example(s) & $\begin{array}{l}\text { Unique opportuni } \\
\text { characterizati }\end{array}$ \\
\hline $\begin{array}{l}\text { Catalyst on nonporous spherical } \\
\text { support }\end{array}$ & Rh on $\mathrm{SiO}_{2}$ spheres & $\begin{array}{l}\text { Electron microscopy } \\
\text { reaction studies }\end{array}$ \\
\hline \multirow{2}{*}{$\begin{array}{l}\text { Catalyst on a conducting, flat, thin } \\
\text { film oxide support }\end{array}$} & $\mathrm{MoO}_{3} / \mathrm{SiO}_{2} / \mathrm{Si}(100)$ & Electron and ion spec \\
\hline & $\mathrm{Rh} / \gamma-\mathrm{Al}_{2} \mathrm{O}_{3} / \mathrm{Mo}(110)$ & $\begin{array}{l}\text { Reflection absorption } \\
\text { spectroscopy, therm } \\
\text { desorption }\end{array}$ \\
\hline Catalyst evaporated on a single & $\mathrm{Pd} / \mathrm{MgO}(100)$ & Thermal desorption, $s$ \\
\hline crystal oxide & $\mathrm{Pt} / \alpha-\mathrm{Al}_{2} \mathrm{O}_{3}$ & studies \\
\hline Catalyst applied on planar graphite & Pt/graphite & Scanning tunneling $\mathrm{m}$ \\
\hline
\end{tabular}


the three-way catalyst with $\mathrm{Pt}$ and $\mathrm{Rh}$ as the active metals and $\mathrm{CeO}_{2}$ as a promoter on a monolithic support; or the acrylonitrile catalyst, based on iron-antimony oxide and containing a host of chemical and structural promoters among which are $\mathrm{SiO}_{2}, \mathrm{MoO}_{3}, \mathrm{CuO}, \mathrm{Te}$, and $\mathrm{K}$. The use of any type of spectroscopic characterization tool (and of surface-sensitive techniques in particular) is often difficult, if not for the experiment itself then certainly so with respect to interpretation. The first level of simplification would be to leave out all the promoters and study, for example, a monometallic catalyst, such as $\mathrm{Pt} / \gamma-\mathrm{Al}_{2} \mathrm{O}_{3}$. This type of catalyst is very well suited for reaction kinetic studies and for spectroscopic characterization by, for example, transmission infrared, Raman and x-ray absorption spectroscopy (EXAFS), but it is still unsuitable for surface science.

The first step towards a model system is to replace the porous support by a spherical one. This type of model system has proven valuable in studying particle morphology and metal-support interaction by transmission electron microscopy. Examples are studies of Rh particles on $\mathrm{SiO}_{2}$ spheres [13] and $\mathrm{Pd}$ on $\mathrm{Al}_{2} \mathrm{O}_{3}$ spheres [14].

In order to use surface-sensitive techniques based on the detection of electrons and ions with their small mean free paths, it has proven useful to apply particles on a flat support, which represents the next level of simplification. If the support is an oxide film with thickness between 0.5 and $5 \mathrm{~nm}$ on a conducting substrate, the system possesses sufficient conductivity to avoid the detrimental charging phenomena that seriously degrade the resolution in XPS of catalysts on high surface area supports. Catalysts on flat model supports are usually prepared by evaporating the active phase onto the support $[8,11,12]$. However, they can also be prepared via the same wet chemical impregnation procedures that are used in the manufacturing of technical catalysts. Model systems prepared in this way may fairly well represent the solid-state chemical properties of the technical catalysts [15-19].

Model catalysts on flat supports are also ideally suited for adsorption/ desorption studies in ultrahigh vacuum, as complications due to diffusion limitation are absent on flat systems [20]. The result is that thermal desorption spectra of flat model systems are much sharper and much easier to interpret than those of catalysts on conventional supports. The most extreme degree of simplification is to model a catalyst by means of a polycrystalline foil or a single crystal. Although far from a technical catalyst, the single crystal is nevertheless the system of choice for investigating the influence of the atomic arrangement of a surface on adsorption and catalytic reactivity [6].

Of course, approaches other than those based on the systems in Fig. 2 and Table 2 can be and have been taken. For example, organometallic complexes may be used to mimic aspects of metal-adsorbate interactions, or of the structure of oxidic and sulfidic catalysts. Clusters in theoretical calculations represent yet another model approach; this is outside the scope of this review, however.

It should be noted that in principle two strategies are conceivable for 
modeling a supported catalyst. One can start from the complex case of the technical catalyst and leave out features to make it simpler. One can also start from the simplest case, the single crystal, and add features to make it more complex. Hence, Fig. 2 can be read either from left to right, corresponding to increased simplification; or from right to left, implying that increasing complexity is added to an initially well defined single crystal. The two approaches will not necessarily result in the same type of model for a particle on a thin film support, or example: In the "simplification" strategy, for example, one might choose to apply the catalytically active phase by wet chemical impregnation, to retain important features from the industrial practices of catalyst preparation in the model. In the "added complexity" philosophy, on the other hand, one may prefer to start with a single crystal support on which the thin film support and next the catalytically active particles are applied by evaporation in ultrahigh vacuum.

Whether one prefers simplifying a complex system or building complexity into a simple system as the strategy, testing of the model system in a catalytic reaction should be a key issue of the investigation. This is the most straightforward test for the validity of the model catalyst and is absolutely required for maintaining credibility within the catalysis community.

\section{CHARACTERIZATION TOOLS}

The purpose of this section is to indicate the potential that several characterization techniques have for studying supported model catalysts. Table 3 gives an overview of the available methods. We do not intend to explain the theory of these techniques; the reader is referred to several textbooks on the subject $[1-3,5,21,22]$. Furthermore, we briefly discuss catalytic reactors that can be used to test the activity of the model catalysts.

\section{A. Electron Spectroscopy}

The use of thin film oxide supports on conducting substrates is extremely beneficial for the application of photoelectron and Auger spectroscopy, as charging is largely circumvented. Although charge shifts can in principle be determined and corrected by measuring the binding energy of an internal reference such as impurity carbon, differential charging is often hard to avoid, and this is the main cause of poor resolution in XPS spectra of high surface area catalysts. Charging is even more severe in electron-excited Auger spectroscopy and usually precludes the application of this method on supported catalysts at all.

Note, however, that charging, although limited to a few tenths of an electron volt, is not entirely absent in particles on thin film oxide supports. Moreover, the layered structure implies that charging builds up gradually to the outside, which makes correction very difficult. In practice, the supported 
TABLE 3

The Most Common Characterization Techniques in the Study of Flat Model Catalysts

\begin{tabular}{|c|c|}
\hline Acronym & Full name and most important information \\
\hline AES & $\begin{array}{l}\text { Auger electron spectroscopy } \\
\text { - Elemental surface composition } \\
\text { - Depth profiling }\end{array}$ \\
\hline AFM/SFM & $\begin{array}{l}\text { Atomic force microscopy (scanning force microscopy) } \\
\text { - Nanometer-scale morphology of surfaces } \\
\text { - Not limited to conducting systems }\end{array}$ \\
\hline CEMS & $\begin{array}{l}\text { Conversion electron Mössbauer spectroscopy } \\
\text { - Oxidation state, lattice symmetry, and magnetism of } \\
\text { Mössbauer elements } \\
\text { - Limited in practice to iron }\end{array}$ \\
\hline EELS & $\begin{array}{l}\text { Electron energy loss spectroscopy } \\
\text { - Vibrational characterization of adsorbed species } \\
\text { - Identification of adsorbed intermediates } \\
\text { - Electronic information on oxidic model supports and supported } \\
\text { phases }\end{array}$ \\
\hline EXAFS & $\begin{array}{l}\text { Extended x-ray absorption fine structure } \\
\text { - Atomic-scale structure information } \\
\text { - Only applicable in reflection or fluorescence modes }\end{array}$ \\
\hline IETS & $\begin{array}{l}\text { Inelastic electron tunneling spectroscopy } \\
\text { - Vibrational information of adsorbed phases } \\
\text { - Disadvantage that a counterelectrode covers the surface }\end{array}$ \\
\hline LEIS & $\begin{array}{l}\text { Low-energy ion scattering } \\
\text { - Quantitative determination of outer layer composition }\end{array}$ \\
\hline RAIRS & $\begin{array}{l}\text { Reflection absorption infrared spectroscopy } \\
\text { - Vibrational characterization of adsorbed species } \\
\text { - Studies under reaction conditions } \\
\text { - Kinetics of surface reactions } \\
\text { - Applicable if oxide support is thin layer on a metal substrate }\end{array}$ \\
\hline RBS & $\begin{array}{l}\text { Rutherford backscattering spectrometry } \\
\text { - Quantitative analysis of supported particle concentrations } \\
\text { - Structural information from channeling phenomena }\end{array}$ \\
\hline SIMS & $\begin{array}{l}\text { Secondary ion mass spectrometry } \\
\text { - Qualitative information on surface composition } \\
\text { - Analysis of trace elements } \\
\text { - Bonding information from molecular cluster ions } \\
\text { - Identification of adsorbed species } \\
\text { - Kinetics of surface reactions }\end{array}$ \\
\hline STM & $\begin{array}{l}\text { Scanning tunneling microscopy } \\
\text { - Atomic-scale morphology of conducting surfaces } \\
\text { - Limited to carbon supported particles }\end{array}$ \\
\hline TDS & $\begin{array}{l}\text { Thermal desorption spectroscopy } \\
\text { - Characterization of adsorption states of molecules } \\
\text { - Concentration of adsorbed molecules } \\
\text { - Adsorption energies }\end{array}$ \\
\hline
\end{tabular}


TABLE 3. Continued

\begin{tabular}{ll}
\hline Acronym & \multicolumn{1}{c}{ Full name and most important information } \\
\hline TEM & Transmission electron microscopy \\
& - Morphology of supported particles \\
& - Structure of particles by electron diffraction \\
& - Sintering studies \\
TPRS & Texcellent opportunities with spherical model supports \\
& - Mechanisms of surface reactions via desorbed products \\
UPS & Ultraviolet photoelectron spectroscopy \\
& - Electronic structure of surface region \\
XPS & - Occupied electron orbitals of adsorbate species \\
& X-ray photoelectron spectroscopy \\
& - Elemental surface composition \\
& - Oxidation states \\
& - Dayer thickness
\end{tabular}

particles again possess a rather homogeneous charge state, meaning that the resolution is highly favorable, whereas the peak position contains a largely systematic error of $0.1-0.3 \mathrm{eV}$, which is difficult to correct.

X-ray photoelectron spectroscopy (XPS) is by far the most important technique for determining the composition of model catalysts. As explained in several textbooks [1-3,5,22], the information of XPS is largely contained in the binding energy, revealing the nature of the element and often its oxidation state, and in relative intensities, relating to concentrations. Angle-dependent measurements are useful in determining layer thicknesses, for example, of the thin oxide films that are used as model supports [23]. This type of measurement has also been used to estimate the number and size of rhodium particles on a flat alumina support [18]. The limited propensity of thin oxide films to acquire electric charge creates ideal opportunities for the application of monochromatic XPS, with the advantage of enhanced energy resolution and almost zero exposure of sensitive samples (such as organometallic catalyst precursors) to stray electrons and heat generated by a standard $\mathrm{X}$-ray source. Ultraviolet photoelectron spectroscopy (UPS) has been applied to study the adsorption of gases on model catalysts [24-31].

Auger electron spectroscopy (AES), used for determining surface compositions, is highly suitable for studying growth modes of evaporated layers [4]. Incidentally, the technique has also been used to make concentration depth profiles of model catalysts, as Fig. 3 illustrates for $\mathrm{ZrO}_{2} / \mathrm{SiO}_{2} / \mathrm{Si}(100)$ model catalysts. Auger spectroscopy offers the possibility of laterally imaging supported particles, as was demonstrated by Liu et al. [32], for example. These authors used a scanning transmission electron microscope to record the Auger image of 2-nm silver particles on an alumina support. However, 


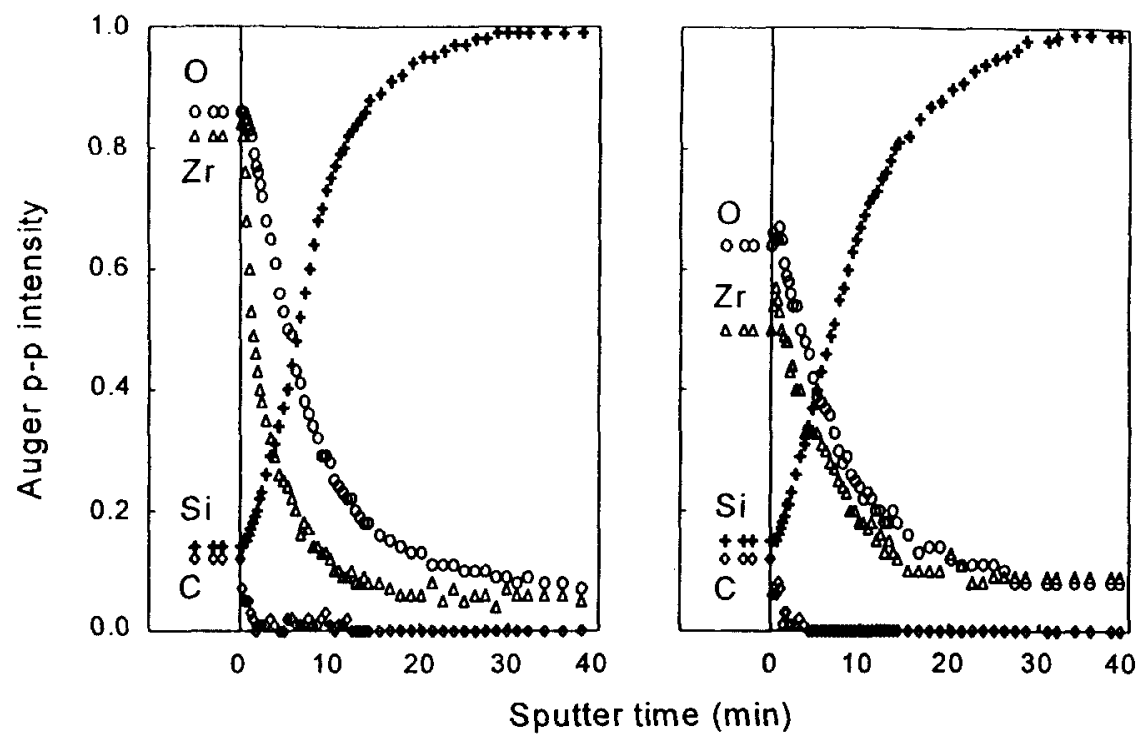

FIG. 3. Auger sputter depth profile of a layered $\mathrm{ZrO}_{2} / \mathrm{SiO}_{2} / \mathrm{Si}$ model catalyst. While the sample is continuously bombarded with argon ions which remove the outer layers of the sample, the Auger signals of $\mathrm{Zr}, \mathrm{O}, \mathrm{Si}$, and $\mathrm{C}$ are measured as a function of time. The depth profile is a plot of Auger peak intensities against sputter time. The profile indicates that the outer layer of the model catalyst contains carbon. Next $\mathrm{Zr}$ and $\mathrm{O}$ are sputtered away, but note that oxygen is also present in deeper layers where $\mathrm{Zr}$ is absent. The left pattern is characteristic for a layered structure and confirms that the zirconium is present in a well-dispersed layer over the silicon oxide. The right pattern is consistent with the presence of zirconium oxide in larger particles (from Eshelman et al. [17]).

standard scanning AES equipment is not yet capable of imaging particles on a scale of a few nanometers.

\section{B. Electron Microscopy}

Transmission electron microscopy (TEM) is probably the most powerful technique in characterizing the morphology of small supported particles and studying phenomena such as particle sintering and migration. Reviews on the application of TEM on flat, supported model catalysts have been written $[8,11,33]$. Preparation of special model supports is the key in obtaining good TEM images of flat systems. From a TEM point of view, single crystalline films $\left(\alpha-\mathrm{Al}_{2} \mathrm{O}_{3}, \mathrm{MgO}\right)$ are the best substrates, because they do not produce substantial phase contrast features [33]. Amorphous films (and an amorphous contamination layer on an otherwise perfect substrate!) do produce these features, which lead to the speckled background seen in high-resolution images (e.g., see Fig. 26). Polycrystalline substrates are even worse, because of the strong contrast arising from the grains. In choosing a substrate, other require- 


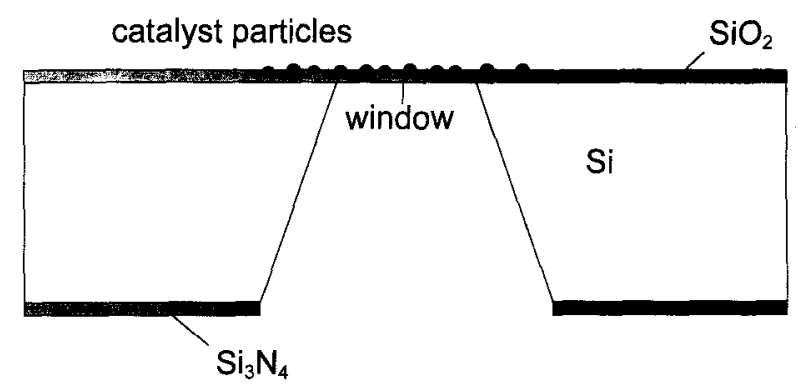

FIG. 4. Schematic cross section of a microfabricated TEM substrate. The substrate consists of a $\mathrm{SiO}_{2}$ window suspended in a silicon frame. The area of the window is $150 \times 150 \mu \mathrm{m}$ and its thickness is between 50 and $200 \mathrm{~nm}$. See Enquist and Spetz [42] for details of fabrication.

ments should also be met, such as relevance for catalysis (see Sect. IV) and stability. Evidently, no substrate fulfills all requirements, so one has to set priorities.

Most preparation methods are based either on evaporation (see also Sect. IV) or on thinning techniques. Films can be evaporated directly onto polymer coated grids [34-38], but transfer methods have also been applied $[39,40]$. The films are then evaporated onto $\mathrm{NaCl}-$ or carbon-coated mica, from which they can be removed easily by floating off in water. The films can be further treated after they have been picked up on the usual grids. Schmidt and coworkers [41] have thinned single crystal Si disks by chemical etching in a $\mathrm{HNO}_{3}$ and $\mathrm{HF}$ solution to a thickness of about $200 \mathrm{~nm}$, and subsequent ion micromilling in an Ar ion discharge until a pinhole at the center of the disk was observed. The regions near the pinhole were estimated to be about 100 $\mathrm{nm}$ thick after oxidation to $\mathrm{SiO}_{2}$. By means of modern silicon micromachining techniques, silica TEM substrates can be made in a more controllable way, as has been shown by Enquist and Spetz [42]. A schematic cross section of their substrate is depicted in Fig. 4. The window thickness obtainable is limited to about $50 \mathrm{~nm}$; for thinner windows the difference in thermal expansion coefficients of silicon and silica lead to severe wrinkling and possible movement as a result of heating and charging during electron beam exposure.

Applications of TEM in studies of particle structure and their thermal stability are discussed in Sect. VI of this paper. An interesting development is the application of TEM on spherical model catalysts, where particles are easily imaged in profile, when they appear at the edge of a projected sphere $[14,43,44]$.

\section{Ion Spectroscopy}

Determination of the concentration of supported material is almost trivial in the preparation of technical catalysts but is much more difficult in model catalysts, where the total number of atoms in the catalytically active phase is 
usually on the order of $10^{14-15}$ atoms per $\mathrm{cm}^{3}$ only. Rutherford backscattering spectrometry [2] is an excellent method for determining these low concentrations, provided the atomic mass of the deposited material is higher than that of the substrate material, which is usually the case. Figure 5 shows RBS measurements of an $\mathrm{MoO}_{3} / \mathrm{SiO}_{2} / \mathrm{Si}(100)$ model catalyst before and after treatment in $\mathrm{H}_{2} \mathrm{~S}$ [45], which allow for the quantitative determination of the surface concentrations of Mo and S $\left(1.3 \times 10^{15}\right.$ Mo and $3.2 \times 10^{15}$ per $\mathrm{cm}^{2}$ in the case of the fully sulfided model catalysts). Several applications of the technique to model catalysts can be found in the literature [17,18,45-48].

Low energy ion scattering (LEIS) and also secondary ion mass spectrometry (SIMS) are greatly facilitated owing to the use of conducting, thin film supports. LEIS offers true outer layer sensitivity and has great potential for determining to what extent a support is covered by, for example, the catalytically active phase [49] but has so far seen little application in the study of model catalysts. SIMS has more often been used. Here the interesting information is mostly in molecular clusters which reveal bonding between elements. For example, the intensities of $\mathrm{RhCl}^{-}$and $\mathrm{RhK}^{+}$cluster ions have been used to demonstrate rhodium-chlorine contact in freshly prepared $\mathrm{Rh} / \mathrm{Al}_{2} \mathrm{O}_{3} / \mathrm{Al}$ catalysts [50] and contact between rhodium and potassium in promoted catalysts [51]. A particularly noteworthy application of SIMS is to study the kinetics of catalytic reactions on supported particles, as was done by Mátolin et al. [52]. We refer to Borg and Niemantsverdriet [51] for a recent review on the use of SIMS in catalysis and surface chemistry.

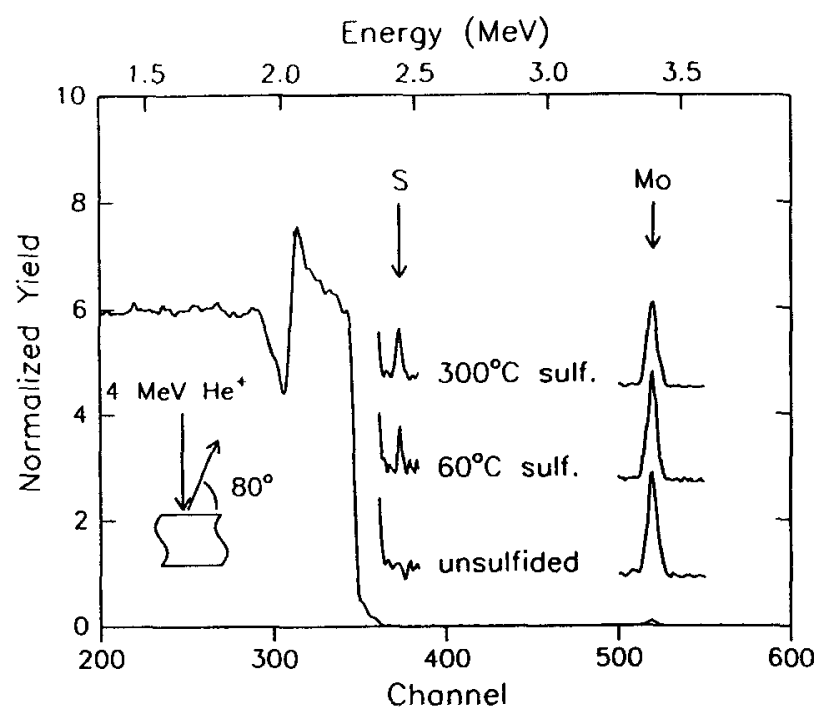

FIG. 5. RBS spectra of a $\mathrm{MoO}_{3}$ model catalyst supported on a flat $\mathrm{SiO}_{2} /$ $\mathrm{Si}(100)$ model support, before and after sulfidation in a mixture of $\mathrm{H}_{2} \mathrm{~S}$ at room temperature, and at $570 \mathrm{~K}$ (from de Jong et al. [45]). 


\section{Vibrational Spectroscopy}

Infrared and electron energy loss spectroscopy (EELS) are the indicated techniques for identifying adsorbed species and studying their bonding geometry. Nevertheless, inelastic electron tunneling spectroscopy was the first vibrational spectroscopy to be applied on flat model systems. In fact this by now largely abandoned technique has greatly contributed to the development of thin film models of catalysts. We refer to Kroeker and Hansma for a review on the subject [9]. Infrared spectroscopy can straightforwardly be applied in the reflection-absorption mode (RAIRS) if the thin oxide support film rests on a metal substrate. This technique has frequently been applied by Goodman and coworkers [12]. If combined with high-pressure cells, it offers the possibility to study adsorption on model catalysts in situ. In principle, the technique is sufficiently fast that kinetics of reactions involving strong infrared absorbers such as $\mathrm{CO}$ and NO can be followed with a time resolution of a few seconds.

EELS is only applicable in ultrahigh vacuum but offers the advantage of a larger accessible range of vibrational frequencies (from below $100 \mathrm{~cm}^{-1}$ to the region of electronic transitions, while RAIRS is in practice limited to approximately $800-4000 \mathrm{~cm}^{-1}$ ). In addition, in the impact mode, EELS detects all vibrations, and not only the dipole-active ones. The work of Kesmodel and coworkers [53-55] and of Frederick et al. [56-58] gives a good impression of the possibilities of the technique. In addition to studying adsorbed molecules, EELS gives valuable information on the electronic structure and the hydroxyl content of oxidic model supports as well.

\section{E. Scanning Probe Microscopy}

Scanning tunneling microscopy (STM) offers morphological information on the atomic scale but requires samples that are electrically conducting. As a consequence, STM studies have concentrated on carbon-supported metal particles, usually prepared by evaporation. Although this type of work is still very much in an exploratory stage, atomic resolution on particles has been demonstrated by several groups [59-62]. Other have explored the possibilities of imaging particles on a somewhat larger scale [59,63-75]. As to oxidic layer supports, it is not yet clear how thick the support layer may be in order to allow useful STM images. It is unlikely, however, that oxide layers with sufficient thickness to meet the requirements for a representative support as formulated in Sect. IV can be used for STM imaging.

Atomic or scanning force microscopy (AFM) is applicable to all types of substrates. For imaging supported particles, the spatial resolution is however limited by the size and shape of the tip. Nevertheless, qualitative information on the size distribution of particles is still obtained. If the particles are sufficiently separated that the tip reaches the free support surface in between, 
one can determine the height of a particle. In addition, AFM can be used to count the number of particles per unit surface area. Examples of AFM applications on model catalysts can be found in Refs. 45, 48, and 76-85.

\section{F. Temperature-Programmed Methods}

Temperature programmed desorption (TPD) and reaction spectroscopy (TPRS) applied in ultrahigh vacuum are very common and extremely well suited for investigating adsorption states and reaction mechanisms on particles on flat model supports. The great advantage over using high surface area catalysts for this type of studies is that diffusion limitations in the transport of both reactants and products are entirely avoided, implying that TPD and TPRS results represent the intrinsic kinetics of the system under study. Analysis procedures for TPD have recently been reviewed and tested [86,87]. Several adsorption studies using TPD are discussed in Sect. VI.E.

\section{G. Other Techniques}

A few surface-sensitive versions of otherwise bulk sensitive techniques have incidentally been applied to study model catalysts. For example extended x-ray absorption fine structure (EXAFS) becomes surface sensitive when measured in reflection (REFLEXAFS) or in fluorescence mode, as demonstrated in a series of papers by Shirai et al. [88-90]. This technique provides local structural information on the atomic scale. Conversion electron Mössbauer spectroscopy (CEMS), the surface science analogue of Mössbauer absorption spectroscopy, is a highly informative technique which gives data on the oxidation state, lattice symmetry, magnetism, and lattice dynamics of certain isotopes, among which ${ }^{57} \mathrm{Fe}$ is the most important one. Dumesic and coworkers used CEMS to characterize iron particles on thin film $\mathrm{TiO}_{2}$ supports [91-94].

\section{H. Reactors for Model Catalysts}

On a typical metal supported catalyst the metal cluster surface area will be only a few percent of the total surface area. However, the total surface area in a model catalyst is on the order of a few square centimeters only, so if it is to have the same surface cluster density as the supported catalyst (a few percent), then the resulting metal surface area will be very small. The small metal area will not interfere with characterization studies like TEM, will decrease the sensitivity of some techniques (AES, XPS, RAIRS, TPD), but will make catalytic tests at high pressures $\left(>10^{-2}\right.$ torr) and temperatures very difficult to carry out. The low metal surface area implies that the amount of products formed by the metal catalyst in a period of time will be more difficult to detect and analyze. In cases where the turnover rate is high $\left(\sim 1 \mathrm{~s}^{-1}\right)$, the 
rates can be measured in a batch reactor (volume $\sim 500 \mathrm{~cm}^{3}$ ) and the products analyzed with a gas chromatograph although the final conversion will be very low. In the case that the turnover rate is low, the alternative is to lower the reactor volume to a few milliliters. A robust design of a reactor with very low volume is still to be accomplished. The current proven designs to measure rates on single crystals at high pressures consist of a high-pressure cell attached to the UHV chamber through a transfer arm or a retractable reactor that encloses the sample [95]. The latter design has been used successfully, for example, to test a Pt model catalyst in the hydrogenation of ethylene [96]. A review of the reactors available for testing of single crystals was presented by Campbell [97]. In the case where the sample can be exposed to air before and after reaction, a much simpler design is possible. For example, Kuipers et al. [98] used a glass reactor (Fig. 6) to study several $\mathrm{SiO}_{2} / \mathrm{Si}(100)$ supported model catalysts [99].

The other problem in testing model catalysts is how to heat the sample. For metallic catalysts, resistive heating can be used. If the catalyst is an oxide, however, indirect heating has to be used. There are a few approaches to solve this problem. If the oxide is deposited on a metal, completely covering it, then resistive heating and a low background reaction can be achieved [100]. Another approach is to deposit a metal on the back of the oxide of interest and heat the metal resistively [101]. One problem with this approach is to make sure that the catalytic activity of the metal is negligible. Direct heating

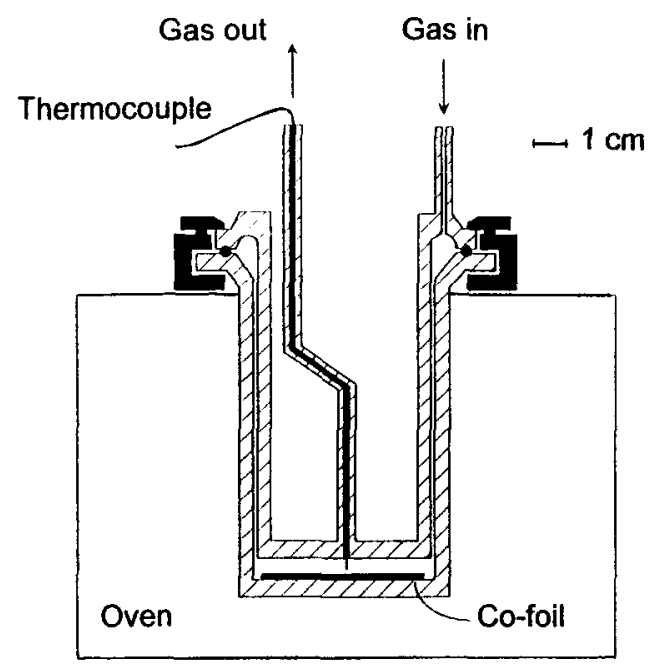

FIG. 6. Schematic representation of the glass reactor used by Kuipers et al. for Fischer-Tropsch synthesis on Co foils. The reactor consists of two parts, which closely fit into one another and are suspended in an oven. Minor temperature gradients inside the reactor cause sufficient convection stirring to warrant CSTR behavior (i.e., perfect mixing). The reactor is operated in flow mode at 1 bar total pressure; the total reactor volume is $10 \mathrm{~cm}^{3}$ (from Kuipers et al. [98]). 
by an infrared spotlight has also been used successfully [102]. Finally, the entire reactor assembly can be heated, provided again that background reactions are negligible. Catalytic reaction studies over flat model catalysts are discussed in Sect. VI.F of this paper.

\section{MODEL SUPPORTS}

Model supports that can be and have been used include single crystal oxides such as $\alpha-\mathrm{Al}_{2} \mathrm{O}_{3}$ and $\mathrm{TiO}_{2}$, graphite, and thin oxide films on conducting substrates. Although from the point of view of definition, the use of single crystal oxides may seem preferable, these substrates cause experimental difficulties with respect to charging phenomena. The same holds for mica, used frequently in TEM studies of nucleation and growth phenomena. Moreover, these supports often differ essentially from their high surface area counterparts. If one primarily aims at making flat replicas of high surface area supports, and definition has less priority, carefully prepared thin oxide films like amorphous $\mathrm{SiO}_{2}$ on a $\mathrm{Si}$ wafer, or $\gamma-\mathrm{Al}_{2} \mathrm{O}_{3}$ made by evaporation in $\mathrm{O}_{2}$ of $\mathrm{Al}$ on a suitable substrate, seem preferable. Graphite supports, either native or functionalized by treatment in concentrated nitric acid to introduce acidic surface groups, offer excellent opportunities for spectroscopic work owing to a high electrical conductivity. This also has been the preferred support for scanning tunneling microscopy. Systems such as $\mathrm{Pt}$ or $\mathrm{Pd}$ on graphite may have some relevance with respect to the $\mathrm{Pt} / \mathrm{C}$ and $\mathrm{Pd} / \mathrm{C}$ catalysts that are used in hydrogenation reactions.

The following paragraphs present a discussion of the different methods by which model supports have been prepared. Resulting model supports are evaluated with respect to definition, but especially to whether they are realistic models of conventional supports.

\section{A. Silica}

Almost all flat silica model supports are either made by (thermal) oxidation of silicon wafers or by reactive evaporation of $\mathrm{Si}$ in oxygen. There is only one example of the use of a commercial $\mathrm{SiO}_{2}$ wafer as a model support [76]. Small silica spheres have been used as model supports by Datye and coworkers [43] to enable HRTEM profile imaging. Table 4 shows all the approaches that have been explored.

The surface to be modeled - that is, the surface of porous silica-is presumably amorphous, although some experimental results [103] suggest some local order. As an example there are the findings of Zhuravlev and others, who have determined the $\mathrm{Si}-\mathrm{OH}$ surface density or silanol number for 100 fully hydroxylated silica prepared by different processes and having different structural characteristics [104]. The numbers found lie in a fairly narrow range from 4 to $5.5 \mathrm{~nm}^{-2}$, with an average value of 4.6 . Based on this number, the 
TABLE 4

Model Silica Supports

\begin{tabular}{|c|c|c|}
\hline Method of preparation & Thickness & Ref. \\
\hline \multicolumn{3}{|l|}{ Native oxide } \\
\hline Si(100) wafer & $0.7 \mathrm{~nm}$ & 65 \\
\hline $\operatorname{Si}(100)$ wafer & & 80 \\
\hline $\mathrm{Si}(100)$ and $(111)$ wafers & & 19,224 \\
\hline Si(100) wafer & & $48,83-85$ \\
\hline $\mathrm{Si}(100)$ wafer & $\sim 1.0 \mathrm{~nm}$ & 17,183 \\
\hline \multicolumn{3}{|l|}{ Reactive evaporation } \\
\hline On $\operatorname{Mo}(110)$ & $\sim 10 \mathrm{~nm}$ & $72,100,119,277,336-339$ \\
\hline On $\mathrm{Mo}(100)$ & $\sim 10 \mathrm{~nm}$ & 340 \\
\hline On Al foils & $\sim 30 \mathrm{~nm}$ & 341 \\
\hline \multicolumn{3}{|l|}{ Thermal oxidation } \\
\hline Si wafer, $\sim 1$ h/1300-1400 K/air & $1 \mu \mathrm{m}$ & $41,272,342,343$ \\
\hline Si wafer, 10 h/1200 K/air & $1 \mu \mathrm{m}$ & 344 \\
\hline Si wafer, 24 h/770 K/air & $6 \mathrm{~nm}$ & 45,260 \\
\hline $\operatorname{Si}(100)$ wafer & $50-200 \mathrm{~nm}$ & 42,79 \\
\hline $\mathrm{Si}(100)$ wafer, $3 \mathrm{~h} / 1400 \mathrm{~K} / \mathrm{O}_{2}$ & $200 \mathrm{~nm}$ & 76 \\
\hline Si wafer, $1500 \mathrm{~K} / \mathrm{O}_{2}$ & $100 \mathrm{~nm}$ & 78 \\
\hline Si film, $\sim 1 \mathrm{~h} / 1300-1400 \mathrm{~K} / \mathrm{air}$ & $1 \mu \mathrm{m}$ & 39 \\
\hline Si film, $36 \mathrm{~h} / 900-1100 \mathrm{~K} / \mathrm{O}_{2}$ & $<30 \mathrm{~nm}$ & $34-38$ \\
\hline Si film, 4 h/1300 K/air & $50-100 \mathrm{~nm}$ & 40,345 \\
\hline \multicolumn{3}{|l|}{ Miscellaneous } \\
\hline Commercial $\mathrm{SiO}_{2}$ wafer & $500 \mu \mathrm{m}$ & 76 \\
\hline $\mathrm{SiO}_{2}$ spheres & $\sim 100 \mathrm{~nm} \phi$ & $13,14,43,123,126,346$ \\
\hline
\end{tabular}

(111) surface of $\beta$-cristobalite has been used by several authors $[103,105]$ as a model for the surface of amorphous silica. This surface, depicted in Fig. 7, is composed of 6-membered rings of $\mathrm{SiO}_{4 / 2}$ tetrahedra and has an $\mathrm{OH}$ density of $4.55 \mathrm{~nm}^{-2}$.

Probably the easiest way to prepare a flat silica is by thermal oxidation of silicon wafers or evaporated silicon films. Depending on temperature and
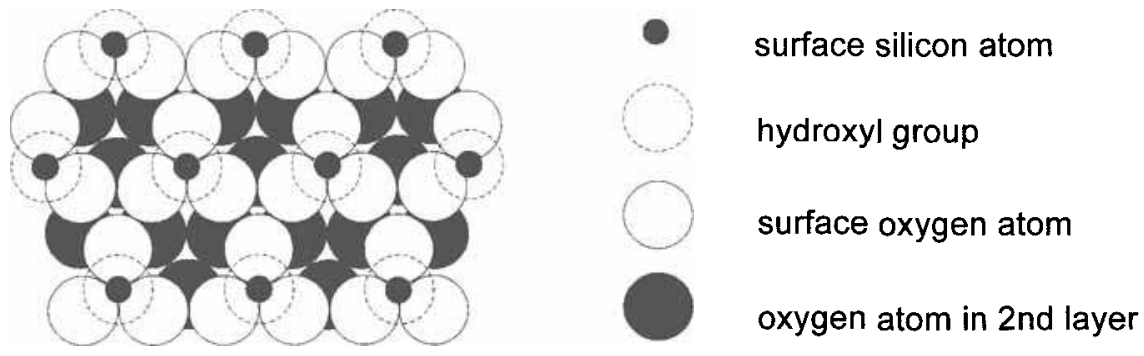

FIG. 7. The (111) surface of the $\mathrm{SiO}_{2}$ polymorph $\beta$-cristobalite. This surface has the same $\mathrm{OH}$ density as amorphous silica [122]. 
oxidation time, silica layers can be made with thicknesses ranging from a few angstrom up to 1 micron and more; see Table 4. Silica growing out of silicon wafers has been studied extensively in relation to the fabrication of electronic devices [106-111]. It is generally agreed upon that prolonged oxidation of the silicon surface results in stoichiometric $\mathrm{SiO}_{2}$ with a structure similar to that of vitreous silica, that is, a random network of rings of 4-9 $\mathrm{SiO}_{4}$ tetrahedra $[112,113]$. The $\mathrm{Si} / \mathrm{SiO}_{2}$ interface is not abrupt: The interface region near to the silicon consists of a few atomic layers containing $\mathrm{Si}$ atoms in intermediate oxidation states- $\mathrm{Si}^{1+}\left(\mathrm{Si}_{2} \mathrm{O}\right), \mathrm{Si}^{2+}(\mathrm{SiO})$, and $\mathrm{Si}^{3+}\left(\mathrm{Si}_{2} \mathrm{O}_{3}\right)-$ the relative occurrence depending on the nature of the Si surface [(100) or (111), steps, impurities, etc.]. A second region extends about $3.0 \mathrm{~nm}$ into the $\mathrm{SiO}_{2}$ layer. The $\mathrm{SiO}_{2}$ in this layer is compressed because the density of $\mathrm{Si}$ atoms is higher for $\mathrm{Si}$ than for $\mathrm{SiO}_{2}$. The compression is effectuated through the formation of 4-membered rings with smaller $\mathrm{Si}-\mathrm{O}-\mathrm{Si}$ bond angles than the average $144^{\circ}$ for amorphous silica. Calculations show that smaller bond angles result in a chemical shift of the Si $2 p$ core level in XPS towards lower binding energies $[114,115]$. The observed chemical shift of about $0.6 \mathrm{eV}$ $[108,110,116]$ in going from a few monolayers of oxide to several nanometers of vitreous silica upon thermal oxidation (see Fig. 8) agrees well with a shift in average bond angle from $144^{\circ}$ down to $\sim 120^{\circ}$ for the compressed region.

The mechanism and kinetics of silicon oxidation have been studied in detail

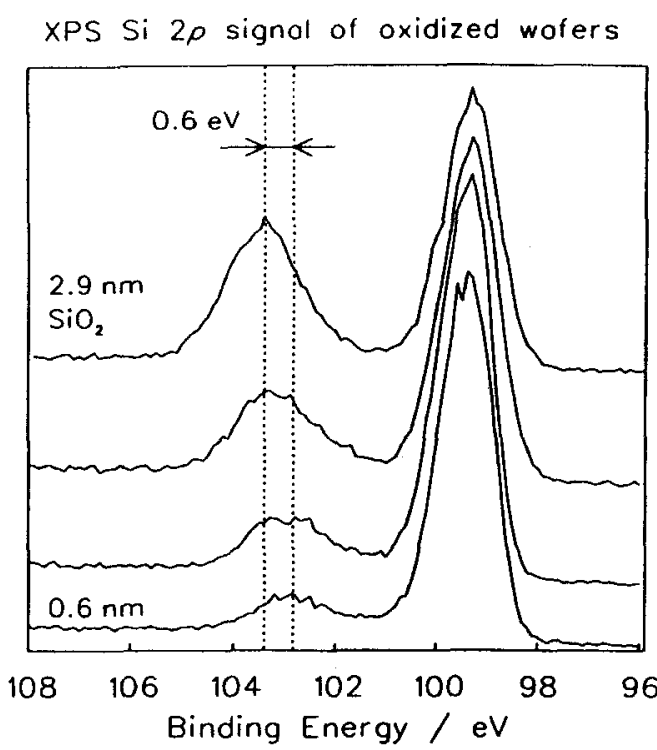

FIG. 8. XPS Si $2 p$ signal as a function of oxide layer thickness. The position of the $\mathrm{Si}^{4+}$ peak originating from the oxide layer shifts about $0.6 \mathrm{eV}$ in going from a few monolayers of oxide towards a $3 \mathrm{~nm}$ thick layer. A low binding energy is indicative of a compressed structure with low $\mathrm{Si}-\mathrm{O}-\mathrm{Si}$ bond angles (adapted from de Jong [116]). 
by numerous authors (for a review, see Ref. 117). It is generally accepted that a rapid initial oxidation step is followed by a regime of parabolic growth, with nondissociated $\mathrm{O}_{2}$ and/or $\mathrm{H}_{2} \mathrm{O}$ dissolving in the oxide diffusing to the interface with the substrate. The initial step, however, is not well understood $[117,118]$. At the beginning of oxide growth, the film is thin enough to allow electrons from the substrate to dissociate molecular $\mathrm{O}_{2}$ at the surface. It might be that this leads to the formation of a more-ordered oxide, because crystallites can grow unconstrained. The formation of microcrystallites has indeed been shown by Rochet et al. [118], but only in very dry oxygen. They present evidence that this rather dense oxide film acts as a barrier for $\mathrm{O}_{2}$ diffusion. The authors suggest that traces of water open up the structure in time, enabling molecular diffusion of oxygen, which marks the transition to the parabolic growth regime. A rather different model assumes that initially an SiOlike layer is formed, which remains at the interface, and through which $\mathrm{Si}$ atoms diffuse to react with molecular $\mathrm{O}_{2}$ diffusing inward through the amorphous oxide layer growing on top of it.

Reactive evaporation of $\mathrm{Si}$ in oxygen (as $\mathrm{SiO}$ ) is another way to prepare flat silica films, and has mainly been used by Goodman and coworkers (see Table 4), who also characterized the nature of the films formed $[12,100,119]$. They prepared ultrathin ( $<5 \mathrm{~nm}$ ) films on $\mathrm{Mo}(100)$ and (110) single crystal surfaces by heating a $\mathrm{Si}$ strip in pure $\mathrm{O}_{2}$ at different pressures. At an oxygen pressure less than $1 \times 10^{-4} \mathrm{~Pa}$, direct $\mathrm{Si}$ evaporation competes with the formation of gaseous $\mathrm{SiO}$ through oxidative etching. The film growing at the Mo surface (which is held at RT) under these conditions is a mix of $\mathrm{SiO}_{2}$, $\mathrm{SiO}$, and $\mathrm{Si}$. At higher pressures, only gaseous $\mathrm{SiO}$ is produced, and a stoichiometric $\mathrm{SiO}_{2}$ film grows on the Mo substrate. However, EELS and IRAS spectra show features attributable to a local structure with broken $\mathrm{Si}-\mathrm{O}$ bonds. Upon annealing to $\sim 1200 \mathrm{~K}$, the long-range $3 \mathrm{D}$ network of vitreous silica is formed.

Small silica spheres $(25-250 \mathrm{~nm}$ ) have been used as model catalysts by Datye and coworkers [43]. The use of spheres enables one to view supported particles in profile by HRTEM (see Fig. 9 for an example). Silica spheres are made by hydrolysis of tetraethylorthosilicate (TEOS) in a water-alcoholammonia system (at RT), a procedure developed by Stöber et al. [120]. The experimental procedure is simple, and the size of the spheres can be set precisely by the water-ammonia concentrations [121]. A generally accepted scheme for the formation and growth of the spheres has not yet been presented. Although Iler ([122], p. 239) describes them as porous spherical aggregates of primary particles less than $5 \mathrm{~nm}$ in size, there is substantial evidence from surface area measurements [121] and HRTEM micrographs [123] that the silica spheres are homogeneous and nonporous. The very smooth particle surface that can be obtained has led van Blaaderen and Vrij [124] to propose that the spheres are formed through a controlled aggregation of nuclei, followed by growth through monomer addition. 


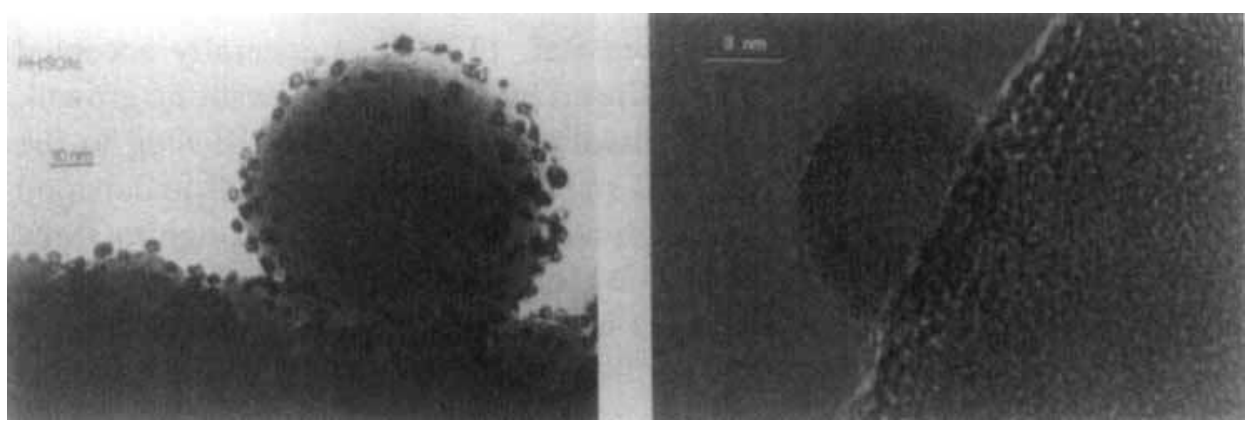

FIG. 9. A small silica sphere, made by hydrolysis of tetraethylorthosilicate (TEOS) in a water-alcohol-ammonia system, supporting $\mathrm{Rh}$ particles (from Datye and Long [43]).

Summarizing the above, we conclude that realistic flat models of the porous silica can be made both by thermal oxidation of silicon wafers or evaporated silicon films, and by reactive evaporation of $\mathrm{Si}$ in oxygen. There are, however, pitfalls to be aware of:

i. Silica on silicon wafers has an approximately $3 \mathrm{~nm}$ thick oxidic interface with the silicon of different structure and therefore possibly different reactivity than true $\mathrm{SiO}_{2}$ has; thus only layers thicker than $\sim 3 \mathrm{~nm}$ can be regarded as "safe" models.

ii. Silicon oxides formed by reactive evaporation are identical to vitreous silica only if the evaporation is performed at oxygen pressures higher than $1 \times 10^{-4} \mathrm{~Pa}$ and is followed by annealing at $\sim 1200 \mathrm{~K}$.

Another point that needs attention is the dehydroxylation of the silica surface, as resulting from thermal treatment. Hydroxyls are essential in the usual catalyst preparation techniques and, consequently also for those model studies in which catalyst preparation is an issue. The dehydroxylation of silicas has been studied extensively by Zhuravlev and coworkers [104,125], and is summarized by Fig. 10. Dehydroxylation produces siloxane bridges, which are strongly hydrophobic. As a consequence, rehydroxylation in gaseous or liquid water is slow; complete rehydroxylation, however, is in principle always possible.

The spherical model silicas have been shown very suitable for HRTEM and reaction studies. Their structure resembles that of the usual porous silicas, and their surface is rich in $\mathrm{OH}$ groups, probably mainly H-bonded ones [126].

\section{B. Alumina}

The structural chemistry of alumina is rich and complicated [127]. Several crystallographic modifications exist, of which $\gamma-\mathrm{Al}_{2} \mathrm{O}_{3}$, which has a defect spinel structure, is catalytically most interesting. Small $\gamma-\mathrm{Al}_{2} \mathrm{O}_{3}$ crystallites 


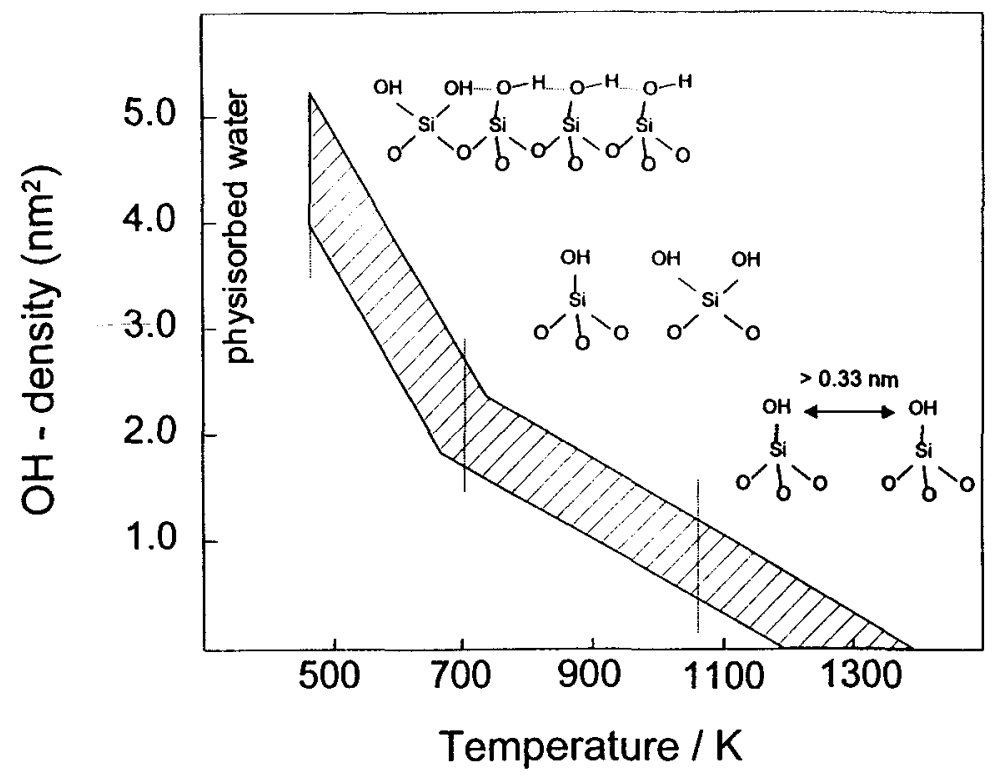

FIG. 10. Dehydroxylation behavior of high surface area silica (adapted from Bergna [125]).

are believed to expose mostly (111) but also (110) and (100) faces. Knözinger and Ratnasamy [128] have discussed the structure of these surfaces in terms of their hydroxyl population. They distinguish five hydroxyl types, ranging from the basic terminal $\mathrm{OH}$, coordinated to a single tetrahedral $\mathrm{Al}^{3+}$ cation, to the acidic bridging $\mathrm{OH}$ coordinated to three $\mathrm{Al}^{3+}$ cations in octahedral interstices. The five different types show up as five bands in the OH-stretching region of IR spectra of $\gamma-\mathrm{Al}_{2} \mathrm{O}_{3}$. The fact that different types of aluminas all show such five band regions has led the authors to conclude that these $\mathrm{OH}$ configurations are a consequence of the common coordinative nature of aluminum ions in all transition aluminas, and hence occur on all of their surfaces. In other words, differences in reactivity of aluminas can be related to the different relative occurrence of the five principal $\mathrm{OH}$ configurations. Furthermore, catalytic activity of aluminas per se is only developed after dehydroxylation, implying that the creation of defects is crucial for the development of surface reactivity. A fully hydroxylated alumina contains 10 to 15 $\mathrm{OH}$ groups per square nanometer; heating to $\sim 650 \mathrm{~K}$ is necessary to remove half of this population, and one third is still present after heating up to $800 \mathrm{~K}$.

A variety of flat aluminum oxides have been used to model porous alumina supports: single crystalline $\alpha-\mathrm{Al}_{2} \mathrm{O}_{3}$; thermally oxidized aluminum single crystals, aluminum foils, and evaporated films; anodized films; and films made by reactive evaporation. Table 5 gives an overview of these different models. Although, as we mentioned in the foregoing paragraph, local struc- 
TABLE 5

Model Alumina Supports

\begin{tabular}{|c|c|c|}
\hline Method of preparation & Thickness & Ref. \\
\hline \multicolumn{3}{|l|}{ Single-crystal alumina } \\
\hline$\alpha-\mathrm{Al}_{2} \mathrm{O}_{3}$ & - & 347 \\
\hline$\alpha-\mathrm{Al}_{2} \mathrm{O}_{3}(1 \overline{1} 02)$ & - & $130,134,348,349$ \\
\hline$\alpha-\mathrm{Al}_{2} \mathrm{O}_{3}(\overline{1} 012)$ & - & $101,135,278,350,351$ \\
\hline$\alpha-\mathrm{Al}_{2} \mathrm{O}_{3}(10 \overline{1} 0)$ & - & 133 \\
\hline$\alpha-\mathrm{Al}_{2} \mathrm{O}_{3}(0001)$ & - & $\begin{array}{l}88,89,131,132,270,271 \\
\quad 335,352-356\end{array}$ \\
\hline \multicolumn{3}{|l|}{ Oxidation of aluminum } \\
\hline $\mathrm{Al}(111), \mathrm{O}_{2}$ mol. beam at $300 \mathrm{~K}$ & $0.5 \mathrm{~nm}$ & 152,357 \\
\hline $\mathrm{Al}(100), 10^{-7}$ torr $\mathrm{O}_{2}$ at $470 \mathrm{~K}$ & $2 \mathrm{~nm}$ & $215-217$ \\
\hline $\mathrm{Al}(100), 10^{-3}$ torr $\mathrm{O}_{2}$ at $875 \mathrm{~K}$ & $>8 \mathrm{~nm}$ & 216,217 \\
\hline $\mathrm{Al}(100), 10^{-4}$ torr $\mathrm{H}_{2} \mathrm{O}$ at $875 \mathrm{~K}$ & $>8 \mathrm{~nm}$ & 154 \\
\hline Foil, $10^{-3}$ torr $\mathrm{H}_{2} \mathrm{O},<900 \mathrm{~K}$ & $50 \mathrm{~nm}$ & 16,139 \\
\hline Foil, native oxide & $3 \mathrm{~nm}$ & $18,50,153$ \\
\hline Foil, $10^{-6}$ torr $\mathrm{H}_{2} \mathrm{O} / \mathrm{O}_{2}, 373 / 673 \mathrm{~K}$ & $0.8-1 \mathrm{~nm}$ & 153 \\
\hline Foil, $10^{-6}$ torr $\mathrm{O}_{2}, 670-720 \mathrm{~K}$ & $0.5 \mathrm{~nm}$ & 55 \\
\hline Foil, air calc. & $?$ & 25,358 \\
\hline Foil, air calc. at $900 \mathrm{~K}$ & $50-100 \mathrm{~nm}$ & 359 \\
\hline Film $(20-200 \mathrm{~nm}), \mathrm{O}_{2}$ and air calc. & $\sim 5 \mathrm{~nm}$ & 360 \\
\hline IETS electrode, air calc. $470 \mathrm{~K}$ & $2 \mathrm{~nm}$ & 361 \\
\hline IETS electrode, discharge $\mathrm{O}_{2}\left(+\mathrm{H}_{2} \mathrm{O}\right)$ & $2 \mathrm{~nm}$ & $362-364$ \\
\hline Film $(5 \mathrm{~nm})$, air at RT & $5 \mathrm{~nm} ?$ & 221 \\
\hline Film $(2-3 \mathrm{~nm}), 10^{-6}$ torr $\mathrm{O}_{2}, 1000 \mathrm{~K}$ & $3 \mathrm{~nm}$ & 149 \\
\hline Film, $10^{-6}$ torr $\mathrm{O}_{2}$ at $1250 \mathrm{~K}$ & $1-2 \mathrm{~nm}$ & 365 \\
\hline Film, $10^{-6}$ torr $\mathrm{O}_{2}$ at $740 \mathrm{~K}$ & $>0.5 \mathrm{~nm}$ & 366 \\
\hline Film $(500 \mathrm{~nm})$ & $500 \mathrm{~nm} ?$ & 367 \\
\hline Film $(2-3 \mathrm{~nm})$, (moist) air at $723 \mathrm{~K}$ & $3 \mathrm{~nm}$ & $56-58,368$ \\
\hline Film $(15 \mathrm{~nm}), 1 \mathrm{~atm} \mathrm{O}_{2}$ at $870 \mathrm{~K}$ & $20 \mathrm{~nm}$ & 38 \\
\hline \multicolumn{3}{|l|}{ Reactive evaporation } \\
\hline $10^{-4}$ torr $\mathrm{O}_{2} ;$ calc. $720 \mathrm{~K}, \mathrm{O}_{2}$ & $10-20 \mathrm{~nm}$ & 148,369 \\
\hline$\sim 10^{-8}$ torr $\mathrm{O}_{2} ;$ vac. anneal $1200 \mathrm{~K}$ & $0.8 \mathrm{~nm}$ & 151 \\
\hline $10^{-4}$ torr $\mathrm{O}_{2} ;$ calc: $770 \mathrm{~K}$, air & $10 \mathrm{~nm}$ & 370 \\
\hline $10^{-4}$ torr $\mathrm{O}_{2}$ & $5-7 \mathrm{~nm}$ & 223 \\
\hline $10^{-6}$ torr $\mathrm{O}_{2}$ at $750 \mathrm{~K}$ & $\sim 1 \mathrm{~nm}$ & 54 \\
\hline $10^{-6}$ torr $\mathrm{O}_{2}$ at $900 \mathrm{~K}$ & $0.5-4 \mathrm{~nm}$ & 156 \\
\hline \multicolumn{3}{|l|}{ Anodization } \\
\hline Tartaric acid & $30 \mathrm{~nm}$ & 157 \\
\hline Tartaric acid; calc: 1070 , air & $50 \mathrm{~nm}$ & 39,371 \\
\hline Tartaric acid; calc: $870 \mathrm{~K}, \mathrm{O}_{2}$ & $5 \mathrm{~nm}$ & 372 \\
\hline Tartaric acid; calc: $1070 \mathrm{~K}$, air & $30 \mathrm{~nm}$ & 373,374 \\
\hline Tartaric acid; calc: $900 \mathrm{~K}$, air & $25 \mathrm{~nm}$ & 375 \\
\hline Tartaric acid (calc: $920 \mathrm{~K}$, air) & $>15 \mathrm{~nm}$ & $148,369,376$ \\
\hline Tartaric acid; calc: $770 \mathrm{~K}$, air & $?$ & 370 \\
\hline Ammoniumcitrate (calc: $1100 \mathrm{~K}$, air) & $14 \mathrm{~nm}$ & 222,377 \\
\hline Sulfuric acid; calc: $770 \mathrm{~K}$, air & $13 \mu \mathrm{m}$ & 344 \\
\hline
\end{tabular}


TABLE 5. Continued

\begin{tabular}{lll}
\hline \multicolumn{1}{c}{ Method of preparation } & Thickness & \multicolumn{1}{c}{ Ref. } \\
\hline Miscellaneous & & \\
$\quad$ Planar alumina & $?$ & 262,263 \\
Oxid. (air, RT) of $100-500 \mathrm{~nm}$ part. & $\sim 2 \mathrm{~nm}$ & 378 \\
High- $\mathrm{T}$ anneals of amorph. $\mathrm{Al}_{2} \mathrm{O}_{3}$ & & \\
$\quad$ TEM films ( $\delta$ and $\eta$ phase) & $\sim 100 \mathrm{~nm}$ & 129 \\
Reactive sputtering (amorphous & $10-25 \mathrm{~nm}$ & 379 \\
$\quad \mathrm{Al}_{2} \mathrm{O}_{3}$ ) & & \\
\hline
\end{tabular}

ture (defects) is considered to be far more relevant for surface reactivity than bulk structure and orientation, Poppa et al. [129] have shown that evaporation of $\mathrm{Fe}$ onto differently oriented single-crystal grains of $\delta-\mathrm{Al}_{2} \mathrm{O}_{3}$ leads to very different crystallographic habits of the particles growing, as can be seen in Fig. 11. Therefore, careful characterization of the model alumina used is recommended.

Sapphire, or single crystalline $\alpha-\mathrm{Al}_{2} \mathrm{O}_{3}$, has been frequently used as support because it is a mechanically and thermally stable material, and, moreover, because its surfaces (primarily the (0001) and (1012) ones have been used) can be cleaned relatively easily [129]. As Poppa and coworkers have pointed out [130], the eventual surface structure strongly depends on the cleaning procedure applied. Argon sputtering amorphizes the sapphire surface and annealing at $1000 \mathrm{~K}$ [131] brings back the LEED pattern, but a full recovery of both the aluminum and the oxygen sublattice requires annealing up to $1300 \mathrm{~K}$. Heating in oxygen $[132,133]$ and exposure to an rf oxygen discharge $[134,135]$ have also been applied as cleaning procedures; both procedures assure complete oxygen saturation of the surface.

Although the oxidation of bare metallic aluminum surfaces has been the subject of extensive studies in the last decades, some of its aspects are still open to discussion, which makes the preparation of thin alumina films by thermal oxidation a nontrivial procedure. It is generally accepted that low temperature $(<650 \mathrm{~K})$ oxidation in air or in UHV leads to the formation of an amorphous $\mathrm{Al}_{2} \mathrm{O}_{3}$ phase [136]. Crowell et al. [137] have presented strong evidence that this is a two-stage process. In what they call the preoxide stage, oxygen dissociatively chemisorbs and occupies both surface and subsurface sites. Oxidation (as evidenced by the formation of the $54 \mathrm{eV} \mathrm{Al}^{3+}$ Auger transition) occurs when a critical number of oxygen atoms cluster together after prolonged $\mathrm{O}_{2}$ exposure or upon slight annealing. Further oxide growth is a slow, logarithmic process. Some controversy consists as to the mechanism of the oxidation. According to Johnson [138], low-temperature oxidation primarily proceeds via $\mathrm{Al}^{0}$ transport from the interface to the surface. Growth by $\mathrm{Al}^{3+}$ migration is favored by Jimenéz-Gonzaléz and Schmeisser [139], and is in agreement with the key assumption in the theory of low-temperature 

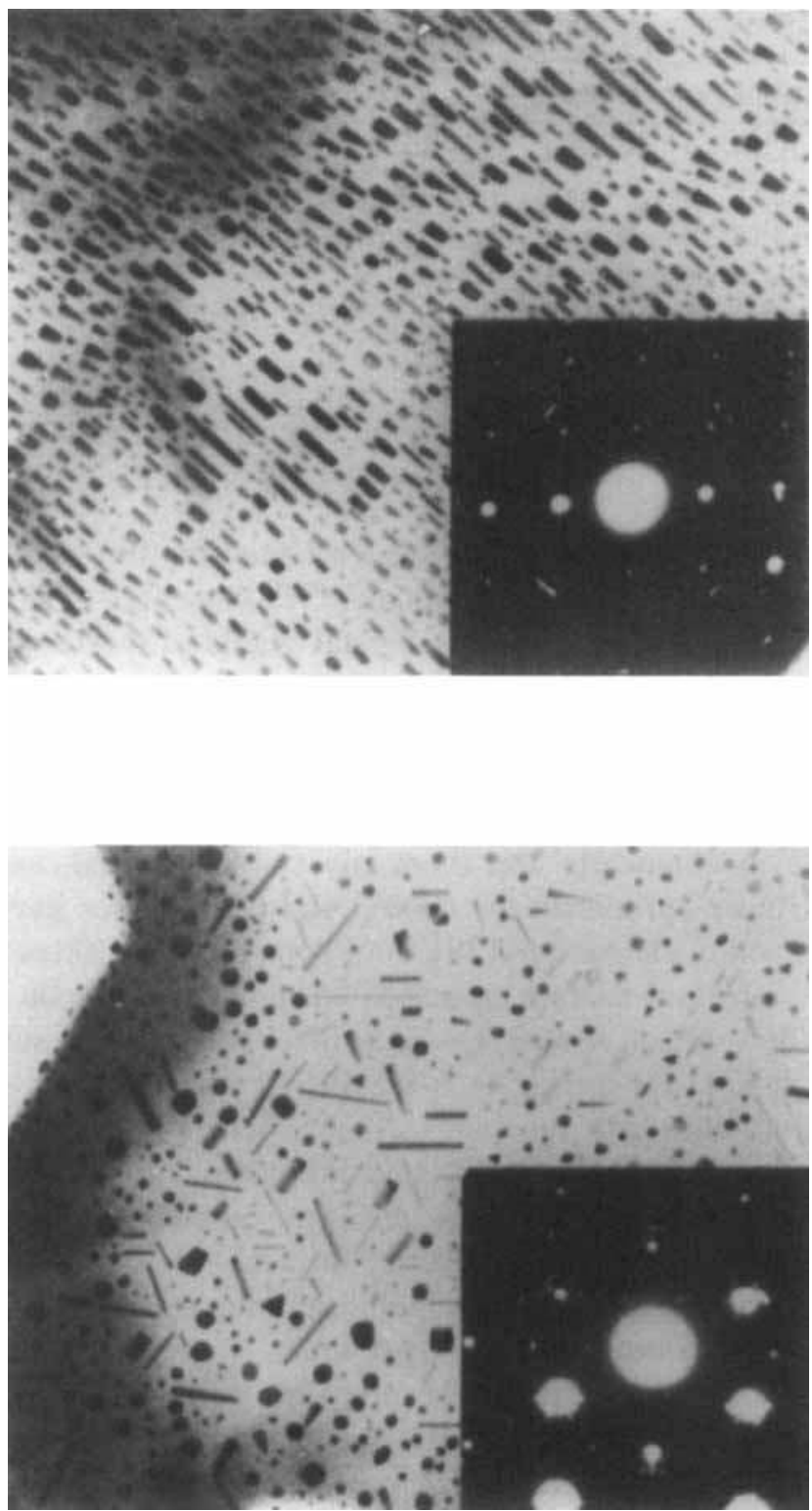

FIG. 11. Low supersaturation epitaxial Fe vapor deposits on two differently oriented single-crystal substrate grains of $\delta-\mathrm{Al}_{2} \mathrm{O}_{3}$; see Poppa et al. [129] for details. 


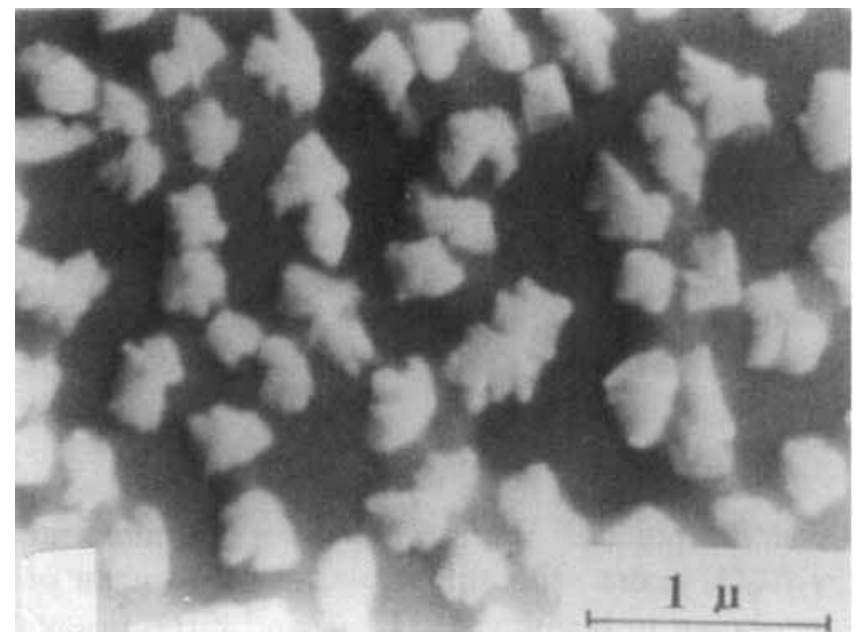

FIG. 12. Scanning electron micrograph of an $\mathrm{Al}(111)$ sample after $270 \mathrm{~min}$ oxidation in $2 \times 10^{-7} \mathrm{mbar}_{2}$ at $775 \mathrm{~K}$ (from Eldridge et al. [144]).

metal oxidation put forward by Cabrera and Mott [140]. Migration is supposed to be driven by the (constant) potential drop across the film caused by trapped oxygen ions. As the film grows, the field decreases, which explains the logarithmic growth kinetics. However, as has been shown by Kirk and Hubner [141], the rate of aluminum oxide growth strongly depends on the oxygen pressure, and much less on the crystallographic orientation of the metal, which strongly suggests that oxygen migration is an essential step in oxide formation. According to Fehlner and Mott [142], aluminum yields a network-forming oxide in which ion transport is $\sim 60 \%$ anionic, so probably both $\mathrm{Al}^{3+}$ and $\mathrm{O}^{2-}$ transport occur during oxidation. Ion mobility in glassy networks depends on the existence of channels. The closing of such channels as the oxide layer grows would yield an alternative explanation for the observed logarithmic growth kinetics, which is needed in case oxygen is mobile [142]. The thickness of amorphous $\mathrm{Al}_{2} \mathrm{O}_{3}$ layers that can be obtained by lowtemperature oxidation (in practical oxidation times) ranges from $\sim 3.0 \mathrm{~nm}$ at room temperature to about $20 \mathrm{~nm}$ at $575 \mathrm{~K}$ [143].

Oxidation at temperatures higher than about $700 \mathrm{~K}$ [143] leads to the formation of $\gamma-\mathrm{Al}_{2} \mathrm{O}_{3}$ crystals. Eldridge et al. [144] have demonstrated that the oxidation in $10^{-7}$ torr $\mathrm{O}_{2}$ at $775 \mathrm{~K}$ of sputter-cleaned and annealed $\mathrm{Al}(111)$ proceeds by nonepitaxial island growth (see Fig. 12). The islands protrude from the surface, probably simply because of lattice expansion $(\sim 40 \%)$ in going from metal to oxide, but growth is predominantly lateral. No amorphous oxide is present between the $\gamma-\mathrm{Al}_{2} \mathrm{O}_{3}$ islands under these conditions. Jimenéz-Gonzaléz and Schmeisser [139] have reported similar observations: 


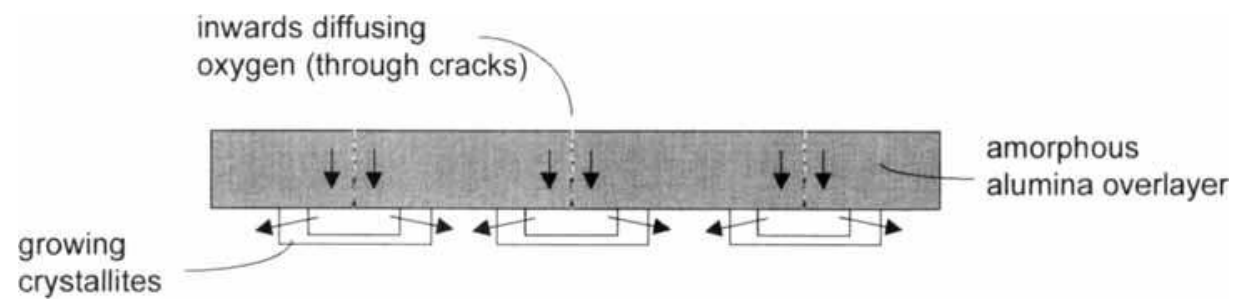

FIG. 13. Model of $\gamma-\mathrm{Al}_{2} \mathrm{O}_{3}$ grain growth beneath the amorphous passivation layer, when exposed to $\mathrm{O}_{2}$ at $T>770 \mathrm{~K}$ (adapted from Shimizu et al. [145]).

Oxidation in water vapor $\left(10^{-3}\right.$ torr, $\left.770 \mathrm{~K}\right)$ for $35 \mathrm{~min}$ resulted in a film consisting of $\gamma-\mathrm{Al}_{2} \mathrm{O}_{3}$ grains with an average grain diameter of $0.2 \mu \mathrm{m}$. The crystallites were shown to have mostly (110) and (100) orientations. A very interesting and important oxidation behavior is observed when aluminum already supporting an amorphous film is oxidized at high temperature. Eldridge et al. have put forward definitive evidence that nucleation then takes place at the metal/oxide interface and is followed by initial inward and subsequently lateral growth of $\gamma-\mathrm{Al}_{2} \mathrm{O}_{3}$ grains. The oxygen transport is through local pathways, as sketched in Fig. 13. The nature of these pathways has been exemplified by Shimizu et al. [145]. At high temperatures, differences in thermal expansion add stress to growth stresses preexisting in the amorphous alumina. These stresses are relieved through cracking of the oxide layer. Molecular oxygen then diffuses through the cracks to react with the exposed bare aluminum surface, forming $\gamma-\mathrm{Al}_{2} \mathrm{O}_{3}$ at the interface. Volume expansion due to

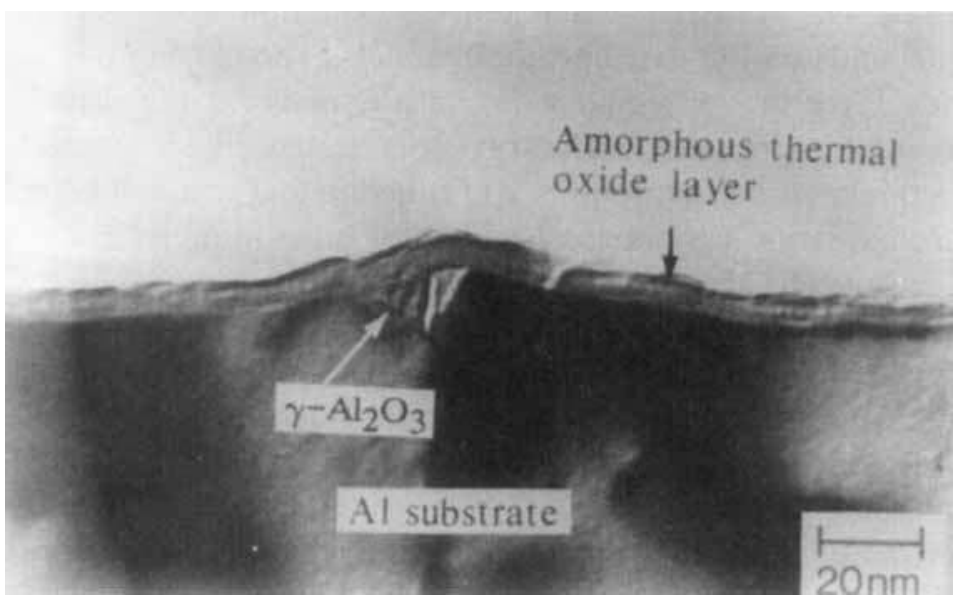

FIG. 14. Transmission electron micrograph of a passivated aluminum substrate, showing the nucleation of a $\gamma-\mathrm{Al}_{2} \mathrm{O}_{3}$ crystal at a metal ridge (from Shimizu et al. [145]). 
crystal growth probably leads to further cracking of the amorphous film. Figure 14 shows a beautiful transmission electron micrograph of the formation of such an interface crystal. At which temperature the amorphous oxide layer itself crystallizes is less clear. Thick layers have been shown to stay amorphous in the absence of oxygen or aluminum metal up to $1300 \mathrm{~K}$ [146]. Bruiesch et al. [147] report that $\gamma-\mathrm{Al}_{2} \mathrm{O}_{3}$ is obtained when an $500 \mathrm{~nm}$ thick amorphous film on silica is tempered (in air) at $1300 \mathrm{~K}$ for $1 \mathrm{~h}$, but it is not clear whether this is a lower temperature limit. Glassl et al. [148] could convert self-supporting amorphous $\mathrm{Al}_{2} \mathrm{O}_{3}$ to the $\gamma$ phase by heating in air above $870 \mathrm{~K}$.

For the use of thin alumina films as model supports, it is important that they are completely oxidized, that is, that no residual $\mathrm{Al}^{0}$ is left in the film. Precisely this aspect has been the subject of some discussion in the literature. Madden and Goodman [149] have studied oxidized thin aluminum films on a W substrate by means of Auger electron spectroscopy. Elemental aluminum is characterized by an $\mathrm{Al} \mathrm{LVV}$ transition at $68 \mathrm{eV}$, whereas this transition occurs at $54 \mathrm{eV}$ for aluminum oxide. Their results show that at an oxygen pressure of $10^{-5}$ torr, a substrate temperature of $\sim 1000 \mathrm{~K}$ is needed to eliminate all traces of elemental aluminum from an originally $3 \mathrm{~nm}$ thick film. At $700 \mathrm{~K}$, elimination of elemental $\mathrm{Al}$ from a similar film on a $\mathrm{Ru}(001)$ sample could only be achieved by prolonged oxidation at atmospheric pressure [57]. Apparently, alumina films made by thermal oxidation contain stable $\mathrm{Al}^{0}$ inclusions that can only be removed under extreme oxidation conditions. For alumina films on Al single crystals and foils, it is very difficult to distinguish $\mathrm{Al}$ inclusions from the substrate Al by means of AES or XPS. There is some evidence, however, that $\mathrm{Al}$ inclusions give rise to the $400 \mathrm{~cm}^{-1}$ peak observed in EELS spectra from alumina films made in Al-rich environments by Chen et al. [150], although this assignment has been questioned by others $[57,58]$.

Another point of discussion needing attention is the apparent "porosity" of thin alumina films, which has been observed in several studies $[51,138,150-155]$. Johnson [138] claims that at low temperatures $(<600 \mathrm{~K})$, aluminum metal can migrate some $3 \mathrm{~nm}$ into amorphous alumina films. Belton and Schmieg [154] report the migration of zero valent Al to the surface of thin $\mathrm{Al}_{2} \mathrm{O}_{3}$ layers prepared by low-temperature aluminum oxidation when annealed in vacuum but do not mention the temperature at which this occurs. Not only $\mathrm{Al}$ migrates into alumina layers, but $\mathrm{Ni}$ and $\mathrm{Rh}$ probably also, as might be concluded from the work presented in Refs. 152, and 153. Chen et al. [152] investigated the $\mathrm{Ni} / \mathrm{Al}_{2} \mathrm{O}_{3} / \mathrm{Al}(111)$ system, where the oxide layer was prepared by heating the crystal to $700 \mathrm{~K}$ in vacuum following the adsorption of oxygen at $300 \mathrm{~K}$, or by exposure of the crystal surface to oxygen at $700 \mathrm{~K}$. From AES and EELS measurements they conclude that upon heating the system, $\mathrm{Ni}$ (deposited at $200 \mathrm{~K}$ ) and $\mathrm{Al}^{\circ}$ interdiffuse in macroscopic channels (cracks) within the alumina layer. From their data, however, interdiffusion in microscopic channels cannot be excluded. The evidence Chen 
and coworkers put forward for the model is that the $870 \mathrm{~cm}^{-1}$ EELS peak is not modified in frequency during inward $\mathrm{Ni}$ diffusion, as they expect it would be if diffusion occurred through microscopic channels. As this peak is not affected by the presence of $\mathrm{Al}^{0}$ throughout the oxide [150]; however, it may not be affected by $\mathrm{Ni}^{0}$ either. Moreover, interdiffusion through microscopic channels would better explain the oxide layer thickness dependence [152] of the onset of Ni diffusion: As mentioned above, closing of channels in glassy oxides has been suggested for the diffusion being rather sharply limited to a few nanometers [142], which is in accordance with the 3- $\mathrm{nm}$ barrier mentioned above [138]. The same explanation was given by Chen et al. for a similar case concerning “disappearing Rh" [151]. They deposited $\mathrm{Rh}$ on thin $\mathrm{Al}_{2} \mathrm{O}_{3}$ films (made by reactive evaporation) on a $\mathrm{Mo}(110)$ substrate. Upon annealing in vacuum the $\mathrm{Rh}$ gradually disappears from the alumina surface, as evidenced by AES and thermal desorption of CO. Apparently Rh diffuses into the aluminum oxide, but, as the authors show, the AES observations strongly suggest that the deposited $\mathrm{Rh}$ remains near the surface region.

Reactive evaporation of aluminum in $\mathrm{O}_{2}$ has been applied by several authors for the growth of $\mathrm{Al}_{2} \mathrm{O}_{3}$ films on different substrates. At a deposition rate of $0.2-0.3 \mathrm{~nm} / \mathrm{min}$, the oxide growing is stoichiometric $\mathrm{Al}_{2} \mathrm{O}_{3}$ if the $\mathrm{O}_{2}$ pressure is higher than $10^{-8}$ torr; if the $\mathrm{O}_{2}$ pressure is less, elemental $\mathrm{Al}$ is present in the film [150]. The structure of the stoichiometric film strongly depends on the temperature at which the deposition takes place and the possible heat treatment afterwards. Glassl et al. [148] deposited alumina films of $10-20 \mathrm{~nm}$ on $\mathrm{NaCl}$, floated them of in water and mounted the films on $\mathrm{Au}$ grids. After heating in $\mathrm{O}_{2}$ at $720 \mathrm{~K}$ for several hours, the films showed only diffraction features attributable to amorphous alumina; heating in air above $870 \mathrm{~K}$, however, led to the formation of $\gamma-\mathrm{Al}_{2} \mathrm{O}_{3}$. Chen et al. [150] used EELS to study the structural changes occurring when a stoichiometric $\mathrm{Al}_{2} \mathrm{O}_{3}$ film formed by codeposition of aluminum and oxygen on $\mathrm{Mo}(110)$ at $110 \mathrm{~K}$ is heated to $1100 \mathrm{~K}$ (in vacuum). Above $700 \mathrm{~K}$, distinct energy loss features develop, indicating some local " $\gamma$-like" ordering. The spectra indicate that long-range ordering requires temperatures as high as $1100 \mathrm{~K}$.

Chen and Goodman [156] have shown that a thin $(0.5-4 \mathrm{~nm})$ epitaxial alumina film can be grown on $\mathrm{Ta}(110)$. The LEED patterns developing when depositing $0.2-0.3 \mathrm{~nm}$ of oxide per minute $\left(\mathrm{O}_{2}\right.$ background of $5 \times 10^{-7}$ torr, substrate temperature of $900 \mathrm{~K}$ ) point to the two-dimensional growth of a long-range-ordered epitaxial $\mathrm{Al}_{2} \mathrm{O}_{3}$ film with a hexagonal lattice corresponding to the close packing of oxygen anions. Since both $\alpha$ - and $\gamma$-alumina involve close-packed oxygen planes, no definitive structural determination of the thin film can be reached based on the LEED data, which only reveal the oxygen ordering.

Anodic film growth on aluminum has received considerable attention because of its importance in producing passivation layers. Ruckenstein and Malhostra [157] were the first to use anodic oxidation for the preparation of planar model alumina supports, and their approach has been followed by quite a 
number of authors; see Table 5 . The films are usually made by anodization in near-neutral $\mathrm{pH}$ electrolytes (among others, ammonium borate, tartarate, citrate), where dissolution at the film/electrolyte interface is insignificant. Film growth then proceeds at high current efficiency, with relatively uniform film thickening with time. The detailed growth mechanism of the anodic films is complex and still controversial. What is generally accepted is that both outward migration of $\mathrm{Al}^{3+}$ and inward miration of $\mathrm{O}^{2-}$ and $\mathrm{OH}^{-}$ions contribute to the film growth. There is, however, a competition between outward film growth and direct ejection of migrating $\mathrm{Al}^{3+}$ ions in the electrolyte. The lower the current efficiency, the more $\mathrm{Al}^{3+}$ is lost by the ejection mechanism; at the so-called critical current density, all $\mathrm{Al}^{3+}$ migrating outward is lost, and film growth is completely inward. Anions of the electrolyte-and their transformation products - may be mobile inward or outward under the applied field. As a consequence, anodic films generally display a region of relatively pure alumina adjacent to the metal/oxide interface and an outer region of anion incorporated alumina. The level of incorporation can amount to 5\%. Obviously, this artefact can be used to incorporate specific ions which have known or potential catalytic consequences.

Concerning film structure, the films formed at ambient temperatures are electron diffraction insensitive and thus are amorphous or composed of relatively fine microcrystallites embedded in an amorphous phase. Under specific conditions, however, the formation of both $\gamma$ - and $\gamma^{\prime}$-alumina (the latter having randomly arranged cations) has been observed. Upon heat treatment, the film crystallizes to give $\gamma-\mathrm{Al}_{2} \mathrm{O}_{3}$. It has been shown that the amorphousto-crystalline transition is sensitive to incorporated anions: Borate, for example, inhibits the structural rearrangements needed for the growth of existing crystalline nuclei in the contaminated region of the alumina film. Below the critical current density, penetration paths existing because of inward $\mathrm{O}^{2-}$ migration cannot be healed by outward moving $\mathrm{Al}^{3+}$. From these penetration paths pores can develop, and anodization then results in a porous film.

Summarizing, the preparation of good alumina model supports is not without difficulties. From the viewpoint of definition, single crystalline supports such as $\alpha-\mathrm{Al}_{2} \mathrm{O}_{3}(\overline{1} 012)$ and (0001), which are thermally stable and can be cleaned easily, are the best candidates. If one aims at preparing a flat replica of the conventional high surface area $\alpha$-aluminas, however, single-crystalline $\alpha-\mathrm{Al}_{2} \mathrm{O}_{3}$ is not preferable. Thin, flat $\gamma-\mathrm{Al}_{2} \mathrm{O}_{3}$ films can be made directly by thermal oxidation. One way to proceed is to completely oxidize a bare aluminum film evaporated onto a suitable substrate. Rather severe conditions are necessary for complete oxidation: $10^{-5}$ torr $\mathrm{O}_{2}$, prolonged treatment at $\sim 1000$ $\mathrm{K}$ is needed to ensure that no residual $\mathrm{Al}^{\circ}$ is left; in air, $700 \mathrm{~K}$ suffices. Thin, stoichiometric alumina films can also be made by evaporation of alumina or of aluminum in $10^{-8}$ torr $\mathrm{O}_{2}$. Yet another method is anodization in suitable electrolytes. In these cases amorphous films are made, which can be converted to the $\gamma$ phase either by annealing in vacuum at $1100 \mathrm{~K}$ or by thermal treatment in air at $\sim 900 \mathrm{~K}$. Films made by anodization can contain up to $5 \%$ 
impurities (originating from the electrolyte), which is a serious drawback of this preparation method. Finally, it should be noted that thermal treatment results in dehydroxylation of the alumina surface, which influences its reactivity considerably.

\section{Titania}

Model $\mathrm{TiO}_{2}$ supports (see Table 6 for an overview) have mainly been used in studies of the SMSI effect and have turned out to be of great value there. Although rutile is by far the most abundant polymorph of $\mathrm{TiO}_{2}$, high surface area catalyst supports are mostly prepared using anatase, which is more stable than rutile at low temperatures. Upon heating such supports to temperatures higher than $1000 \mathrm{~K}$, anatase is converted to rutile and the surface area is drastically reduced. To our knowledge there are no model studies concerning the anatase polymorph of $\mathrm{TiO}_{2}$ specifically: All single crystal supports used are of the rutile type; regarding the foils and films used in model studies, Tatarchuk and Dumesic report that oxidation of $\mathrm{Ti}$ produces mostly rutile overlayers [91]. The most stable faces of $\mathrm{TiO}_{2}$ (rutile) and $\mathrm{TiO}_{2}$ (anatase) are depicted in Fig. 15. The surfaces differ in that the coordinatively unsaturated Ti ions in the rutile surface are surrounded by oxygen atoms of zero charge excess, whereas two of the oxygens surrounding the $\mathrm{Ti}$ ions in the anatase

TABLE 6

Model $\mathrm{TiO}_{2}$ Supports

\begin{tabular}{|c|c|c|}
\hline Method of preparation & Thickness & Ref. \\
\hline \multicolumn{3}{|l|}{ Single crystals } \\
\hline Rutile (001) & - & 69,211 \\
\hline Rutile (100) & - & $24,53,380$ \\
\hline Rutile (110) & - & $\begin{array}{l}27,29,161,212-214 \\
381,382\end{array}$ \\
\hline $\mathrm{Ti}(0001)$, sev. $\min 10^{-4}$ torr $\mathrm{O}_{2}, 400 \mathrm{~K}$ & $4 \mathrm{~nm}$ & 160,383 \\
\hline $\mathrm{Ti}(0001), 30 \mathrm{~min} 10^{-6}$ torr $\mathrm{O}_{2}, 775 \mathrm{~K}$ & $?$ & 254,258 \\
\hline \multicolumn{3}{|l|}{ Foils } \\
\hline $5 \min 10^{-6}$ torr $\mathrm{O}_{2}$ at $670 \mathrm{~K}$ & $>5 \mathrm{~nm}$ & 384 \\
\hline "Mild oxidation"” & $?$ & 64 \\
\hline $30 \mathrm{~min} 10^{-6}$ torr $\mathrm{O}_{2}$ at $820 \mathrm{~K}$ & $>8 \mathrm{~nm}$ & 385 \\
\hline $2-3 \mathrm{~h} 760$ torr $\mathrm{O}_{2}$ at $570-670 \mathrm{~K}$ & $-50 \mathrm{~nm}$ & $91-94$ \\
\hline \multicolumn{3}{|l|}{ Films } \\
\hline $5 \mathrm{~nm}$; ir at RT & $\sim 5 \mathrm{~nm}$ & 15 \\
\hline \multicolumn{3}{|l|}{ Reactive evaporation } \\
\hline On rhenium & $?$ & 386,387 \\
\hline On rhodium in $10^{-7}$ torr $\mathrm{O}_{2}$ & $\sim 1 \mathrm{~nm}$ & 388 \\
\hline \multicolumn{3}{|l|}{ Microspheres } \\
\hline $\mathrm{TiO}_{2}$ and $\mathrm{TiO}_{2} / \mathrm{SiO}_{2}$ & $\sim 50 \mathrm{~nm}$ & $13,14,123,346,389$ \\
\hline
\end{tabular}




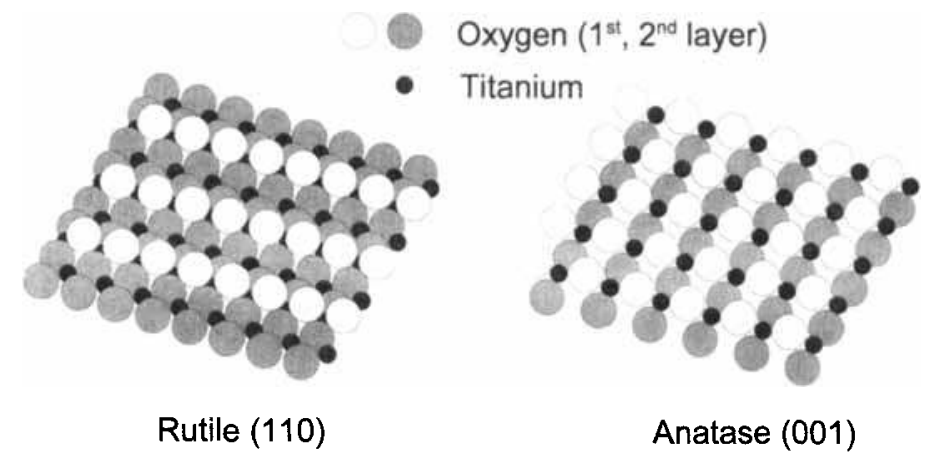

FIG. 15. The most stable face of $\mathrm{TiO}_{2}$ (rutile) and of $\mathrm{TiO}_{2}$ (anatase). Top layer oxygens are open circles, deeper oxygens are shaded.

surface have an ion charge excess of $-2 / 3$. Consequently, the two surfaces are expected to show different chemical reactivity [158].

The rutile (110) surface can be obtained in a nearly perfect state by simple polishing and annealing treatment. Both $(1 \times 1)$ and $(2 \times 1)$ LEED patterns have been observed, but the electronic properties of the respective surfaces appear to be essentially the same [159]. The other two surfaces used in single crystalline form as model supports are the (100) and (001) ones. The (100) surface reconstructs upon polishing and annealing to create (110) facets; the (001) face, which is the least stable, exhibits both faceting and disorder when it is ion bombarded and/or annealed [159].

Ion bombarding and annealing of $\mathrm{TiO}_{2}$ surfaces are known to create point defects in the form of oxygen ion vacancies very easily, which has dramatic consequences for the electronic configuration $[29,159]$ and can lead to nonreproducing results $[53,160]$. The effect is sometimes used to enhance the conductivity of the crystal bulk when studying the surface with techniques sensitive to charging [161].

Air-exposed $\mathrm{TiO}_{2}$ powders are always covered with a monolayer of $\mathrm{OH}^{-}$. Van Veen has studied the hydroxyl population of high surface area anatase [162]. The population turns out to be inhomogeneous: Some $70 \%$ of the $\mathrm{OH}$ groups, corresponding to an IR band at $3730 \mathrm{~cm}^{-1}$, has a basic character as they can be exchanged with $F$ ions and are responsible for the adsorption of $\mathrm{HCl}$; the other $30 \%$ (IR band at $3670 \mathrm{~cm}^{-1}$ ) are acidic; for example, they interact strongly with $\mathrm{NaOH}$. As dehydroxylation of $\mathrm{TiO}_{2}$ powders takes place upon heating in vacuum to $775 \mathrm{~K}$ [159], both the usual preparation procedures for single $\mathrm{TiO}_{2}$ crystals and thermal oxidation of Ti lead to (partly) dehydroxylated model surfaces. If a fully hydroxylated surface is desired, annealing and subsequent quenching in a background of $\mathrm{H}_{2} \mathrm{O}$ is probably sufficient, as the point defects created by annealing are very effective in dissociating $\mathrm{H}_{2} \mathrm{O}$ to give adsorbed $\mathrm{OH}^{-}$ions [159]. 


\section{Magnesium Oxide}

$\mathrm{MgO}$, being a rocksalt oxide, cleaves extremely well along the (100) plane. For that reason, the $\mathrm{MgO}(100)$ surface has been used in quite a number of model studies; see Table 7 . The (100) plane represents the crystal face of lowest energy and is assumed to occur preferentially as the surface of high surface area $\mathrm{MgO}$ powders, although naturally occurring faces often include (111) [159]. The (100) surfaces made by cleavage in air are different from those made in UHV: The air-cleaved ones present a great number of defects (especially monatomic steps) which cause inhomogeneities in the deposit of metal particles by evaporation [163]. Moreover, as is clear from the comparative study of Metois et al. [164], the (100) surface is sensitive to high temperatures as well as to electron beam radiation (AES, TEM). The (111)oriented $\mathrm{MgO}$ surface seems to be cleaner and better defined, and might therefore be a better candidate for model support studies.

Thin films of $\mathrm{MgO}$ can be deposited by evaporating $\mathrm{MgO}[163,165,166]$ or by evaporating $\mathrm{Mg}$ in an oxygen background [167,168]. On dehydroxylated mica, vapor deposition of $\mathrm{MgO}$ at $600 \mathrm{~K}$ results in epitaxial alignment with (111) planes parallel to the surface [165,166]. The thin film formed is stable and has bulk-like electronic properties but is enriched in $\mathrm{Mg}$, probably due to a $\mathrm{Mg}$ termination. Preparation at room temperature, however, results in a more disordered film with grain boundaries. Upon annealing of these films after deposition of particles, oxygen diffusing over the grain boundaries to the Mg-rich surface has been seen to deactivate the metallic particles.

TABLE 7

Model MgO Supports

\begin{tabular}{lll}
\hline \multicolumn{1}{c}{ Method of preparation } & Thickness & \multicolumn{1}{c}{ Ref. } \\
\hline Single crystals & - & 164,390 \\
e-beam cleaved $\mathrm{MgO}(100),(111)$ & - & 391 \\
Air-cleaved $\mathrm{MgO}(100)$ & - & $273,392,393$ \\
Cleaved $\mathrm{MgO}(100)$ & - & 275 \\
UHV- and air-cleaved $\mathrm{MgO}(100)$ & - & 394 \\
UHV-cleaved $\mathrm{MgO}(100)$ & & 163 \\
Reactive evaporation & $60 \mathrm{~nm}$ & 165 \\
$\mathrm{MgO}(100) / \mathrm{LiF}, \sim 600 \mathrm{~K}$ & $7-10 \mathrm{ML}$ & 166 \\
$\mathrm{MgO} / \mathrm{mica}, \mathrm{RT}$ and $620 \mathrm{~K}$ & $7-10 \mathrm{ML}$ & \\
$\mathrm{MgO}(111) / \mathrm{mica}, \mathrm{RT}$ and $620 \mathrm{~K}$ & & 167 \\
$\mathrm{MgO}(100) / \mathrm{Mo}(100), 10^{-7}$ torr $\mathrm{O}_{2}$, & $<14 \mathrm{ML}$ & 168 \\
$\quad 200-600 \mathrm{~K}$ & $5 \mathrm{~nm}$ & \\
$\mathrm{MgO}(111) / \mathrm{Mo}(110), 10^{-7}$ torr $\mathrm{O}_{2} \mathrm{RT}$ & & $43,171,389,391$ \\
\hline Microcubes and platelets & $50-100 \mathrm{~nm}$ & \\
MgO smoke &
\end{tabular}


Evaporation of $\mathrm{Mg}$ in oxygen produces stoichiometric $\mathrm{MgO}$ films, if the oxygen background pressure is in the order of $10^{-7}$ torr or higher [167]. On $\mathrm{Mo}(100)$, the films grow epitaxial with the (100) face of $\mathrm{MgO}$ oriented parallel to the substrate. Films with long-range order can be formed in the 200-600 K substrate temperature range. On the (110) face of Mo, epitaxial $\mathrm{MgO}(111)$ films can be grown under similar conditions [168]. Ion scattering spectroscopy shows that the surface of these films is composed of both oxygen and magnesium; the films are stable up to $1400 \mathrm{~K}$.

High surface area $\mathrm{MgO}$ is usually prepared by decomposition of the hydroxide and retains both chemisorbed and physisorbed water. Upon heating in vacuo, all physisorbed water is desorbed at $\sim 550 \mathrm{~K}$; half of the chemisorbed water is removed at about $700 \mathrm{~K}$, whereas dehydroxylation is complete at $1100 \mathrm{~K}$ [169]. Rehydroxylation is possible at room temperature, as is evident from single crystal studies [159]: When cleaved $\mathrm{MgO}(100)$ surfaces are exposed to air, point defects are formed due to reaction with water vapor.

$\mathrm{MgO}$ supports suitable for TEM analysis can be made by burning a ribbon of magnesium in a gas flame [170]. The smoke produced mainly consists of small cubic crystals, which can be used to make profile images [171]. Under special conditions, however, the smoke also contains platelets of $\mathrm{MgO}$, of about $1 \times 2 \times 0.05 \mu \mathrm{m}$. These platelets are perfect crystals [exposing the (100) face] with very few atomic steps, and they are transparent enough to be used as TEM supports.

\section{E. Zinc Oxide}

$\mathrm{ZnO}$ is well known in catalysis for its use in methanol synthesis catalysts [172]. The interaction between $\mathrm{Cu}$ and $\mathrm{ZnO}$ is crucial for the performance of these catalysts and has been the subject of numerous studies, of which some can be considered as model studies in the way we define them, in that they concern $\mathrm{Cu}$ metal particles on single crystalline $\mathrm{ZnO}[26,173-178]$.

Although the nonpolar $(10 \overline{1} 0)$ face is the most interesting in relation to methanol synthesis [172], the polar (0001)- $\mathrm{Zn}$ and (0001)-O faces have most been used. The interaction between $\mathrm{ZnO}$ surfaces and metal deposits is quite strong and varies between the surface types. More details on the structure and properties of $\mathrm{ZnO}$ surfaces can be found in the books of Henrich and Cox [159] and of Kung [179].

\section{F. Zirconia}

$\mathrm{ZrO}_{2}$ is interesting both as support and as catalyst per se. The impetus for using model supports $[17,90,180-183]$ is mainly to better understand the apparent strong metal- $\mathrm{ZrO}_{2}$ support interactions. Commercial single-crystalline $\mathrm{ZrO}_{2}$ is yttria stabilized and has a cubic structure. The cubic structure is only stable at high temperatures $\left(>2650 \mathrm{~K}\right.$ [184]) for pure $\mathrm{ZrO}_{2}$, the low 
temperature polymorph being monoclinic; additives such as $\mathrm{Y}_{2} \mathrm{O}_{3}, \mathrm{CeO}_{2}$, $\mathrm{MgO}$, and $\mathrm{CaO}$ kinetically stabilize the high-T tetragonal and cubic forms.

De Jong et al. [17,182,183] have made a thin film $\mathrm{ZrO}_{2}$ support by exposing a passivated silicon wafer to a solution of zirconium ethoxide and acetic acid in ethanol. Some of the ethoxide groups exchange with acetate groups, and the zirconium ethoxide/acetate reacts with the silanol groups present at the silica surface. Upon calcination, about one monolayer of $\mathrm{ZrO}_{2}$ is formed.

\section{G. Ceria and Lanthana}

Ceria $\left(\mathrm{CeO}_{2}\right)$ and lanthana $\left(\mathrm{La}_{2} \mathrm{O}_{3}\right)$ model supports have been used by Gorte and coworkers [185-189] to study the role of these oxides in automobile emission control catalysis. Gorte et al. prepare these films by spray pyrolysis of aqueous solutions of $\mathrm{Ce}$ and $\mathrm{La}$ nitrates onto hot $(600-700 \mathrm{~K}) \mathrm{Al}_{2} \mathrm{O}_{3}$ or $\mathrm{NaCl}$ crystals. The nitrates decompose to form ceria (lanthana) after a subsequent heat treatment. The films produced have a thickness of $10-20 \mu \mathrm{m}$, are amorphous, and are macroscopically rough.

\section{H. Mica}

Muscovite mica $\left[\mathrm{KAl}_{2}\left(\mathrm{AlSi}_{3} \mathrm{O}_{10}\right)(\mathrm{OH})_{2}\right]$ consists of sheets of $(\mathrm{Al}, \mathrm{Si}) \mathrm{O}_{4}$ tetrahedra with a layer of aluminum ions in between, which are octahedrally coordinated by oxygen ions of the tetrahedra and additional hydroxyl groups [190]. Mica is well available in its high-grade natural form and is easily cleavable because of its layered structure, which are major advantages for a substrate material for epitaxial nucleation experiments. Therefore, mica has been used frequently as support for model catalyst investigations [52,77,81, 191-203].

Since mica contains structural water, a freshly cleaved surface is always more or less hydroxylated [191,197,198], the state of hydroxylation being slightly influenced by the outgassing history of the sample [197]. As the state of hydroxylation strongly influences nucleation and mobility of metals, it has been suggested that mica substrates be annealed for about $1 \mathrm{~h}$ at $770 \mathrm{~K}$ after cleavage to obtain reproducible surface conditions for metal nucleations [197].

\section{Carbon}

Although carbon supports come in many different forms [204], they essentially consist of more or less crystalline graphite. Because graphites are highly conducting, a flat graphite such as HOPG (highly oriented pyrolitic graphite) is a perfect candidate for model studies. Indeed, HOPG and the less well ordered high-purity graphites are the most used carbon model supports; see Table 8. For TEM studies, however, amorphous supports are preferred; 
TABLE 8

Model Carbon Supports

\begin{tabular}{lll}
\hline \multicolumn{1}{c}{ Method of preparation } & Thickness & \multicolumn{1}{c}{ Ref. } \\
\hline Single crystals & & \\
Graphite plate & - & 31 \\
Amorphized graphite & - & 395 \\
Graphite sheets & - & 396 \\
HOPG and (functionalized) graphite & - & $59,73-75$ \\
Sputtered graphite & - & 60 \\
HOPG & & $61,62,66-68,70,71,397$ \\
Thin film & $10-100 \mathrm{~nm}$ & $28,205-207$ \\
$\quad$ Evaporated carbon, amorphous &
\end{tabular}

they can be made by evaporation of carbon onto suitable substrate like mica or $\mathrm{NaCl}[28,205-207]$.

Wolf and coworkers investigated the influence of functionalization of graphite substrates on the behavior of metal deposits [59,73-75]. They conclude that the flatness and well-ordered nature of HOPG make its surface lubricating, which strongly enhances the mobility of deposited crystallites. Exposure to concentrated nitric acid introduces acidic functional groups as well as some surface roughness, which leads to better anchoring of the supported crystallites. With the same objective, graphite surfaces in UHV are sometimes exposed to charged particles for several hours [60,208]: Adsorbed ions acting as nucleation centers increase the affinity of the surface for metal vapor.

\section{SYNTHESIS OF CATALYSTS ON MODEL SUPPORTS}

Several approaches have been explored to deposit the catalytically active phase on top of the model support. Straightforward evaporation of a metal onto the model support represents the most often used technique, but alternatives that come closer to industrial catalyst manufacture such as impregnation and exchange in solution have been applied as well. Also chemical vapor deposition and lithographic procedures as used in the fabrication of electronic devices have incidentally been used.

No matter which method is selected to make a model system, two important requirements have to be fulfilled if the model is to be subjected to reaction conditions (which is the ultimate test for its validity). The first is that the system must be thermally stable against sintering, volatilization, and reaction with the support, at the temperature of the catalytic reaction. The second is 
that the number density of particles per unit surface area is sufficiently high, both for reactivity and for spectroscopic studies.

\section{A. Deposition of Metals by Evaporation}

Evaporation is by far the most applied method to deposit metal particles on a substrate. The particle size depends on nucleation and growth phenomena; important are metal flux during evaporation, substrate conditions (smooth, homogeneous, or defects and impurities acting as preferred nucleation sites) and temperature; and parameters such as heat of adsorption of the metal on the substrate, diffusion energy over the substrate, hopping distance, and concentration of preferred nucleation centers.

Because the surface free energy of an oxide surface is relatively low, metal atoms deposited on the surface usually form three-dimensional particles. Nucleation theory predicts that stable particles can exist up to a certain number density $N_{\max }$; for higher densities the particles coalesce. Two kinds of nucleation need to be considered, random and preferred. Random nucleation occurs if all sites on the support are equivalent and the interaction with the adatoms is moderate, corresponding to adatom-substrate adsorption energies of 1-1.5 $\mathrm{eV}(100-150 \mathrm{~kJ} / \mathrm{mol})$ [8]. Actually, the important parameter which governs the average particle size is the difference between the adsorption energy $E_{a}$ and its activation energy for diffusion across the surface, $E_{d}$. The latter is assumed to be of the order of half the adsorption energy. For typical deposition temperatures of 500-750 K, one may roughly expect a maximum number on the order of $1-2 \times 10^{12}$ particles per $\mathrm{cm}^{-2}$ on the defect free surfaces of $\alpha-\mathrm{Al}_{2} \mathrm{O}_{3}$, sapphire or mica $[8,135,194]$.

Preferred nucleation takes place if the substrate contains sites (defects, impurities) where adatoms bind stronger than on sites where random nucleation occurs. Adatom adsorption energies have been estimated to be 200$300 \mathrm{~kJ} / \mathrm{mole}$ for palladium atoms on defect-rich $\alpha-\mathrm{Al}_{2} \mathrm{O}_{3}$, sapphire and mica $[8,135,194]$. The maximum number of particles approaches that of the defects. Because the nucleation rate is high, all particles have had approximately the same length of time for growth, causing particle size distributions to be considerably narrower than in the case of random nucleation.

In practice, metal deposition by evaporation will occur in a mixture of homogeneous and heterogeneous nucleation. For both, the maximum achievable number density increases with stronger adatom-substrate interaction, higher flux, and decreasing temperature, but is typically in the range of $1 \times$ $10^{11}-5 \times 10^{12}$ particles per $\mathrm{cm}^{2}$, that is, of the same order of magnitude as in supported catalysts.

An important conclusion from the nucleation and growth studies of palladium particles on various substrates is that model catalysts with realistic particle densities can be prepared with the substrate at high temperature, such that thermal stability is ensured [8]. Although preparations at room temper- 


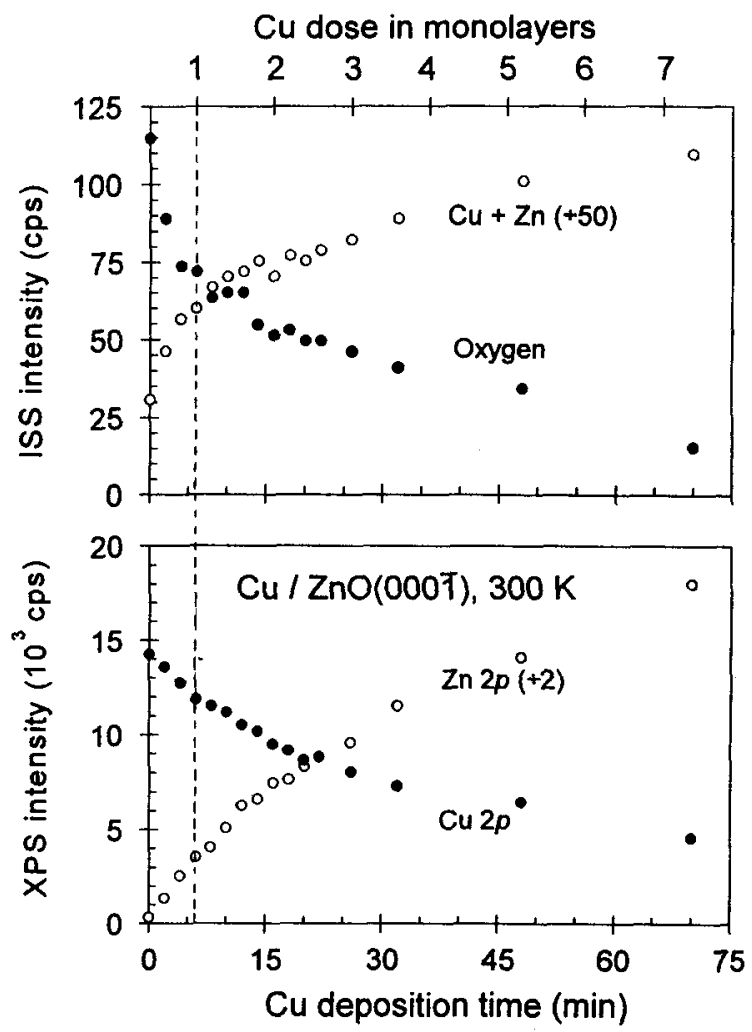

FIG. 16. Exposure calibration plots [175] for $\mathrm{Cu}$ deposits on $\mathrm{ZnO}(001)$. $\mathrm{Cu}(2 p)$ and $\mathrm{Zn}(2 p)$ XPS intensities as well as oxygen and $\mathrm{Cu}+\mathrm{Zn}$ LEIS intensities are plotted as a function of deposition time at room temperature. The data in this figure and additional LEED data evidence that the first $\mathrm{Cu}$ atoms form a $p(1 \times 1)$ overlayer $\left(1.1 \times 10^{15} \mathrm{Cu}\right.$ atoms $\left.\mathrm{cm}^{-2}\right)$, and that further $\mathrm{Cu}$ growth is predominantly as $\mathrm{Cu}(111)\left(1.77 \times 10^{15} \mathrm{~cm}^{-2}\right)$; see Campbell et al. [175] for details.

ature will give samples with higher number densities of particles, these will inevitably coalesce when used at higher temperature.

Evaporation represents a convenient way for depositing metals on model supports. Evaporator devices for application in vacuum are commercially available or are relatively easily constructed. Determining the number of deposited atoms is possible with the electron or ion spectroscopies (XPS, AES, LEIS, RBS). Figure 16 shows an example of an exposure calibration curve [175]. The disadvantage of the evaporation technique is that one always obtains rather broad particle size distributions, particularly if the homogeneous nucleation mechanism operates; see Fig. 17 [163]. Heterogeneous nucleation results in narrower distributions, but this mechanism acts on defect-rich surfaces, implying a support surface with less definition.

An elegant (though not accessible for every laboratory) variation on metal 


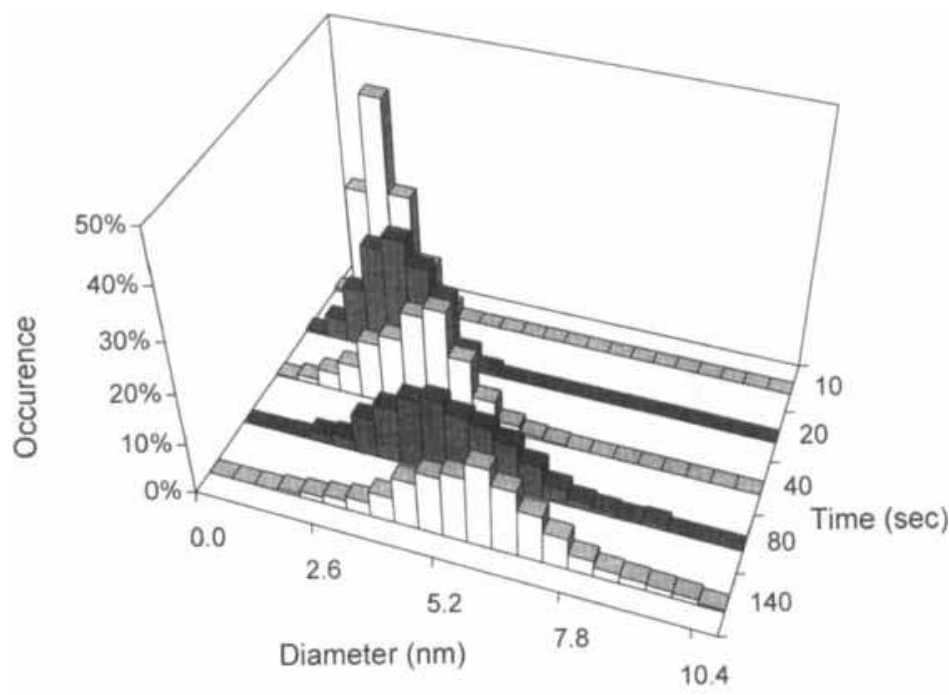

FIG. 17. Particle size distributions corresponding to increasing exposures of a $\mathrm{MgO}(100)$ film to a $\mathrm{Pd}$ beam $\left(10^{13} \mathrm{~cm}^{-2} \mathrm{~s}^{-1}\right.$ ) at $670 \mathrm{~K}$ (with data from Chapon et al. [163]).

evaporation is to use a beam of mass-selected clusters, which are subsequently deposited on the model support [209]. Although this appears as the ultimate procedure to produce monodisperse particles, the main problem is thermal stability, as bonding between the clusters and the support is very weak. Yet another procedure captured mass selected Ag clusters in an inert liquid; the colloidal suspension was subsequently used to impregnate the (high surface area) support. The size distribution of the Ag clusters remained essentially unaltered after oxidation and reduction treatments [210]. Experiments on $\mathrm{Pd} / \mathrm{C}$, prepared by depositing palladium clusters without mass selection on a highly oriented pyrolytic graphite support, were reported by Cadete Santos Aires et al. [62].

\section{B. Preparation of Model Catalysts by Chemical Vapor Deposition}

Chemical vapor deposition, sometimes referred to as molecular vapor deposition, is a method to apply organometallic catalyst precursors to a model support in vacuum. Clusters that have been used for this purpose are the carbonyl and allyl complexes of rhodium and rhenium; see Table 9.

If the organometallic precursor has a sufficiently high vapor pressure at room temperature (e.g., millitorrs or higher), dosing of the compound in vacuum through a needle valve is easily accomplished. After exposure of the model support to the vapor, the system is heated in vacuum or under hydrogen to remove the ligands and convert the metal in the zero-valent state. Examples 
TABLE 9

CVD Preparations of Model Catalysts

\begin{tabular}{lll}
\hline \multicolumn{1}{c}{ Precursor } & \multicolumn{1}{c}{ Support } & \multicolumn{1}{c}{ Ref. } \\
\hline $\mathrm{Co}_{2}(\mathrm{CO})_{8}$ & $\alpha_{-}-\mathrm{Al}_{2} \mathrm{O}_{3}(0001)$ & 88,89 \\
$\left.\mathrm{Rh}_{(\mathrm{CH}} \mathrm{CHCH}_{2}\right)_{2}$ & $\mathrm{TiO}_{2}(001)$ & 398 \\
$\left.\mathrm{Rh}_{(\mathrm{CH}} \mathrm{CHCH}_{2}\right)_{3}$ & $\mathrm{TiO}_{2}(001)$ & 211 \\
{$\left[\mathrm{Rh}(\mathrm{CO})_{2} \mathrm{Cl}\right]_{2}$} & $\mathrm{Al}_{2} \mathrm{O}_{3} / \mathrm{Al}$ & $215-217$ \\
{$\left[\mathrm{Rh}(\mathrm{CO})_{2} \mathrm{Cl}\right]_{2}$} & $\mathrm{TiO}_{2}(110)$ & $212-214$ \\
$\mathrm{Rh}_{4}(\mathrm{CO})_{12}, \mathrm{Rh}_{6}(\mathrm{CO})_{16},\left[\mathrm{Rh}(\mathrm{CO})_{2} \mathrm{Cl}\right]_{2}$ & $\mathrm{Al}_{2} \mathrm{O}_{3} / \mathrm{Al}$ & 153,395 \\
$\mathrm{Re}_{2}(\mathrm{CO})_{10}$ & $\mathrm{MgO} / \mathrm{Mo}(110)$ & 168 \\
\hline
\end{tabular}

are the decomposition of rhenium carbonyl, $\operatorname{Re}_{2}(\mathrm{CO})_{10}$, according to the scheme [168]

$$
\begin{gathered}
{\left[\operatorname{Re}(\mathrm{CO})_{5}\right]_{2} \frac{-\mathrm{CO}}{\mathrm{MgO}, 320 \mathrm{~K}} \frac{\operatorname{Re}(\mathrm{CO})_{4}-\operatorname{Re}(\mathrm{CO})_{4}}{\frac{\mathrm{O}_{\mathrm{s}}}{\mathrm{O}_{\mathrm{s}}}}} \\
\frac{-\mathrm{CO}}{>400 \mathrm{~K}} \frac{\operatorname{Re}(\mathrm{CO})_{3}}{(\mathrm{OOO})_{\mathrm{s}}} \frac{-\mathrm{CO}}{>600 \mathrm{~K}} \operatorname{Re}_{\text {clusters }}
\end{gathered}
$$

or the decomposition rhodium tris allyl, $\mathrm{Rh}\left(\mathrm{CH}_{2} \mathrm{CHCH}_{2}\right)$, according to [211]

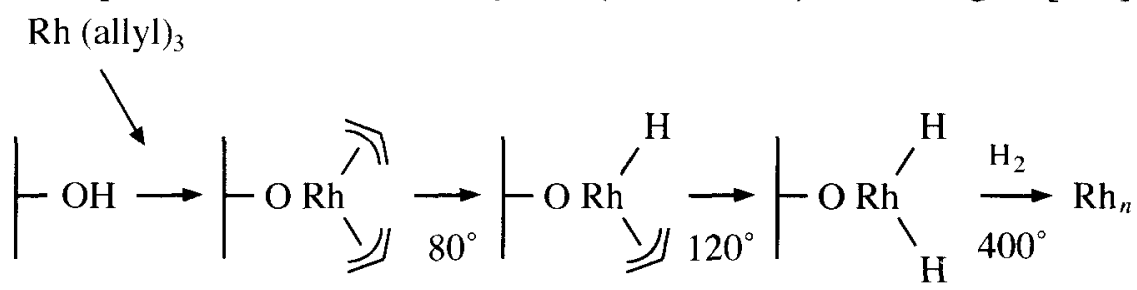

The rhodium carbonyl clusters in Table 9 have been found to decompose via the rhodium gem-dicarbonyl, $\mathrm{O}_{\mathrm{s}}-\mathrm{Rh}(\mathrm{CO})_{2}$, where $\mathrm{O}_{\mathrm{s}}$ stands for an oxygen of the support [153,212-214].

In order to study the decomposition reactions of these compounds on the support, thermal desorption is the indicated method to monitor the evolution of the ligands [168,212-217], while RAIRS is the best-suited technique to characterize the species on the support [168,212-214]. With respect to RAIRS, the identification of, for example, the subcarbonyl species that arise in the decomposition of the cluster $\operatorname{Re}_{2}(\mathrm{CO})_{10}$ could be done by comparison with the vibrational spectra of clusters such as $\left[\operatorname{Re}(\mathrm{CO})_{4} \mathrm{Cl}\right]_{2}$ and $\left[\operatorname{Re}(\mathrm{CO})_{4} \mathrm{I}\right]_{2}$ [168]. Interesting information on the bonding of the compounds with the support can be obtained from XPS and UPS, as the work of Chang et al. [211] on $\mathrm{TiO}_{2}(001)$-supported rhodium allyl clusters illustrates. 
Preparing model catalysts from organometallic precursors is a versatile method because a range of different metal complexes is available, while in principle also suitable heteronuclear clusters may be used to devise multicomponent catalysts [218].

Strongly related to these methods is atomic layer epitaxy (ALE) [219]. In this method, a volatile metal compound is used to deposit a monolayer of metal at saturation coverage. A reducing agent (hydrogen, for example) is then utilized to remove the ligand or anion (chlorine, for example) and to produce a metallic monolayer. By repeating the same two-step process, metal particles are produced whose size and separation can be controlled. The same ALE technology has been employed to deposit catalyst particles on high surface area oxide supports [220]. For example, nickel or chromium particles were produced by first depositing a monolayer of the volatile metal halides until saturation coverage was reached. Then, by reaction with hydrogen, the transition metal ions were reduced to the metallic state while the halogen was removed as $\mathrm{HCl}$ :

$$
\mathrm{MCl}_{x}+\frac{1}{2} x \mathrm{H}_{2} \rightarrow \mathrm{M}+x \mathrm{HCl} \uparrow
$$

The formation of each monolayer is arrested at saturation coverage, and the size of the metal particles depends on the number of layers deposited. The distance between the initially deposited metal atoms can be controlled by the size of the anion or liquid in the volatile metal-containing species. For example, acetyl acetonate may be used instead of halide ions to yield more widely separated metal atoms.

\section{Wet Chemical Impregnation of Model Supports}

Almost all supported catalysts are made by wet chemical impregnation of the support. The exchange preparation makes use of the fact that oxide support surfaces contain hydroxyl groups, which can be used to chemically anchor species to the support. This method can straightforwardly be applied to make model catalysts, provided the model support is sufficiently hydroxylated. Several possibilities exist; for example, metal alkoxides in ethanol react with hydroxyl groups on the surface according to

$$
\begin{aligned}
& \text { Support- } \mathrm{OH}+\mathrm{M}\left(\mathrm{OC}_{n} \mathrm{H}_{2 n+1}\right)_{x} \rightarrow \text { Support- } \mathrm{O}-\mathrm{M}\left(\mathrm{OC}_{n} \mathrm{H}_{2 n+1}\right)_{x-1} \\
& \quad+\mathrm{C}_{n} \mathrm{H}_{2 n+1} \mathrm{OH}
\end{aligned}
$$

This type of reaction has been applied to make model systems for silicasupported vanadia $[15,221]$ and zirconia catalysts $[17,183]$.

If water is the solvent, the support behaves like a giant ion. The charge of this polyion depends on the $\mathrm{pH}$ of the solution: The surface charges positively below and negatively above the isoelectric point. As a consequence, complexes of opposite charge can be anchored electrostatically to the support: 


$$
\text { Support- } \mathrm{OH}_{2}^{+} \cdots \mathrm{M}(\text { complex })^{n-}
$$

After drying and calcination, the catalyst is further activated-for example, by reduction in $\mathrm{H}_{2}$, or sulfidation in $\mathrm{H}_{2} \mathrm{~S}$ - as required for the particular application. This reaction has been utilized for the preparation of $\mathrm{Al}_{2} \mathrm{O}_{3} / \mathrm{Al}$ supported platinum, rhodium, and molybdena catalysts $[16,18,50,139,222]$. An important point is that a model support impregnated in this way is carefully rinsed with solvent (preferable of adjusted $\mathrm{pH}$ ) to prevent complexes in solution from depositing randomly on the surface during drying.

Also organometallic compounds can be anchored to the support in solution. Tesche et al. [223] report that impregnation of a planar alumina with an $n$-octane solution of the osmium cluster $\mathrm{Os}_{3}(\mathrm{CO})_{12}$ leads to the formation of a $(\mu-\mathrm{H}) \mathrm{Os}_{3}(\mathrm{CO})_{10}\left(\mu-\mathrm{O}_{\mathrm{s}}\right)$ structure, where $\mathrm{O}_{\mathrm{s}}$ denotes an oxygen from the support. Hydrogen reduction at $580 \mathrm{~K}$ produces Os clusters with sizes in the $1-2 \mathrm{~nm}$ range.

By far the most common method of catalyst preparation in industry is that of pore volume impregnation, often also called "incipient wetness impregnation"; see Fig. 18. A solution of the catalyst precursor, for example, iron nitrate in water, is added to the porous support under continuous stirring, until the incipient wetness point is reached. At this point all the pores are filled with the impregnating solution. Next the catalyst is dried to remove the solvent, after which it is calcined, reduced, or sulfided, depending on the application. As the impregnation is based on the filling of pores by capillary forces, this method is not directly transferable to flat supports. Here the spin-coating technique, developed by Kuipers and coworkers [19,224,225], offers attractive opportunities to mimic the process of pore volume impregnation.

\section{Pore volume impregnation}
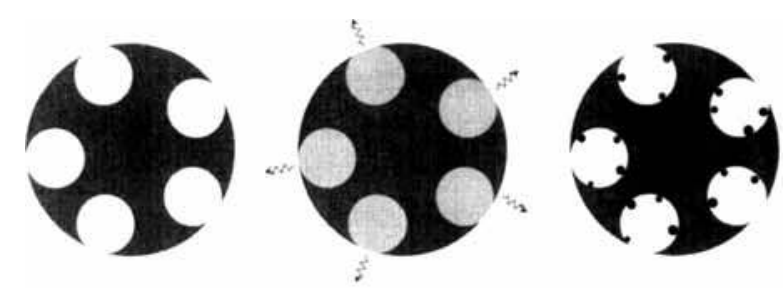

Spin-coating
impregnation
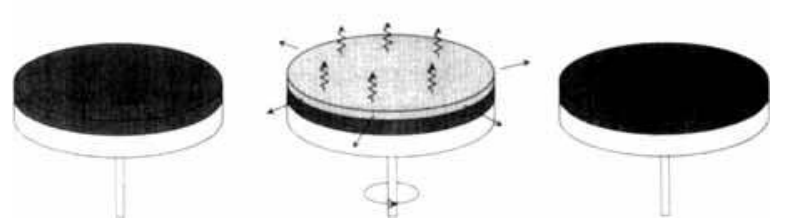

FIG. 18. Analogy of spin coating with incipient wetness impregnation: As use is made of hydrodynamic forces to immobilize the solvent, these methods can be applied when there is not sufficient chemical interaction between support and precursor. 


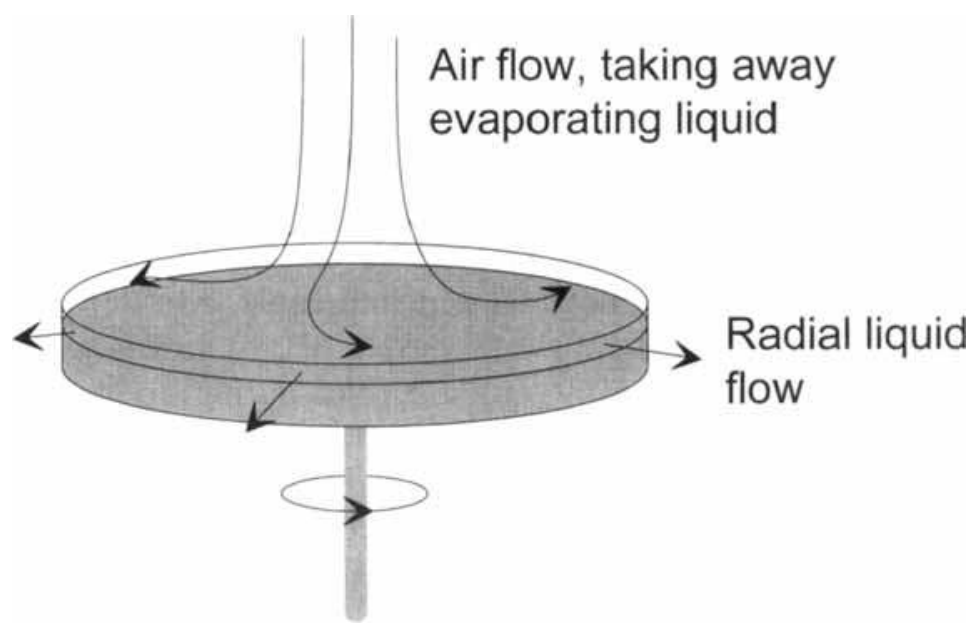

FIG. 19. Schematic representation of the major processes taking place during spin coating (adapted from van Hardeveld et al. [225]).

Spin coating is a well known technique for the preparation of thin uniform films, which has mainly been investigated in relation to its industrial application as a method to deposit layers of polymeric photoresist on silicon wafers. In short (see Fig. 19), a solution of the coating material is dispensed on a disk which is subsequently accelerated to $\sim 10^{3} \mathrm{rpm}$. Most of the solution is ejected from the disk but a thin film remains; the balance set up between centrifugal and shear forces keeps this film uniform while the solvent evaporates.

Kuipers was the first to recognize the possibilities of spin coating for the preparation of model supported catalysts $[19,224]$. It turns out that the spincoating process of dilute solutions of inorganic salts can be modeled straightforwardly $[19,224,225]$, allowing accurate predictions $( \pm 10 \%)$ of the amount of material eventually deposited. The balance between centrifugal and shear forces in the stationary state results in a decrease of liquid film height $h$ proportional to $h^{3}$. On top of that, there is a constant loss of liquid due to evaporation. There is a point in time $t_{e}$, at which these contributions are equal; and in a first approximation, one can assume that before $t_{e}$, evaporation is negligible, while after $t_{e}$, evaporation is the only source of decrease in film height. This assumption implies that the amount of material deposited per unit area equals $h_{e}$ times the initial solute concentration, where $h_{e}^{3}$ equals the evaporation speed times a proportionality constant, which depends on spinning speed, and on the viscosity and density of the liquid. Van Hardeveld et al. [225] compared calculations based on this simple model to data obtained by Rutherford backscattering spectrometry; their results are presented in Fig. 20. The average deviation in the calculated loading values is about $+10 \%$, and mainly systematic, suggesting that more refined spin-coat models would probably lead to even more accurate predictions. 

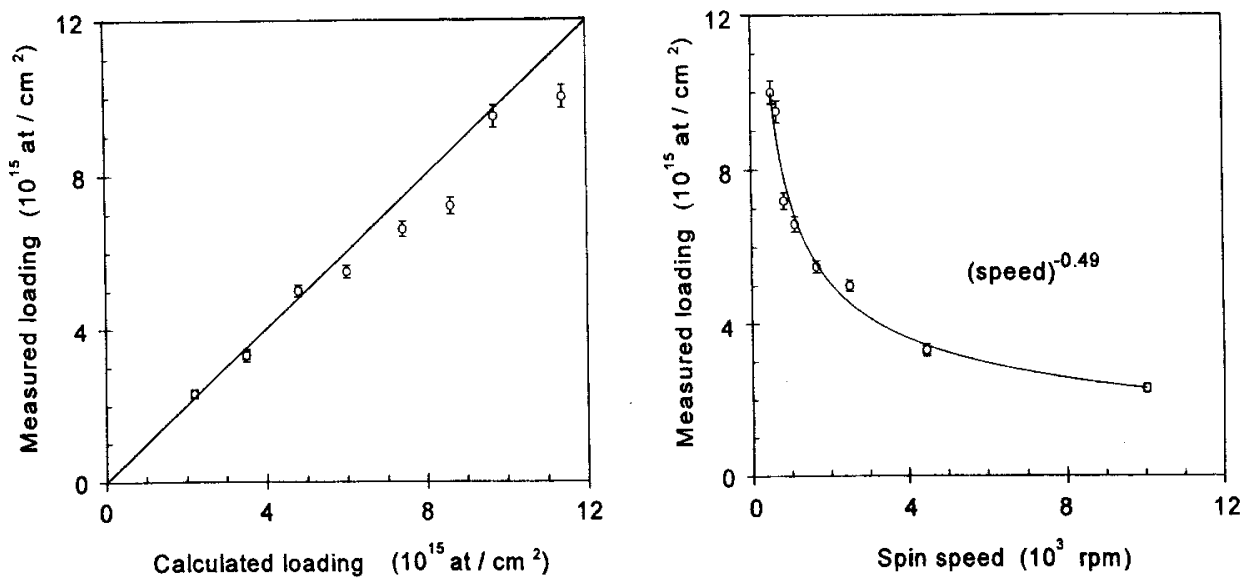

FIG. 20. Quantification of Mo loading on a silicon wafer obtained by spin coating with a $0.62 \mathrm{wt} \% \mathrm{MoO}_{2} \mathrm{Cl}_{2}$ solution in ethanol. The measured (Rutherford backscattering, see Sect. III.C) loading is compared to the predicted loading (a), and depends on the spinning frequency as shown in (b) (for details, see van Hardeveld et al. [225]).

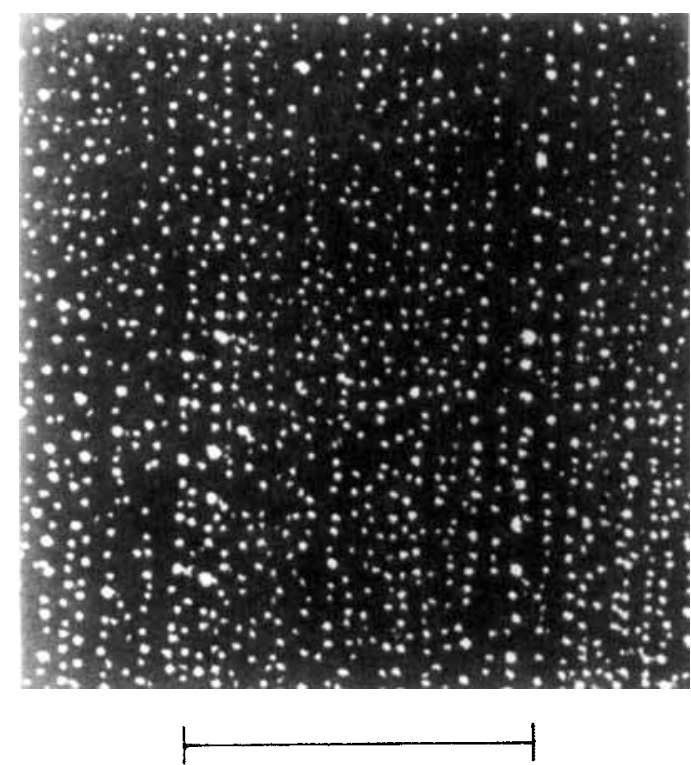

\section{$50 \mu \mathrm{m}$}

FIG. 21. Spin-coated $\mathrm{Cu}\left(\mathrm{NO}_{3}\right)_{2}$ particles decorating aligned polymers obtained by rubbing a silicon wafer with a rod of PTFE (from Doornkamp et al. [226]). 
While the amount of material deposited can thus be controlled relatively easy, it is much more difficult to control the morphology of the deposit [226]. Upon evaporation of the solvent, a critical concentration of the solute will eventually be reached, at which nucleation of crystallites starts. Doornkamp et al. [226] have shown that nucleation is - at least sometimes-heterogeneous by spin impregnation with copper nitrate in butanol of a Si wafer coated with aligned PTFE. The spin-coated $\mathrm{Cu}\left(\mathrm{NO}_{3}\right)_{2}$ particles appear in straight rows, apparently decorating the aligned polymers; see Fig. 21. However, there is evidence $[83,226,227]$ that spin coating with more volatile solvents results in a continuous film, which breaks up when exposed to water and/or elevated temperatures.

Wet chemical methods offer the opportunity to study the surface chemistry of catalyst preparation, which has high industrial relevance, on the model scale. It is important to realize that the eventual structure, morphology, and catalytic properties are uniquely related to the method of preparation. Hence if one wishes to optimize a certain catalyst, it has to be done through one or more of the steps in the preparation.

\section{Microfabricated Model Catalysts: Lithography}

The dream of the experimentalist working with supported metal model catalysts is to be able to vary the size, shape, and distance between the metal particles at will. As is discussed here, the current technologies will not permit "catalysis by design," but much progress has been made in this area. Before discussing the emerging techniques, it is necessary to stress that any technique must satisfy at least two requirements to be useful in the preparation of catalysts. The first one is that the structure of the nanometer-size metal particles need to be varied in a predictable fashion. Ideally, it should be possible to vary the particle size in the range of $1-10 \mathrm{~nm}$ in order to study the effect of particle morphology on the reactivity of high surface area supported catalysts. The most rigorous way to vary the structure is to build the metal clusters by the direct placement of its atoms. For example, Crommie et al. [228] were able to precisely move $\mathrm{Fe}$ atoms over a $\mathrm{Cu}(111)$ substrate forming a quantum corral. However, the time required to assemble such structures is many minutes, which brings us to the second requirement, the number of clusters. For a signal to be detected during characterization and reaction studies with the current analytical techniques, a large number of nanoclusters are necessary. Assuming that a metal surface area of at least $0.01 \mathrm{~cm}^{2}$ is required for detection of catalytic rates and that flat clusters with $10 \mathrm{~nm}$ diameter are present, then about $1 \times 10^{10}$ clusters will be necessary! Thus, a second requirement is that the fabrication time for each structure has to be of the order of nanoseconds. Hence, the requirements of size and number of clusters makes most current fabrication techniques inadequate for applications in catalysis. 
A promising approach to build structures that can be used as catalysts is to be found in the constant effort by the microelectronics industry for miniaturization of circuits. Although the dimension of the features that are mass produced nowadays, in computer chips, for example, are too big to be of use as catalysts (sizes of about $0.5 \mu \mathrm{m}$ ), emerging techniques, like electron-beam lithography, might provide the answer for the fabrication of catalysts [229]. This technique (see Fig. 22) uses a beam of electrons to develop the resist (e.g., PMMA) which is deposited over the oxide substrate. After electronbeam exposure, the photoresist is removed where it has been exposed, and the substrate is etched to produce holes where the metal clusters will bind. Then, a few monolayers of the metal are evaporated over the sample. When the remaining photoresist is removed, a periodic array of holes is left behind, all filled with metal clusters of equal size. A scanning electron microscope picture of a particle array is shown in Fig. 23 [230]. Creating the pattern in the resist is the key step in the fabrication since the rest of the sample processing is the same as used for the commercial production of chips. Current commercial equipment [231] can achieve a theoretical resolution of $8 \mathrm{~nm}$ and time between two consecutive exposures of $4 \times 10^{-8} \mathrm{~s}$. It is predicted that a device that could produce features with a theoretical size of $2.5 \mathrm{~nm}$ and resolution of $1 \mathrm{~nm}$ with a time between consecutive exposures of $4 \times 10^{-8} \mathrm{~s}$

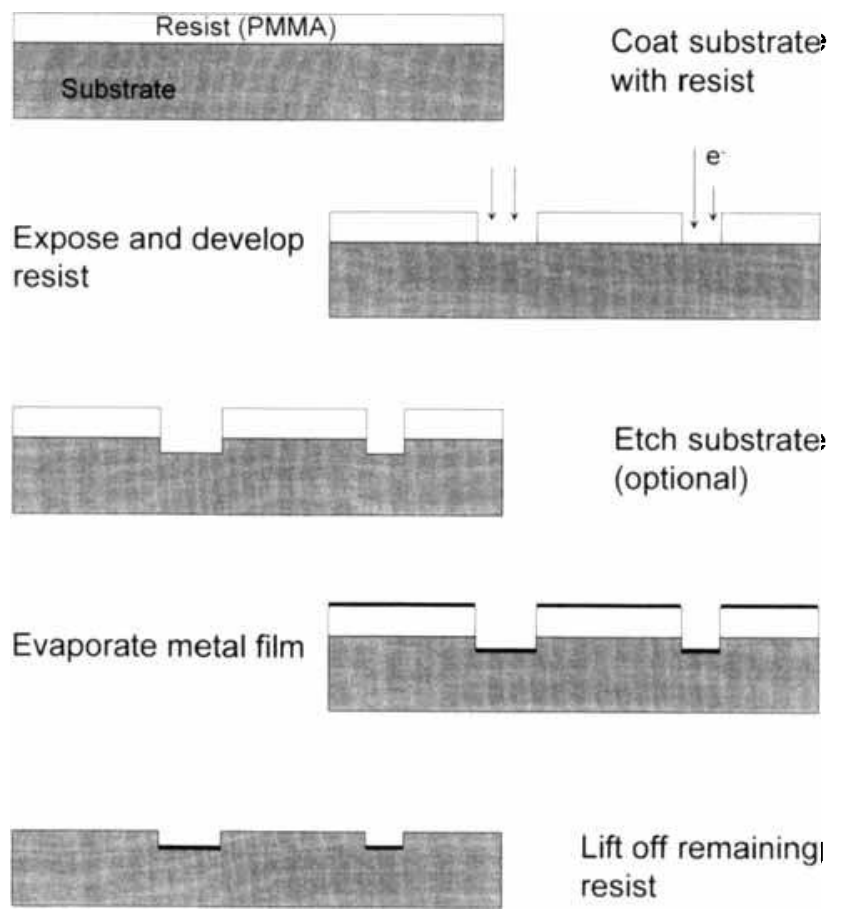

FIG. 22. Steps in the preparation of model catalysts by electron-beam lithography (adapted from Ribeiro and Somorjai [230]). 


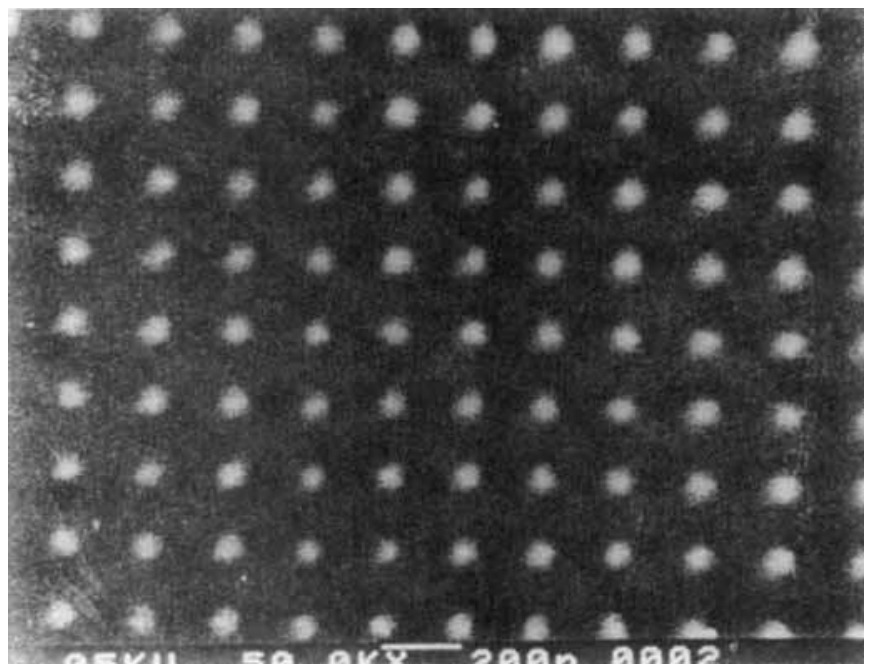

FIG. 23. Scanning electron micrograph of a microfabricated Pt modelcatalyst. The Pt particles, $150 \mathrm{~nm}$ apart, are $\sim 50 \mathrm{~nm}$ in diameter. The total catalyst area is $1 \mathrm{~cm}^{2}$ (from Ribeiro and Somorjai [230]).

can be constructed [232]. With this setup, only $8 \mathrm{~s}$ will be necessary to expose the pattern of $0.01 \mathrm{~cm}^{2}$ described above. In practice, more time will be necessary because the e-beam cannot be deflected with lenses to cover very wide angles; the substrate has to be moved mechanically to allow large areas to be exposed. It should be emphasized, however, that the use of e-beam lithography to draw structures in the nanometer range over large areas is still in the research stage. For example, new resists have to be developed to attain the desired resolution in the final stage. A number of other problems related to particle stability under reaction conditions and procedures to clean the sample before reaction without damaging them have to be developed.

Reports on catalysts prepared by microelectronics techniques are beginning to appear in the literature [230,233,234]. Zuburtikudis and Saltsburg [233] prepared a system composed of alternated layers of $\mathrm{Ni}$ and $\mathrm{SiO}_{2}$. Etching of this structure formed a "forest of pillars" exposing the Ni layers, which had a thickness of 4-10 nm and length of a few micrometers. This catalyst could catalyze the hydrogenolysis of ethane at rates comparable to the ones on supported catalysts. Krauth et al. [234] have used conventional photoresist techniques to prepare $\mathrm{Pd}$ clusters with dimensions of about $5 \mu \mathrm{m}$ over an oxidized $\mathrm{Si}(100)$ wafer. The catalyst was active for the hydrogenation of $1,3-$ butadiene.

\section{E. Concluding Remarks on Catalyst Preparation}

For fundamental studies, the key issue in the synthesis of catalysts on model supports is how to prepare uniform particles with enough interaction 
to the support that the system is thermally stable under reaction conditions. The most employed method is to deposit metals by evaporation. However, this almost always leads to Gaussian-like distributions in particle size. Deposition of clusters of selected mass, either by soft landing or via colloidal solutions, does not establish sufficient bonding between the particle and the support. Also attempts to anchor magic number clusters have failed, because the particles loose their stability as soon as the ligands are removed.

Lithography has great potential for producing arrays of uniform particles and to fabricate unique designs. For example, an array where the clusters alternate between two different metals can be made in any geometric configuration. With currently available technology a device can be designed to make clusters as small as $3 \mathrm{~nm}$ and in sufficient numbers to be useful as a model catalyst.

For catalyst preparation studies, it is essential that the application of the active phase occurs in the same way as in the manufacture of real catalysts. In this respect, impregnations involving reactions between hydroxyls of the support or acid sites on the support and species in solution can be applied without limitation. Pore volume impregnation occurs by virtue of capillary forces which are absent on flat surfaces. In this case spin coating offers the way to apply a thin layer of solution. Chemical vapor deposition and atomic layer epitaxy, finally, can be applied straightforwardly to produce catalysts on model supports, provided these satisfy the requirements of a realistic support as formulated in Sect. IV.

\section{PARTICLES ON MODEL SUPPORTS IN CATALYSIS RESEARCH}

The purpose of this section is to give an overview of the possibilities that particles on flat model supports offer for research in catalysis. Model catalysts have been applied not only in studying materials science aspects such as the structure of supported particles, their sintering and redispersion behavior, and interactions with the support and catalyst preparation, but also in studies of chemisorption and catalytic reactions. We have aimed at describing illustrative examples rather than giving an exhaustive overview.

\section{A. Structure of Supported Particles}

There are essentially two techniques to study directly the morphology and structure of small particles: transmission electron microscopy (TEM) and scanning tunneling microscopy (STM). Medium-resolution TEM techniques such as selected zone dark-field and weak beam dark-field imaging, yielding three-dimensional information about small particles, require the application of flat, electron-transparent model substrates [33]. High-resolution TEM, aimed at direct lattice imaging, is performed on both porous and nonporous 


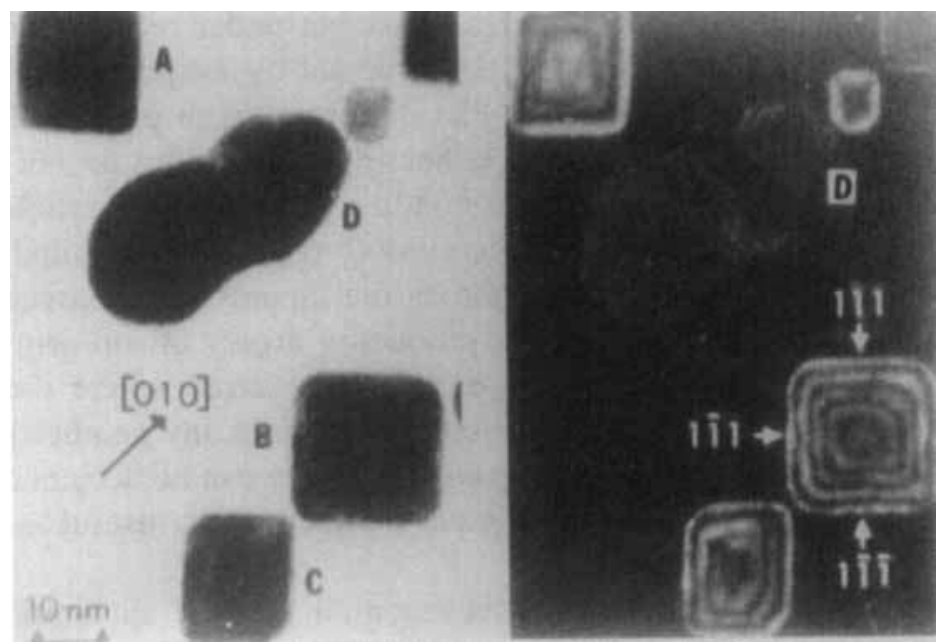

FIG. 24. Bright-field (left) and WBDF (right) images of Au particles on $\mathrm{NaCl}$, showing square and rectangular (001) oriented pyramids with (111) faces $(\mathrm{A}, \mathrm{B}, \mathrm{C})$, and (001) oriented pyramidal particle sections with (001) faces (from JoséYacamán and Avalos-Borja [33]).

model systems $[33,44]$. The use of flat, well-conducting model supports such as highly oriented pyrolitic graphite (HOPG) is imperative for STM studies.

Standard bright-field TEM imaging of particles on flat supports produces images like Fig. 24(a), which shows a projection of the shape of Au particles. Note that the substrate is $\mathrm{NaCl}$, which probably enables better contrast than a more realistic model support would do. From the bright-field image, one cannot conclude whether these particles are cubes, square pyramids, or have another shape allowing the square projection. In dark-field imaging the intensity of the diffracted beam varies as a function of specimen thickness, which gives rise to fringes, consisting of periodic bright and dark bands. In weak beam dark-field (WBDF) imaging [33], this effect is exploited to determine three-dimensional particle shapes, the fringes playing the role of height contours; see Fig. 24(b).

Selected zone dark-field (SZDF) imaging is a TEM imaging mode developed to study the arrangement of lattice planes of small (model) supported particles. An annular aperture is used to select diffracted intensities that have the same interplanar spacings. By slightly defocusing the objective lens, the particle images produced by the diffracted beams are displaced perpendicular to the plane that produced the spots (see the example in Fig. 25). Combination of the information obtained in this way by using different apertures enables one to deduct the particle's configuration.

Although these special dark-field imaging techniques yield much information about particle shape and structure, the most exciting information has been produced mainly by the high-resolution mode enabling lattice imaging. 


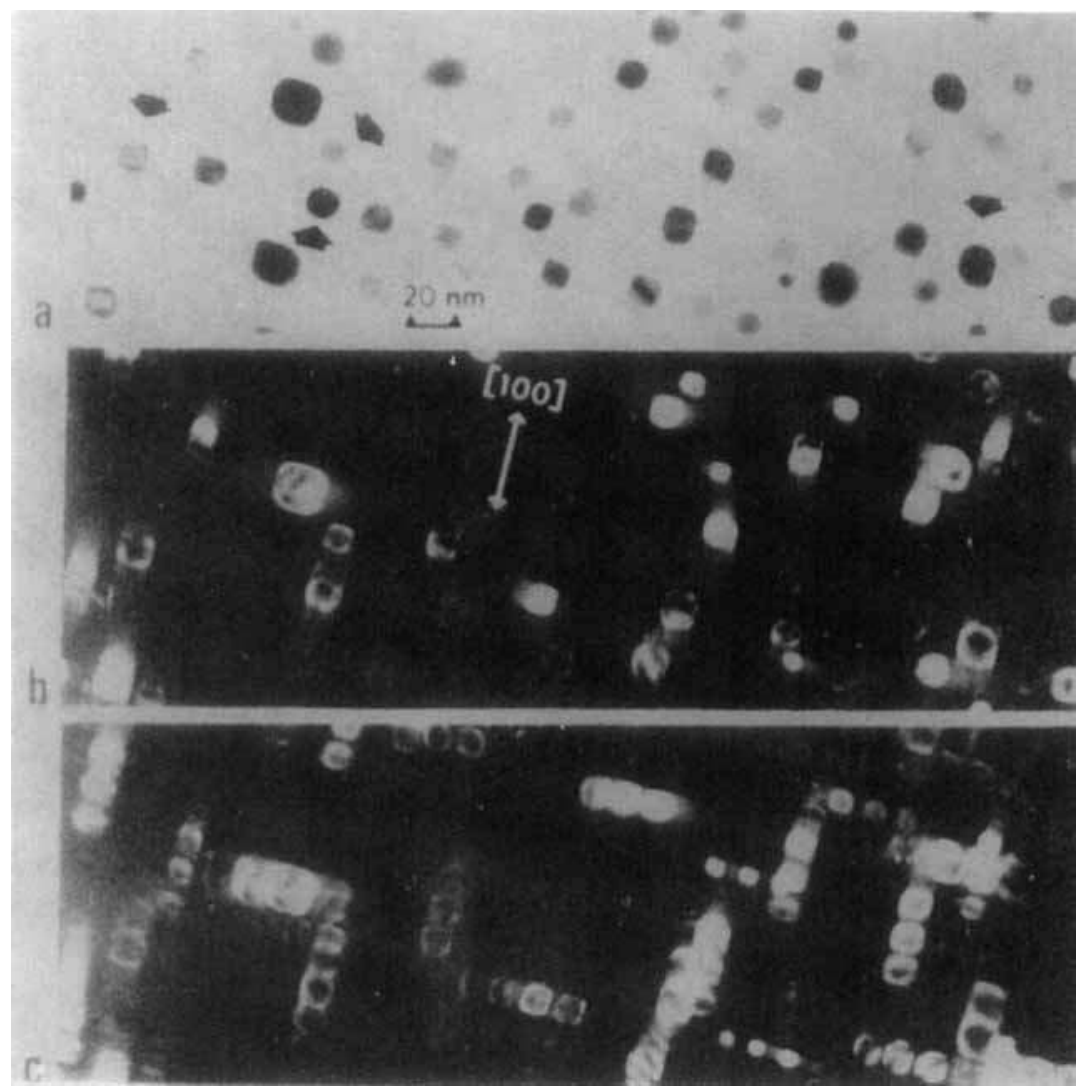

FIG. 25. Transmission electron micrographs of gold crystals on a $\mathrm{KCl}$ substrate: (a) bright-field image; (b) focused (200) SZDF; (c) defocused (200) SZDF. The displacement of the images reveals the orientation of their (100) planes (from José-Yacamán and Avalos-Borja [33]).

Figure 26 shows a high-resolution image of a $\mathrm{Ag}$ particle created by coalescence of two icosahedral multiply twinned particles (MTPs). The interpretation of such images is in general very difficult and cannot be done reliably without the aid of computational simulation techniques [235-237]. As Mark puts it, "the hardest area in electron microscopy of small particles is not the imaging, but rather the interpretation" [235].

José-Yacamán and Gómez [238] have systematically studied the structure of some metal particles important for catalysis $(\mathrm{Au}, \mathrm{Pt}, \mathrm{Rh}, \mathrm{Ni}$, and Ir) with TEM techniques. They conclude that the most common shapes are those depicted in Fig. 27, their population depending strongly on metal-support combination and preparation conditions. Twinned particles are found to occur mostly as a result of sintering. Winterbottom has shown [239] that, as in the case of a liquid film in contact with a substrate, capillary forces determine the overall (i.e., flat vs. spherical) equilibrium shape of supported solid particles. However, the differences in surface energy of solid particles result in 


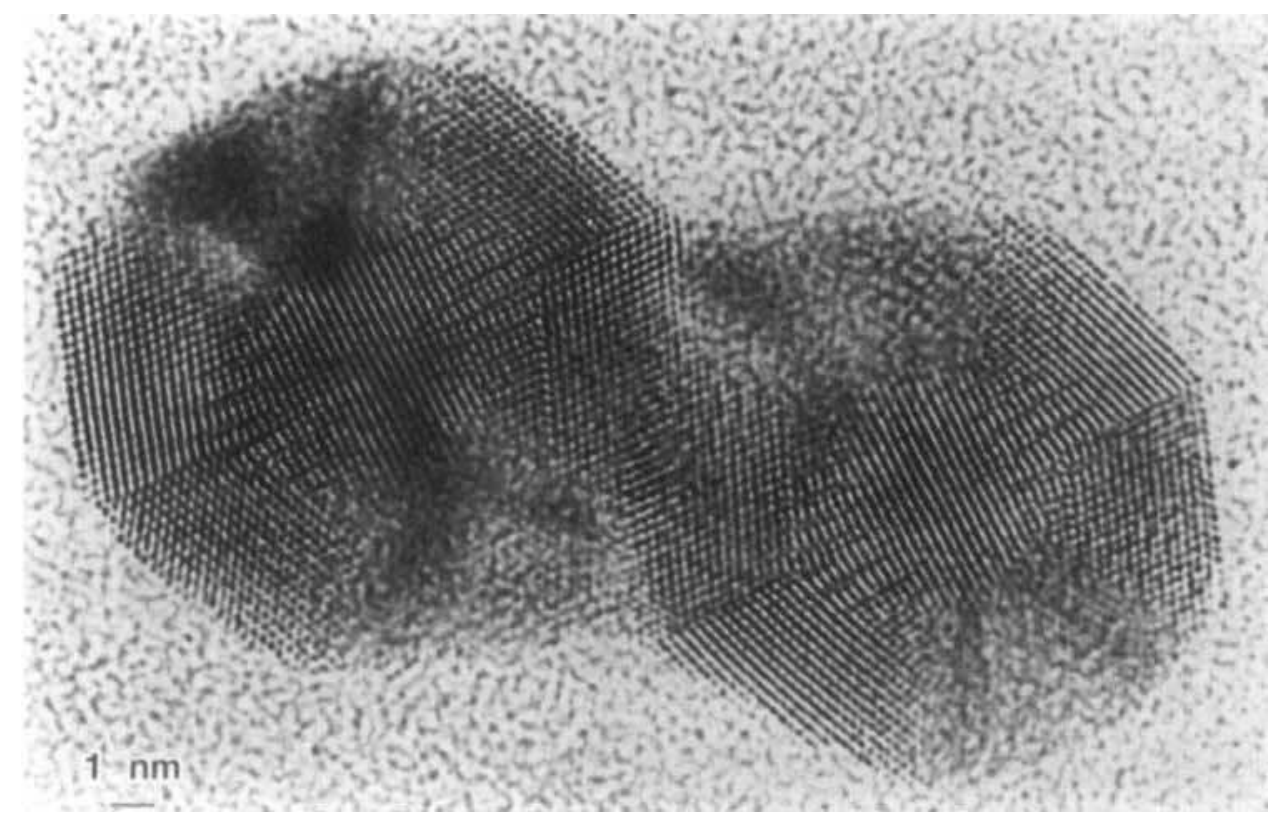

FIG. 26. High-resolution transmission electron micrograph of coalesced multiply twinned particles (MTPs) of silver. The MTPs are icosahedrons consisting of 20 tetrahedra (from Marks [235]).

the "truncated" shapes of Fig. 27. Masel and coworkers [240] have pointed out that surface energy differences between clean crystal faces are relatively small ( $\sim 1 \mathrm{kcal} / \mathrm{mole}$ for $\mathrm{Pt}$ ) compared to differences in heat of adsorption (up to $\sim 5 \mathrm{kcal} / \mathrm{mole}$ ), so that at temperatures high enough for atoms to become mobile (e.g., above $\sim 800 \mathrm{~K}$ for $\mathrm{Pt}$ ), the gaseous environment determines the detailed particle shape. They show by experiment that the equilibrium shape of truly clean Pt particles is almost spherical [240,241].

Dynamic HREM observations have shown [242-245] that very small particles $(<5 \mathrm{~nm})$ are subject to rapid structural fluctuations at moderate temperatures ( $370 \mathrm{~K}$ for $2-\mathrm{nm}$ particles [244]). Larger crystals show local "column hopping," and clouds of moving atoms have been seen outside some specific surfaces of gold clusters [246,247]. Thus the interpretation of electron microscopy features have to be made with great care.

With scanning tunneling microscopy, real-space imaging with atomic resolution has become possible. On flat, conducting substrates, "atomic imaging' is rather straightforward nowadays, but obtaining atomic resolution when scanning supported particles remains difficult. Figure 28(a) presents a state of the art example from a study by Wolf and coworkers on the morphology of Pt crystallites supported by different kinds of graphite substrates [74]. The image reveals the presence of several domains of (111)-type closepacked arrangements. From such an image, the lattice parameters can be directly measured. In this case, they were close to the (111) $\sqrt{3} \times \sqrt{3}$ struc- 

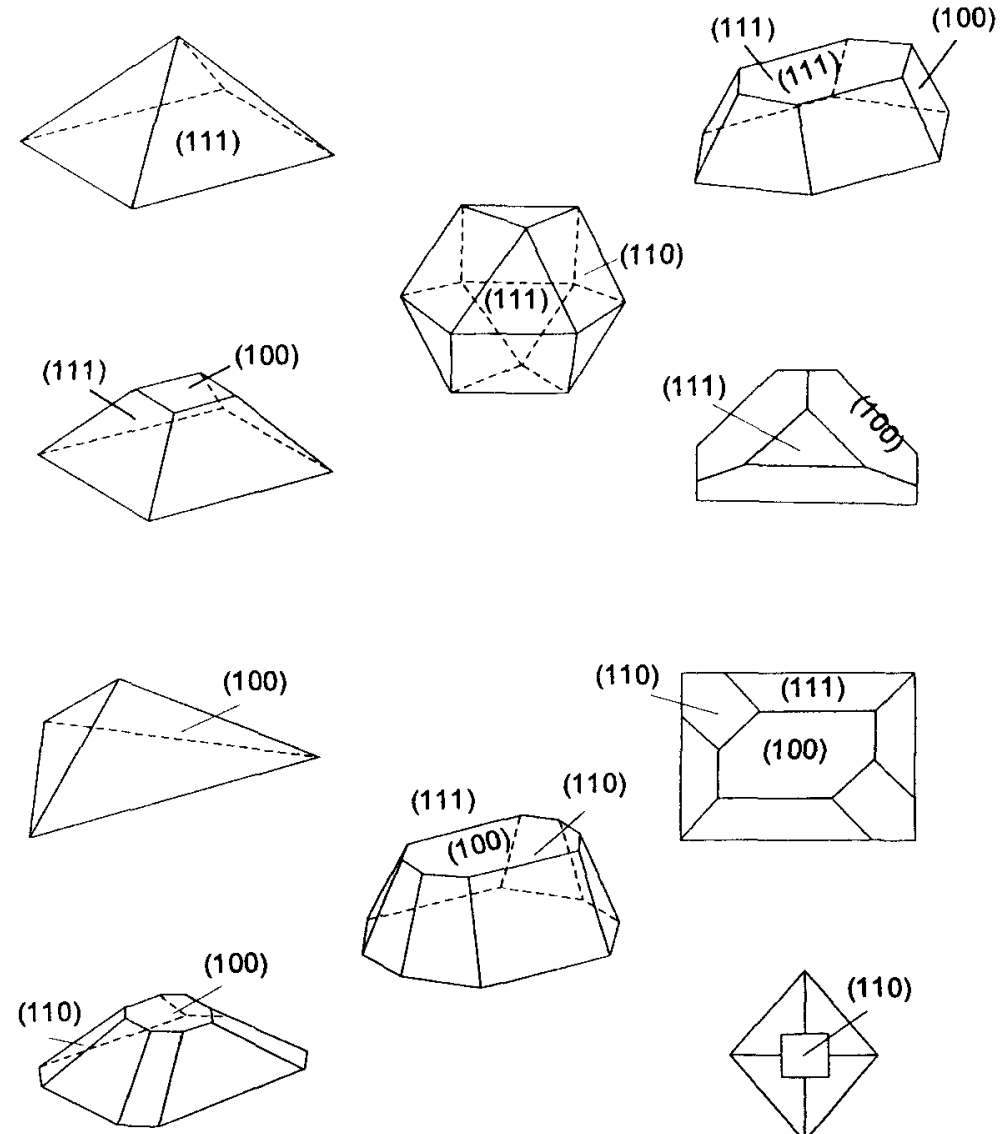

FIG. 27. Most common particle shape for $\mathrm{Au}, \mathrm{Pt}, \mathrm{Rh}, \mathrm{Ni}$, and $\mathrm{Ir}$ deposits on different substrates (from José-Yacamán and Gomez [238]).

ture, suggesting that the layer imaged could be an adsorbate layer. STM offers unique possibilities to image particles only a few atoms large. Müller et al. [67] have shown this for vapor-deposited Pt on HOPG. The deposit contained single $\mathrm{Pt}$ atoms, dimers, trimers, and small clusters. Figure 28(b) shows a STM picture of a single $\mathrm{Pt}$ atom. Because the structure of the support is so clearly resolved, the adsorption site for such monomers could be determined, as well as the orientation and bond length of the dimers. Trimers occurred both as linear chains and as equilateral triangles. The imaging of clusters of this size and of two-dimensional islands (e.g., see Ref. 61) is the important contribution STM can make to the structural analysis of supported particles.

\section{B. Sintering and Redispersion}

The use of model supports in studies of sintering and redispersion has turned out to be a very fruitful approach. Most important is the clear advan- 


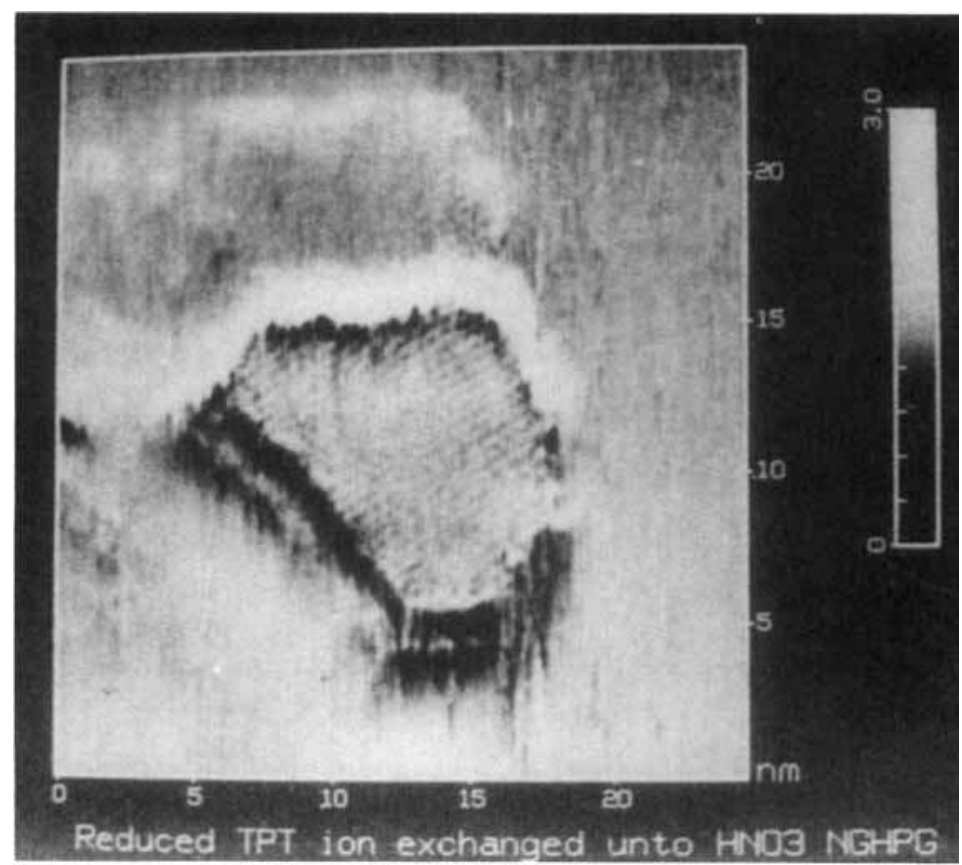

(a)

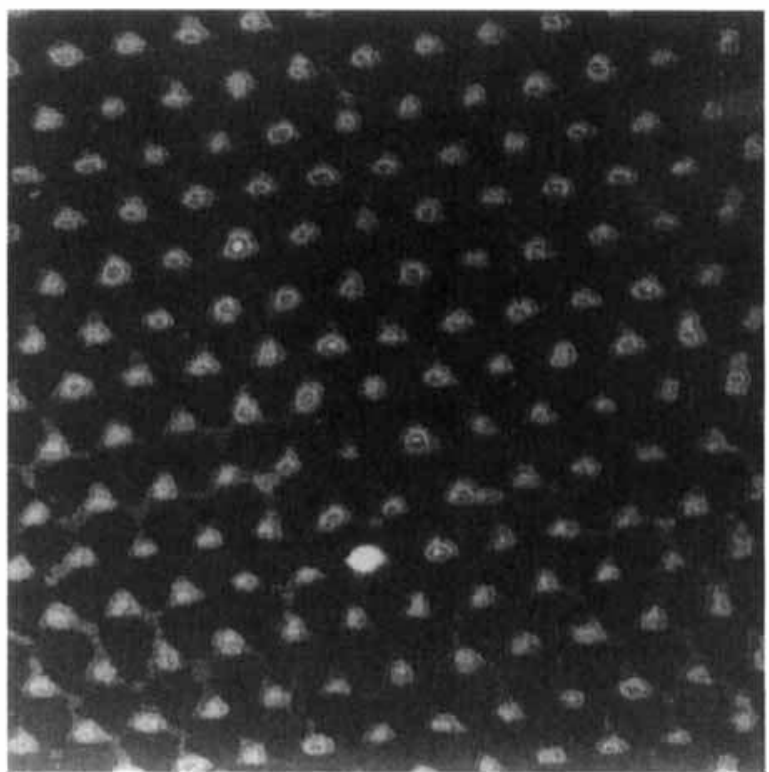

(b)

FIG. 28. Atomic resolution STM images of (a) a Pt crystallite on functionalized graphite (from Yeung and Wolf [59]), and (b) a single Pt atom on HOPG (from Müller et al. [67]). 
tage of thin electron transparent supports that enable the direct microscopic examination of metal particle behavior, but also the straightforward application of techniques like AES and XPS has contributed to a better understanding of sintering and redispersion phenomena. It should be stressed that the emphasis in model studies is best put on pinpointing mechanisms, rather than on a quantitative comparison with conventionally supported systems. There are two main reasons for this. First, support morphology can be expected to have an important effect on sintering rate, in the sense that particle mobility should be higher on the smooth, nonporous surfaces of model supports. Secondly, the application of some surface analytical techniques requires unrealistically high metal loadings, while metal surface concentration is known to influence sintering rates.

Bartholomew has recently reviewed sintering and redispersion studies of model supported metal particles [10]. One of his main conclusions is that the model studies have made clear that very complex mechanistic phenomena take place during both sintering and redispersion. Depending on the metalsupport combination and the conditions, metal crystallites deform, spread, form films, and grow, contract, or disappear, due to both crystallite and atomic migration. In this section, we highlight a few of the model studies summarized in Table 10 to sketch the possibilities of model supports in this area of research. We emphasize the need for carefully prepared and well-characterized model systems, as sintering mechanisms appear to be sensitive to the presence of impurities and contamination.

Ruckenstein and Lee [248] have studied the behavior of model $\gamma-\mathrm{Al}_{2} \mathrm{O}_{3}$ supported $\mathrm{Ni}$ crystallites upon heating in $\mathrm{O}_{2}$ and $\mathrm{H}_{2}$. The $30 \mathrm{~nm}$ thick model alumina was prepared by the anodization technique described in Sect. III.B; $\mathrm{Ni}$ was applied by evaporation. Figure 29 presents a time sequence of the same region, during heating at $800 \mathrm{~K}$ in $\mathrm{O}_{2}$ and subsequently in $\mathrm{H}_{2}$. The sequence provides a nice example of the complexity of sintering and redispersion phenomena occurring during such treatments. Figure 29(a) represents the initial state of the $\mathrm{Ni}$ crystallites, which have sizes in the range of 7.5 to $45 \mathrm{~nm}$. During heating in $\mathrm{O}_{2}$ for $0.5 \mathrm{~h}$ [Fig. 29(b)], the Ni crystallites are oxidized in $\mathrm{NiO}$. The larger crystallites extend on the substrate and change their shape from droplet to torus like, while the smaller ones spread or disappear. Longer heating [Fig. 29(c)] does not produce significant changes. Upon subsequent heating in $\mathrm{H}_{2}, \mathrm{NiO}$ is reduced to $\mathrm{Ni}$, which is accompanied by quite dramatic changes in morphology, as can be seen in Fig. 29(d). The toroidal particles split up into small particles, which grow [Fig. 29e)] by coalescence or ripening and eventually [Fig. 29(f)] migrate out of the initial ring.

Although HRTEM on model supported catalysts thus enables one to see directly the different effects of processes taking place during heating, it must be kept in mind that single atoms and/or molecules cannot be detected by this technique, and that it depends on the quality (uniform thickness and intrinsic electron transparency) of the model support whether particles smaller 
TABLE 10

Sintering and Redispersion Studies on Model Supports

\begin{tabular}{|c|c|c|c|}
\hline Suptd. phase & Support & Conditions & Ref. \\
\hline $\mathrm{Ag}$ & $\mathrm{Al}_{2} \mathrm{O}_{3}$ & Vac.; $870-1020 \mathrm{~K}$ & 399 \\
\hline $\mathrm{Ag}$ & $\gamma-\mathrm{Al}_{2} \mathrm{O}_{3}$ & $\mathrm{C}_{2} \mathrm{H}_{4}, \mathrm{H}_{2}$ and $\mathrm{O}_{2} ; 520-670 \mathrm{~K}$ & 400 \\
\hline $\mathrm{Ag}$ & $\mathrm{C}$ & Vac.; $870-1020 \mathrm{~K}$ & 399 \\
\hline $\mathrm{Ag}$ & $\mathrm{SiO}_{2}$ & Vac.; $870-1020 \mathrm{~K}$ & 399 \\
\hline $\mathrm{Co}$ & $\gamma-\mathrm{Al}_{2} \mathrm{O}_{3}$ & $\mathrm{H}_{2}, \mathrm{H}_{2} \mathrm{O} ; 970 \mathrm{~K}$ & 401 \\
\hline Co & $\gamma-\mathrm{Al}_{2} \mathrm{O}_{3}$ & $\mathrm{CH}_{4}, \mathrm{H}_{2} \mathrm{O}, \mathrm{H}_{2}$, and $\mathrm{CO}(\mathrm{mix})$ & 402 \\
\hline $\mathrm{Co}$ & $\mathrm{SiO}_{2}$ & Air, $\mathrm{H}_{2} ; 570-770 \mathrm{~K}$ & 403 \\
\hline $\mathrm{Fe}$ & $\gamma-\mathrm{Al}_{2} \mathrm{O}_{3}$ & $\mathrm{H}_{2}, \mathrm{O}_{2} ; 670-1070 \mathrm{~K}$ & 404 \\
\hline $\mathrm{Fe}$ & $\gamma-\mathrm{Al}_{2} \mathrm{O}_{3}$ & $\mathrm{H}_{2}, \mathrm{H}_{2} \mathrm{O} ; 970 \mathrm{~K}$ & 401 \\
\hline $\mathrm{Fe}$ & $\gamma-\mathrm{Al}_{2} \mathrm{O}_{3}$ & $\mathrm{CH}_{4}, \mathrm{H}_{2} \mathrm{O}, \mathrm{H}_{2}$, and $\mathrm{CO}$ (mix) & 402 \\
\hline $\mathrm{Ir}+\mathrm{Ba}, \mathrm{Ca}$ ox. & $\gamma-\mathrm{Al}_{2} \mathrm{O}_{3}$ & $\mathrm{O}_{2} ; 670-1070 \mathrm{~K}$ & 249 \\
\hline Ir & $\gamma-\mathrm{Al}_{2} \mathrm{O}_{3}, \mathrm{SiO}_{2}$ & $\mathrm{H}_{2}, \mathrm{O}_{2} ; 420-870 \mathrm{~K}$ & 344 \\
\hline Ir & Graphite & $\mathrm{H}_{2} ; 1235 \mathrm{~K}$ & 405 \\
\hline Ir & $\mathrm{SiO}_{2}$ & Air, $\mathrm{H}_{2} ; 570-1070 \mathrm{~K}$ & 406 \\
\hline $\mathrm{Ni}$ & $\gamma-\mathrm{Al}_{2} \mathrm{O}_{3}$ & $\mathrm{H}_{2}, \mathrm{O}_{2} ; 1000 \mathrm{~K}$ & 248 \\
\hline $\mathrm{Ni}$ & $\gamma-\mathrm{Al}_{2} \mathrm{O}_{3}$ & $\mathrm{H}_{2}, \mathrm{H}_{2} \mathrm{O} ; 970 \mathrm{~K}$ & 401 \\
\hline $\mathrm{Ni}$ & $\gamma-\mathrm{Al}_{2} \mathrm{O}_{3}$ & $\mathrm{CH}_{4}, \mathrm{H}_{2} \mathrm{O}, \mathrm{H}_{2}$, and $\mathrm{CO}$ (mix) & 402 \\
\hline $\mathrm{Ni}$ & $\alpha-, \gamma-\mathrm{Al}_{2} \mathrm{O}_{3}$ & Air, $\mathrm{H}_{2} ; 775-1075 \mathrm{~K}$ & 407 \\
\hline $\mathrm{Ni}$ & $\gamma-\mathrm{Al}_{2} \mathrm{O}_{3}$ & $\mathrm{H}_{2} ; 870,970$ and $1070 \mathrm{~K}$ & 375 \\
\hline $\mathrm{Ni}$ & $\mathrm{Nb}_{2} \mathrm{O}_{5} / \mathrm{SiO}_{2}$ & $\mathrm{H}_{2} ; 570,770$ and $920 \mathrm{~K}$ & 345 \\
\hline $\mathrm{Pd}$ & $\gamma-\mathrm{Al}_{2} \mathrm{O}_{3}$ & $\mathrm{H}_{2} ; 920,1000$, and $1070 \mathrm{~K}$ & 374 \\
\hline $\mathrm{Pd}$ & $\gamma-\mathrm{Al}_{2} \mathrm{O}_{3}$ & $\mathrm{H}_{2}, \mathrm{O}_{2} ; 820-1020 \mathrm{~K}$ & 408 \\
\hline $\mathrm{Pd}$ & $\gamma-\mathrm{Al}_{2} \mathrm{O}_{3}, \mathrm{TiO}_{2}$ & $\mathrm{H}_{2} ; 1070 \mathrm{~K}$ & 409 \\
\hline $\mathrm{Pd}$ & Graphite & $\mathrm{C}_{2} \mathrm{H}_{2}, \mathrm{C}_{2} \mathrm{H}_{4}, \mathrm{O}_{2}, \mathrm{Ar} ; 500-1120 \mathrm{~K}$ & 410 \\
\hline $\mathrm{Pd}$ & Mica & $\mathrm{O}_{2}+\mathrm{CO} ; 570 \mathrm{~K}$ & 200 \\
\hline $\mathrm{Pt}$ & $\mathrm{Al}_{2} \mathrm{O}_{3}$ & Air; 770 and $870 \mathrm{~K}$ & 157 \\
\hline $\mathrm{Pt}$ & $\mathrm{Al}_{2} \mathrm{O}_{3}$ & $\mathrm{H}_{2} ; 425-1075 \mathrm{~K}$ & 411 \\
\hline $\mathrm{Pt}$ & $\mathrm{Al}_{2} \mathrm{O}_{3}$ & Vac.; $870-1020 \mathrm{~K}$ & 399 \\
\hline $\mathrm{Pt}$ & $\mathrm{Al}_{2} \mathrm{O}_{3}$ & Vac. & 412 \\
\hline $\mathrm{Pt}$ & $\alpha-\mathrm{Al}_{2} \mathrm{O}_{3}$ & $\mathrm{H}_{2}, \mathrm{~N}_{2}, \mathrm{O}_{2} ; 620-820 \mathrm{~K}$ & 133 \\
\hline $\mathrm{Pt}$ & $\gamma-\mathrm{Al}_{2} \mathrm{O}_{3}$ & $\mathrm{O}_{2}, \mathrm{~N}_{2} ; 870-1170 \mathrm{~K}$ & 413 \\
\hline $\mathrm{Pt}$ & $\gamma-\mathrm{Al}_{2} \mathrm{O}_{3}$ & $\mathrm{H}_{2}, \mathrm{~N}_{2}, \mathrm{O}_{2} ; 770-1120 \mathrm{~K}$ & 373 \\
\hline $\mathrm{Pt}$ & $\gamma-\mathrm{Al}_{2} \mathrm{O}_{3}$ & $\mathrm{H}_{2}, \mathrm{O}_{2}, \mathrm{~N}_{2} ; 1020-1120 \mathrm{~K}$ & 414 \\
\hline $\mathrm{Pt}$ & $\gamma-\mathrm{Al}_{2} \mathrm{O}_{3}$ & $\mathrm{H}_{2}, \mathrm{O}_{2} ; 570-1070 \mathrm{~K}$ & 415,416 \\
\hline $\mathrm{Pt}$ & $\gamma-\mathrm{Al}_{2} \mathrm{O}_{3}$ & Air, $2 \% \mathrm{O}_{2}$ in $\mathrm{N}_{2} ; 970 \mathrm{~K}$ & 417 \\
\hline $\mathrm{Pt}$ & $\gamma-\mathrm{Al}_{2} \mathrm{O}_{3}$ & $\mathrm{Ar}, \mathrm{O}_{2}, \mathrm{H}_{2} ; 510$ and $720 \mathrm{~K}$ & 148 \\
\hline $\mathrm{Pt}$ & $\gamma-\mathrm{Al}_{2} \mathrm{O}_{3}$ & Air; 770 and $870 \mathrm{~K}$ & 418 \\
\hline Pt & $\gamma-\mathrm{Al}_{2} \mathrm{O}_{3}$ & Air; $770 \mathrm{~K}$ & 419 \\
\hline $\mathbf{P t}$ & $\gamma-\mathrm{Al}_{2} \mathrm{O}_{3}, \mathrm{SiO}_{2}$ & $\mathrm{H}_{2}, \mathrm{~N}_{2} ; 870 \mathrm{~K}$ & 371 \\
\hline $\mathrm{Pt}$ & $\mathrm{C}$ & $\mathrm{Ar}, \mathrm{H}_{2}, \mathrm{~N}_{2}, \mathrm{O}_{2} ; 770$ and $870 \mathrm{~K}$ & 420 \\
\hline $\mathrm{Pt}$ & $\mathrm{C}$ & $\mathrm{H}_{2} ; 425-1075 \mathrm{~K}$ & 411 \\
\hline $\mathrm{Pt}$ & $\mathrm{C}$ & Vac.; $870-1020 \mathrm{~K}$ & 399 \\
\hline $\mathrm{Pt}$ & $\mathrm{SiO}_{2}$ & $\mathrm{Cl}_{2}, \mathrm{O}_{2}, \mathrm{~N}_{2}, \mathrm{H}_{2} \mathrm{O} ; 820-1300 \mathrm{~K}$ & 342 \\
\hline $\mathrm{Pt}$ & $\mathrm{SiO}_{2}$ & $\mathrm{H}_{2} ; 425-1075 \mathrm{~K}$ & 411 \\
\hline $\mathrm{Pt}$ & $\mathrm{SiO}_{2}^{-}$ & Vac.; $870-1020 \mathrm{~K}$ & 399 \\
\hline $\mathrm{Pt}$ & $\mathrm{TiO}_{2}$ & $\mathrm{H}_{2} ; 425-1075 \mathrm{~K}$ & 411 \\
\hline
\end{tabular}


TABLE 10. Continued

\begin{tabular}{llll}
\hline \multicolumn{1}{c}{ Suptd. phase } & \multicolumn{1}{c}{ Support } & \multicolumn{1}{c}{ Conditions } & \multicolumn{1}{c}{ Ref. } \\
\hline $\mathrm{Pt}-\mathrm{Ce}$ & $\mathrm{SiO}_{2}$ & $\mathrm{H}_{2}, \mathrm{O}_{2} ;$ up to $920 \mathrm{~K}$ & 35 \\
$\mathrm{Pt}-\mathrm{Rh}$ & $\mathrm{SiO}_{2}$ & $\mathrm{Air}, \mathrm{N}_{2} ;$ up to $1270 \mathrm{~K}$ & 41 \\
$\mathrm{Pt}-\mathrm{Rh}$ & $\mathrm{SiO}_{2}$ & $\mathrm{Air}, \mathrm{H}_{2} ; 350-970 \mathrm{~K}$ & 39,343 \\
$\mathrm{Pt}-\mathrm{Rh}$ & $\mathrm{SiO}_{2}$ & $\mathrm{H}_{2}, \mathrm{O}_{2} \mathrm{He}, \mathrm{N}_{2} ;$ up to $1270 \mathrm{~K}$ & 34 \\
$\mathrm{Pt}-\mathrm{Sn}$ & $\mathrm{SiO}_{2}$ & $\mathrm{H}_{2}, \mathrm{O}_{2} ;$ up to $820 \mathrm{~K}$ & 36 \\
$\mathrm{Rh}$ & $\gamma-\mathrm{Al}_{2} \mathrm{O}_{3}, \mathrm{SiO}_{2}$ & $\mathrm{Air}, \mathrm{H}_{2} ; 420-970 \mathrm{~K}$ & 39,343 \\
$\mathrm{Rh}$ & $\gamma-\mathrm{Al}_{2} \mathrm{O}_{3}, \mathrm{SiO}_{2}$ & $\mathrm{H}_{2}, \mathrm{O}_{2} ; 420-870 \mathrm{~K}$ & 344 \\
$\mathrm{Rh}(-\mathrm{Ce})$ & $\gamma-\mathrm{Al}_{2} \mathrm{O}_{3}, \mathrm{SiO}_{2}$ & $\mathrm{NO}+\mathrm{CO}$ in $\mathrm{He}, \mathrm{H}_{2} ; 600 \mathrm{~K}$ & 37,38 \\
$\mathrm{Rh}-\mathrm{Ce}$ & $\mathrm{SiO}_{2}$ & $\mathrm{H}_{2}, \mathrm{O}_{2} ;$ up to $920 \mathrm{~K}$ & 35 \\
$\mathrm{Rh}-\mathrm{Sn}$ & $\mathrm{SiO}_{2}$ & $\mathrm{H}_{2}, \mathrm{O}_{2} ;$ up to $820 \mathrm{~K}$ & 36 \\
\hline
\end{tabular}

than $1 \mathrm{~nm}$ can be detected. The study of Rickard et al. [133] on the redispersion of $\mathrm{Pt} / \mathrm{Al}_{2} \mathrm{O}_{3}$ in oxygen shows that this statement is not a triviality. They resolved apparent contradictions in the literature as to whether treatment in $\mathrm{O}_{2}$ at $\sim 800 \mathrm{~K}$ of $\mathrm{Pt}$ crystallites supported by alumina leads to redispersion of the metal. Chemisorption measurements on conventional catalysts pointed towards redispersion, while TEM studies on both conventional and model systems showed particle growth by coalescence, and hence sintering instead of redispersion. Explanations were sought in contamination and preferential adsorption, which are notorious troublemakers in chemisorption methods and, in the presence of crystallites so small, could not be detected by TEM. Rickard et al. prepared a model support suitable for HRTEM by thinning an $\alpha$ $\mathrm{Al}_{2} \mathrm{O}_{3}(10 \mathrm{~T} 0)$ single crystal from the backside around the center by ion-beam etching until a small hole was formed; the edge of the hole was sufficiently electron transparent. Deposition of Pt by evaporation resulted in Pt crystallites with a mean diameter of $1.9 \mathrm{~nm}$; see Fig. 30(a) and 30(b). Treatment in 20 torr $\mathrm{O}_{2}$ at $770 \mathrm{~K}$ for $1 \mathrm{~h}$ led to the bimodal size distribution shown in parts (c) and (d) of Fig. 30. In conclusion, particle growth, as indicated by earlier TEM studies, indeed occurs, but it is accompanied by the appearance of a large number of subnanometer clusters, which were formerly not detected by TEM but, of course, do contribute significantly in chemisorption studies. It should be clear that even smaller clusters and single metal atoms, which play important roles in ripening theories, are simply not directly detectable in this way. Therefore, it should be very fruitful to apply quantitative techniques like $\mathrm{x}$-ray photoelectron spectroscopy, Rutherford backscattering, and ion scattering spectroscopy to complement TEM studies aimed at a complete description of the phenomena occurring during heat treatment.

Another reason to include more surface analytical techniques in sintering and redispersion studies is the apparently large influence of contamination. Carbon is a well-known example [10]. Metal crystallites supported by carbon 


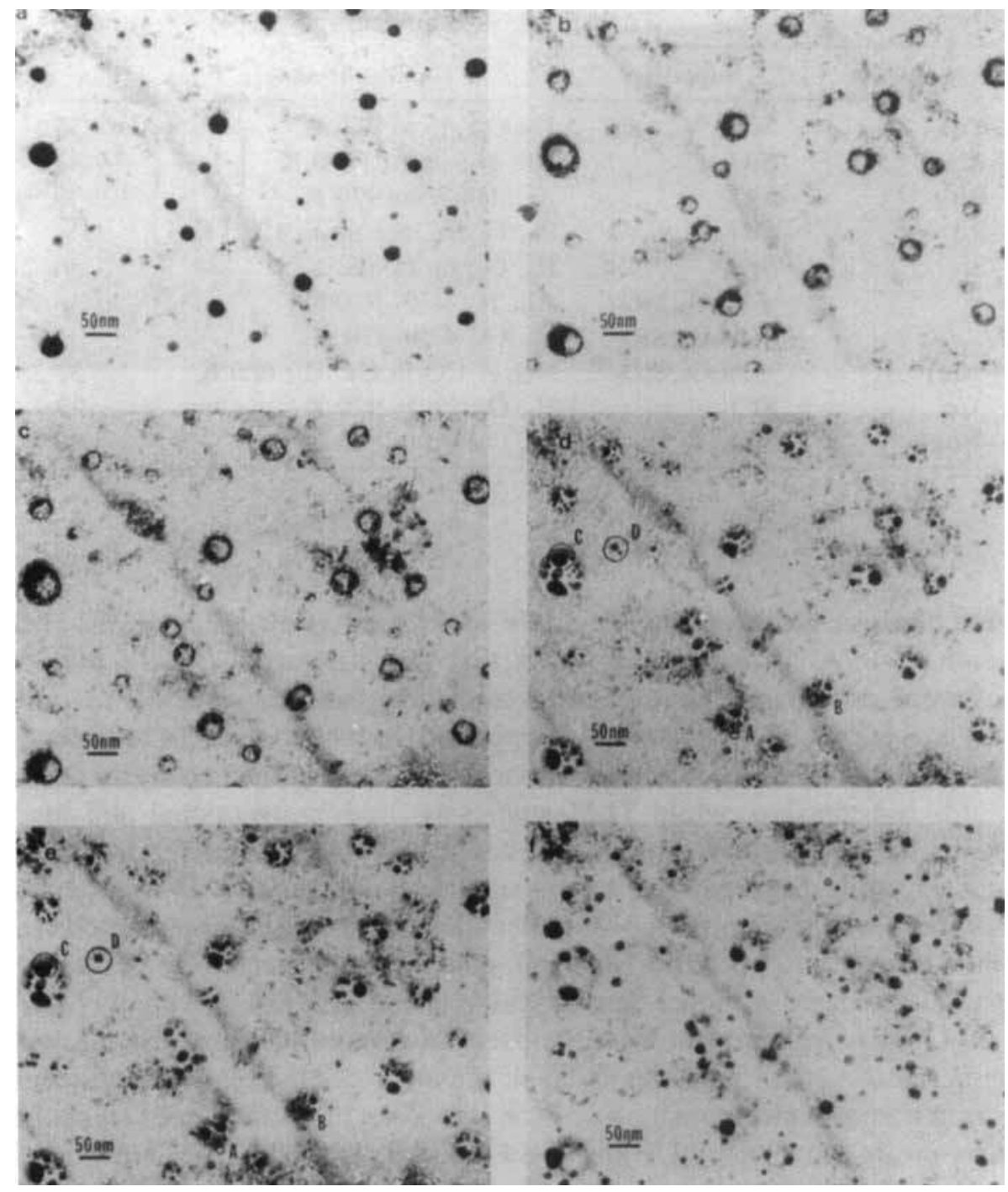

FIG. 29. HRTEM time sequence of a sample of $\mathrm{Ni} / \gamma-\mathrm{Al}_{2} \mathrm{O}_{3}$ : (a) initial state; heated in $\mathrm{O}_{2}$ at $800 \mathrm{~K}$ for (b) $0.5 \mathrm{~h}$ and (c) $3 \mathrm{~h}$; subsequently heated in $\mathrm{H}_{2}$ at $800 \mathrm{~K}$ for (d) $1 \mathrm{~h}$, (3) $2 \mathrm{~h}$, and (f) $3 \mathrm{~h}$ (from Ruckenstein and Lee [248]).

sinter mainly due to migration of the entire crystallite, especially in $\mathrm{H}_{2}$ and $\mathrm{O}_{2}$ atmospheres. Metal-promoted reactions between the carbon support and $\mathrm{H}_{2}$ or $\mathrm{O}_{2}$, forming $\mathrm{CH}_{4}$ or $\mathrm{CO}$ and $\mathrm{CO}_{2}$, respectively, are held responsible for this behavior. These gases lift the metal particles, causing them to float over the surface. Evidence for this mechanism are TEM micrographs showing channels left behind by the migrating particles. The point now is that similar behavior has been reported for Ni crystallites supported by a carbon-contaminated $\mathrm{Al}_{2} \mathrm{O}_{3}$ model support [248]. Figure 31 shows TEM micrographs of the 
model catalyst taken after heating at $1000 \mathrm{~K}$ in 760 torr $\mathrm{H}_{2}$ for 8 and $20 \mathrm{~h}$, respectively. The channels behind the migrating particles are clearly visible. It should be noted that completely different behavior is reported for Ni crystallites on clean alumina model substrates (see above). Increased crystallite mobility has also been reported for nickel on alumina and silica supports treated with fluoride and chloride salts [10].

The influence of group IIA oxide dopants on the sintering and redispersion of $\mathrm{Al}_{2} \mathrm{O}_{3}$-supported Ir crystallites has been studied by McVicker et al. [249]. A few percent of oxides of $\mathrm{Ca}, \mathrm{Sr}$, and $\mathrm{Ba}$ were shown to completely inhibit sintering under oxygen of well-dispersed catalysts up to $920 \mathrm{~K}$, where the undoped catalyst was readily sintered at $750 \mathrm{~K}$. This oxidative stabilization is consistent with the capture of mobile, molecular, iridium oxide species through formation of immobile surface iridates with the group IIA oxides.

Impurities have thus been shown to influence sintering behavior by enhancing crystallite mobility and also by immobilization of atomic (molecular) surface phases formed by emission from larger metal crystallites. Surface characterization by means of, for example, AES or XPS seems thus advisable, especially when contamination is inherent to the technique used to prepare the model support. Anodization, for example, is often used to make thin selfsupporting films of $\gamma-\mathrm{Al}_{2} \mathrm{O}_{3}$, which are suitable for TEM (see Sect. III.B). It is well known, though, that during anodization electrolyte is incorporated in the growing oxide film, up to concentrations of $5 \%$ by weight. In view of the foregoing, this could have considerable effects on the sintering and redispersion of metal crystallites supported by such oxides.

Summarizing, the main advantage of the model support approach in the study of sintering and redispersion of supported metal crystallites is that it enables direct visualization by means of TEM. Mechanistic processes such as migration and spreading can be directly observed. It has become clear that in general very complex phenomena are involved in both sintering and redispersion, and that it strongly depends on atmosphere and metal/support combination which phenomena occur. Due to the evident importance of microscopy in these studies, surface analytical techniques have perhaps not been exploited to their full potential. Also in light of the consequences of impurities in the model support material, extensive characterization should be part of sintering and redispersion studies.

\section{Metal-Support Interactions}

Model catalysts have played a significant role in disclosing the nature of the so-called strong metal-support interaction, or SMSI effect. At the end of the 1970s, scientists at Exxon discovered that metal particles supported on titania, alumina, ceria, and a range of other oxides lose their ability to chemisorb gases such as $\mathrm{H}_{2}$ or $\mathrm{CO}$, after reduction at temperatures of about $770 \mathrm{~K}$. Electron microscopy revealed that the decreased adsorption capacity was not 

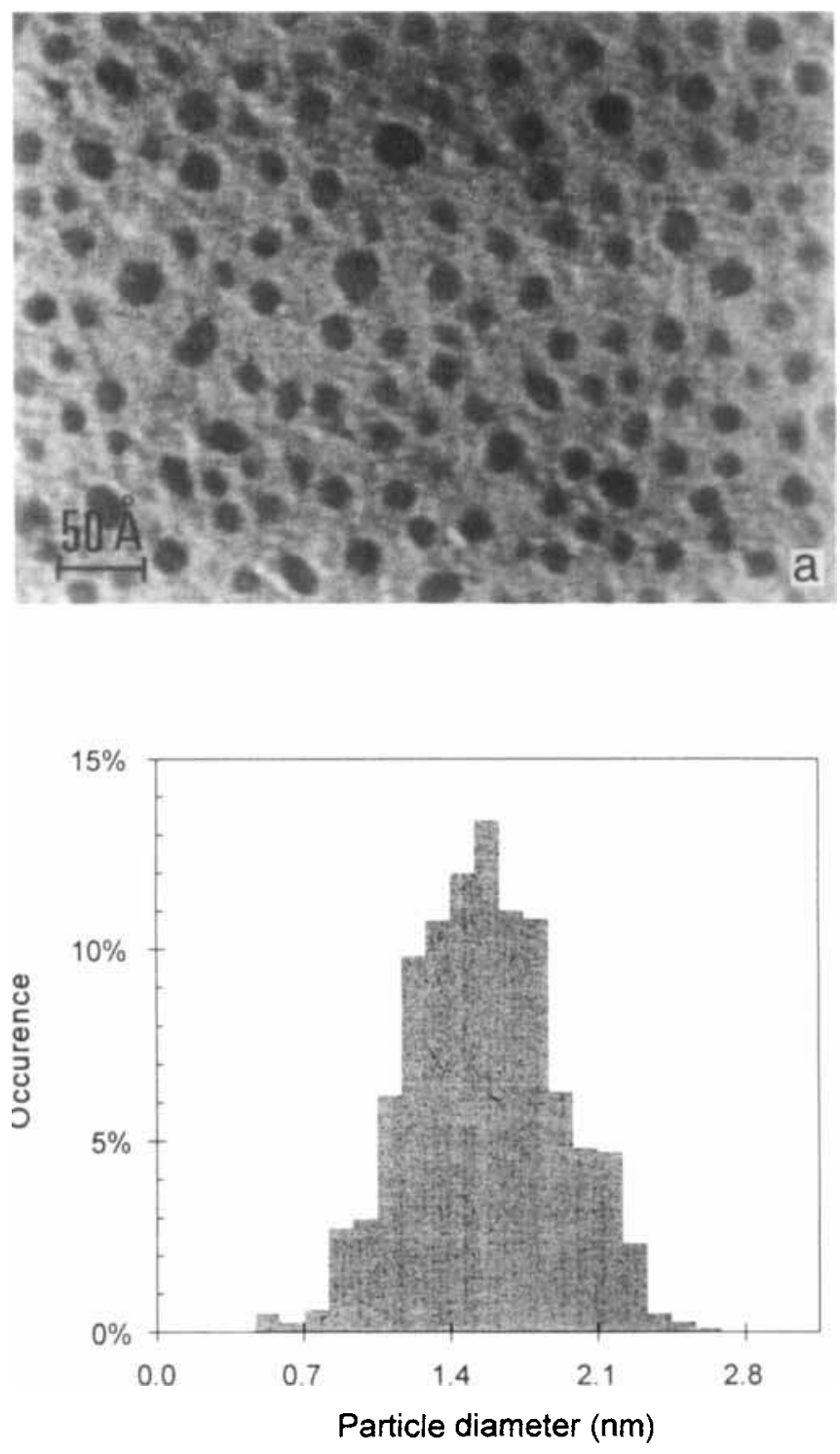

FIG. 30. Micrographs and corresponding size distributions of similar Pt/ $\mathrm{Al}_{2} \mathrm{O}_{3}$ deposits: (a) deposited at $470 \mathrm{~K}$, (b) treated in $\mathrm{O}_{2}(20$ torr, $770 \mathrm{~K}$ ) (for details, see Rickard et al. [133]). 

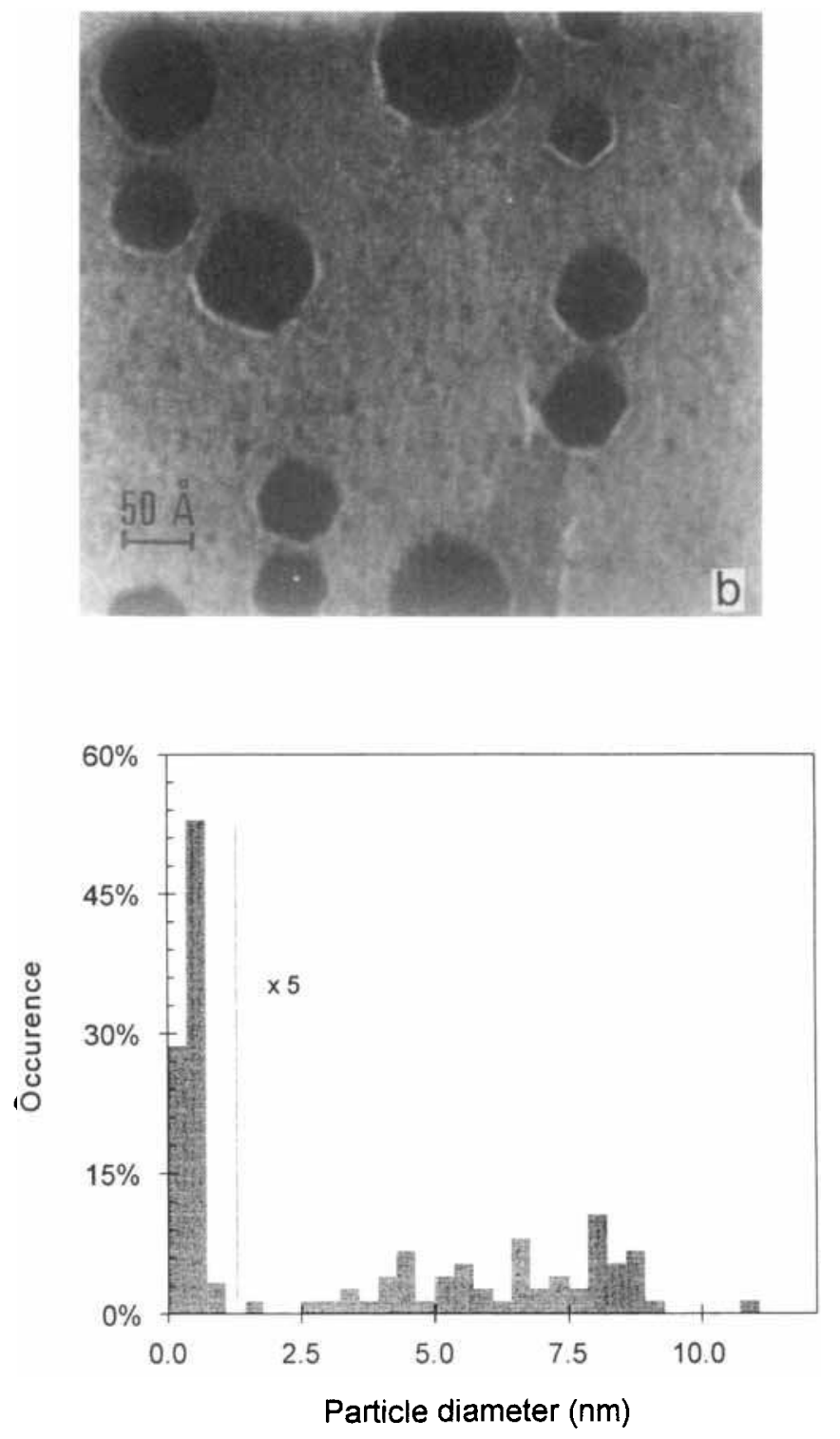

FIG. 30 (Continued) 
caused by particle sintering. Oxidation, followed by reduction at moderate temperatures restored the adsorption properties of the metal in full. The suppression of adsorption after high-temperature reduction was attributed to a strong metal-support interaction, abbreviated at SMSI [250].

This strong metal-support interaction in $\mathrm{Pt} / \mathrm{TiO}_{2}$ catalysts was initially explained with an electronic effect: Charge transfer from the $\mathrm{TiO}_{2}$ support to the Pt particles was thought to modify the electronic configuration of platinum towards that of gold, on which $\mathrm{H}_{2}$ and $\mathrm{CO}$ do not adsorb [251]. Unfortunately, this electronic picture does not explain why a metal such as rhodium exhibits SMSI behavior, as the addition of electrons to rhodium would make it similar to palladium, which activates both $\mathrm{H}_{2}$ and $\mathrm{CO}$ successfully. Photoemission studies, undertaken to observe changes in the electronic structure of metal particles in the SMSI state, led to contradicting conclusions. Chung and coworkers [252], using a model system of very small $\mathrm{Ni}$ particles evaporated onto $\mathrm{TiO}_{2}$, initially concluded that charge was transferred from the support to the metal [27,252]; while Huizinga and Prins using high surface area Pt/ $\mathrm{TiO}_{2}$ [253], and Belton et al. [254,255] working with Pt evaporated onto oxidized $\mathrm{Ti}(0001)$ concluded that there was no charge transfer at all. The apparent contradiction stems largely from the fact that binding energies and also the density of states of the valence electrons are a function of particle size, and likely of morphology as well. These and later studies on the SMSI phenomenon, many employing model systems, strongly suggest that coverage

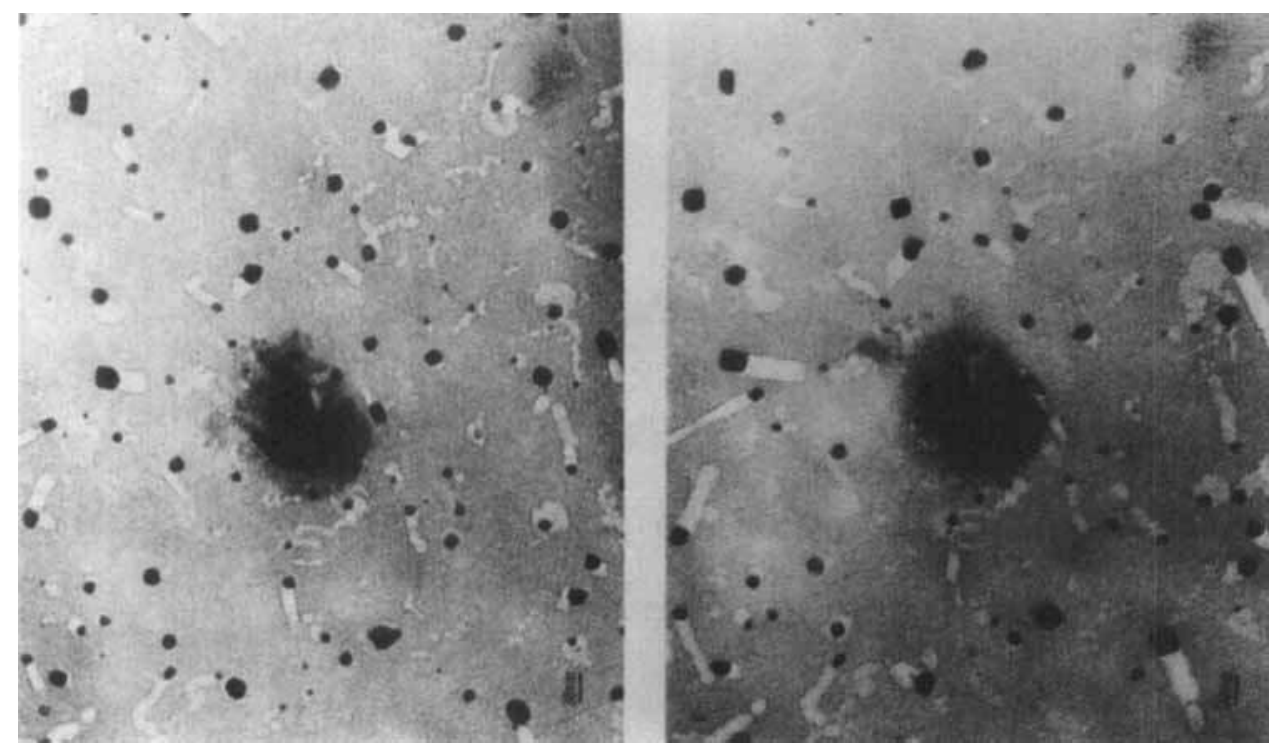

FIG. 31. Particle migration on a carbon-contaminated alumina substrate during heating of the specimen in 1 atm $\mathrm{H}_{2}$ at $1000 \mathrm{~K}$ for (left) $8 \mathrm{~h}$ and (right) 12 more $\mathrm{h}$. The tracks, indicating rapid movement of the crystallites, are caused by (metal-catalyzed) reaction between carbon and $\mathrm{H}_{2}$ (from Ruckenstein and Lee [248]). 
of the metal by partially reduced, mobile suboxides from the support together with the chemical interaction between metal and suboxides are the key elements of SMSI. As an example we mention the TEM image in Fig. 32 of a $\mathrm{Rh} / \mathrm{TiO}_{2}$ catalyst after high-temperature reduction, which clearly shows the presence of amorphous surface layers on the metal particles. Such layers are absent after reduction at lower temperatures [256]. During reduction at high temperature, $\mathrm{TiO}_{2}$ reduces, possibly assisted by the noble metal, to a suboxide of composition $\mathrm{Ti}_{4} \mathrm{O}_{7}$, which because of its partially unsaturated character

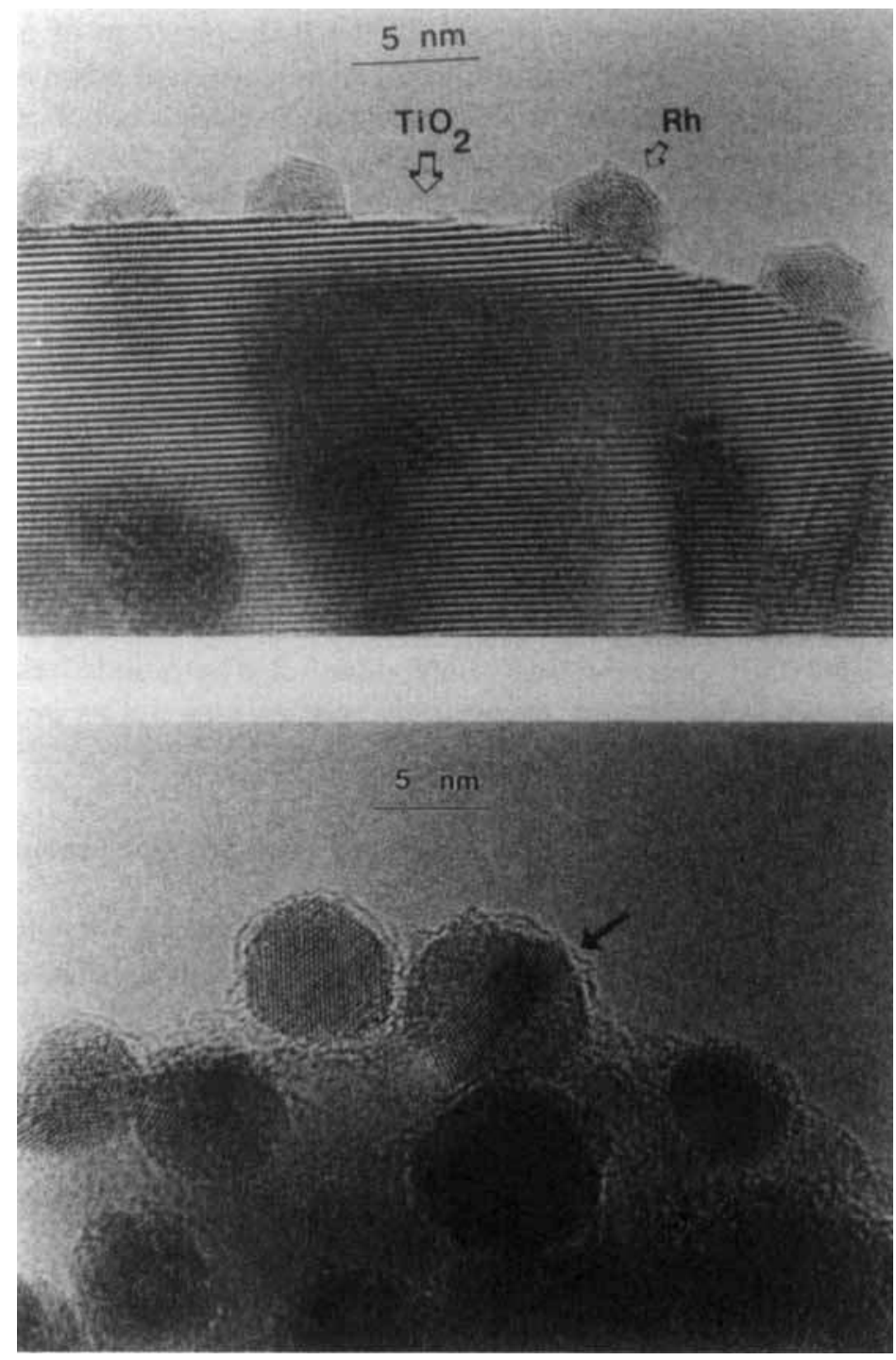

FIG. 32. TEM micrograph of a model $\mathrm{Rh} / \mathrm{TiO}_{2}$ catalyst in the SMSI state (after reduction at $770 \mathrm{~K}$ ). An amorphous overlayer can be clearly discerned (from Logan et al. [256]). 
maximizes its contact with the metal by spreading over the particle [257]. On the basis of angle-resolved XPS work, Bardi et al. estimated the maximum coverage of $\mathrm{TiO}_{x}$ species on the order of a full monolayer [24]. As a consequence, adsorption sites of the metal are blocked. Interestingly, thermal desorption studies of $\mathrm{CO}$ and $\mathrm{H}_{2}$ from these model catalysts indicate that the metal-adsorbate bond is affected by the $\mathrm{TiO}_{x}$ species on the metal [258]. This effect, however, is not necessarily related to charge transfer between the metal and the oxide, but can also have an electrostatic origin.

The following example shows how the promoting effect of suboxides has been addressed by using a "reverse" model catalyst, in which the oxide is on top of a metal foil or single crystal. In the hydrogenation of a molecule containing a $\mathrm{C}-\mathrm{O}$ bond there is a turnover rate enhancement when a reducible oxide contacts the metal. Boffa et al. [102] have prepared model catalysts by depositing submonolayer layers of $\mathrm{AlO}_{x}, \mathrm{TiO}_{x}, \mathrm{VO}_{x}, \mathrm{FeO}_{x}, \mathrm{ZrO}_{x}, \mathrm{NbO}_{x}, \mathrm{TaO}_{x}$, and $\mathrm{WO}_{x}$ over a $\mathrm{Rh}$ foil. The catalytic properties were tested in the hydrogenation of $\mathrm{CO}$ and $\mathrm{CO}_{2}$. The maximum rate enhancement occurs when the metal-oxide interfacial area is maximized, at half a monolayer. The mechanism for the rate enhancement is attributed to the partially reduced oxides at the edge of the oxide islands that form Lewis acid-base complexes between the oxygen on the $\mathrm{CO}$ molecule and anionic vacancies present at the edge of the oxide-metal boundary. The degree of rate enhancement on the various catalysts is found to increase with the average oxidation state of the metal on the oxide overlayer.

We conclude that strong metal support interaction is in fact an incorrect name for a phenomenon which is satisfactorily explained by the blocking of adsorption sites due to the covering of metal particles by mobile oxide species from the support. Additionally, these oxide species may act as promoters in catalytic reactions.

\section{Studies of Catalyst Preparation Using Model Systems}

The development of new catalysts and the improvement of existing catalysts requires a detailed insight in the surface chemical aspects of catalyst preparation, such as the anchoring of catalyst precursors to the support during impregnation, or the solid-state reactions that occur in typical activation procedures as reduction or sulfidation. Using flat model catalysts for this purpose has great potential as several examples in the recent literature show; see Table 11. As explained earlier in this review, model catalysts can be prepared in ways that are essentially equal to industrial procedures:

- Impregnation involving reactions between hydroxyls of the support or acid sites on the support and species in solution (or even in the gas phase as in atomic layer epitaxy) can be applied without limitation, provided the model support possesses a realistic number of such sites. 
- Pore volume impregnation occurs by virtue of capillary forces, which are absent on flat surfaces. In this case spin coating offers a convenient way to apply thin layers of solution; when the solvent evaporates, the solute remains on the surface, similarly to what happens during drying of an impregnated porous support.

Studies of catalyst preparation using realistic model supports have direct relevance for industrial practice. We discus examples of both categories mentioned above.

Catalysts consisting of vanadium oxide on $\mathrm{TiO}_{2}$ exhibit excellent activity for the selective catalytic reduction of $\mathrm{NO}$ by $\mathrm{NH}_{3}$. Nickl et al. [15,221] used a model approach to accurately determine the active state of vanadium with XPS. The support consisted of a thin layer of $\mathrm{TiO}_{2}$, obtained by evaporating and subsequently oxidizing $\mathrm{Ti}$ on a $200-\mathrm{nm}$ Au film supported by an aluminum nitride substrate. The vanadia phase was applied by reacting the $\mathrm{OH}$ groups of $\mathrm{TiO}_{2}$ with an alkoxide ligand of vanadyl tri-isopropoxide in $n$ hexane solution, similarly to reaction (1) of Sect. V, followed by calcination in air at $570 \mathrm{~K}$ to burn off the ligands. XPS revealed that submonolayer quantities of vanadium were present in the $4+$ oxidation state, while higher loadings gave rise to agglomeration of vanadium species with a higher oxidation state. Interestingly, the sample containing interfacial vanadia species only; exchanged oxygen much more easily than samples of higher loading did. The study clearly illustrates the advantage of using thin oxide layers as

TABLE 11

Catalyst Preparation by Impregnation of Flat Model Supports

\begin{tabular}{lll}
\hline \multicolumn{1}{c}{ Model system } & \multicolumn{1}{c}{ Impregnated with: } & \multicolumn{1}{c}{ Ref. } \\
\hline $\mathrm{Rh} / \mathrm{Al}_{2} \mathrm{O}_{3} / \mathrm{Al}$, foil & $\mathrm{RhCl}_{3}$ in $\mathrm{H}_{2} \mathrm{O}$ & 18,50 \\
$\mathrm{~V}_{2} \mathrm{O}_{5} / \mathrm{TiO}_{2} / \mathrm{Au} / \mathrm{AIN}$ & $\mathrm{VO}\left(\mathrm{OC}_{2} \mathrm{H}_{5}\right)_{3}$ in $\mathrm{C}_{2} \mathrm{H}_{5} \mathrm{OH}$ & 15,80 \\
$\mathrm{~V}_{2} \mathrm{O}_{5} / \mathrm{SiO}_{2} / \mathrm{Si}(100)$ & $\mathrm{VO}\left(\mathrm{OC}_{2} \mathrm{H}_{5}\right)_{3}$ in $\mathrm{C}_{2} \mathrm{H}_{5} \mathrm{OH}$ & 221 \\
$\mathrm{VO}_{x} / \mathrm{ZrO}_{2}(100)$ & $\mathrm{VO}\left(\mathrm{OC}_{2} \mathrm{H}_{5}\right)_{3}$ in $\mathrm{C}_{2} \mathrm{H}_{5} \mathrm{OH}$ & 90 \\
$\mathrm{ZrO}_{2} / \mathrm{SiO}_{2} / \mathrm{Si}(100)$ & $\mathrm{Zr}\left(\mathrm{OC}_{2} \mathrm{H}_{5}\right)_{4}$ in $\mathrm{C}_{2} \mathrm{H}_{5} \mathrm{OH}$ & 17,183 \\
$\mathrm{Cu} / \mathrm{SiO}_{2} / \mathrm{Si}(100)$ & $\mathrm{Cu}\left(\mathrm{NO}_{3}\right)_{2}$ in n- $\mathrm{C}_{4} \mathrm{H}_{9} \mathrm{OH}$ & $19,85,224$ \\
$\mathrm{Cu} / \mathrm{SiO}_{2} / \mathrm{Si}(100)$ & $\mathrm{Cu}\left(\mathrm{C}_{7} \mathrm{H}_{5} \mathrm{O}\right)_{2}$ in $\mathrm{C}_{3} \mathrm{H}_{7} \mathrm{OH}$ & \\
$\mathrm{MoO}_{3} / \mathrm{SiO} / \mathrm{Si}(100)$ & $\mathrm{MoO}_{2} \mathrm{Cl}_{2}$ in $\mathrm{C}_{2} \mathrm{H}_{5} \mathrm{OH}$ & 45,260 \\
$\mathrm{MoO}_{3} / \mathrm{Al} \mathrm{O}_{3} / \mathrm{Al}$ & $\left(\mathrm{NH}_{4}\right)_{6} \mathrm{Mo}_{7} \mathrm{O}_{24}$ in $\mathrm{H}_{2} \mathrm{O}$ & 16,222 \\
$\mathrm{Os} / \mathrm{Al}_{2} \mathrm{O}_{3} / \mathrm{Al}$ & $\mathrm{Os}_{3}\left(\mathrm{CO}_{12}\right.$ in $n-\mathrm{C}_{8} \mathrm{H}_{18}$ & 223 \\
$\mathrm{Pd} / \mathrm{Al}_{2} \mathrm{O}_{3} /-$ & $\mathrm{Pd}_{\left(\mathrm{NH}_{3}\right)_{4} \mathrm{Cl}_{2} \text { in } \mathrm{H}_{2} \mathrm{O}}$ & 358 \\
$\mathrm{Pt} / \mathrm{Al}_{2} \mathrm{O}_{3} / \mathrm{Al}$ & $\mathrm{H}_{2} \mathrm{PtCl}_{6}$ in $\mathrm{H}_{2} \mathrm{O}$ & 16 \\
$\mathrm{Co} / \mathrm{C}$ & $\mathrm{Co}_{\left(\mathrm{NO}_{3}\right) \text { in } \mathrm{H}_{2} \mathrm{O}}$ & 68 \\
$\mathrm{Mo} / \mathrm{C}$ & $\left(\mathrm{NH}_{4}\right)_{6} \mathrm{Mo}_{7} \mathrm{O}_{24}$ in $\mathrm{H}_{2} \mathrm{O}$ & 68 \\
$\mathrm{Ag} / \mathrm{C}(\mathrm{HOPG})$ & $\mathrm{AgNO}_{3}$ in $\mathrm{H}_{2} \mathrm{O}$ & 70 \\
$\mathrm{Pt} / \mathrm{C}(\mathrm{HOPG})$ & $\mathrm{H}_{2} \mathrm{PtCl}_{6}$ in $\mathrm{H}_{2} \mathrm{O}$ & 70,73 \\
$\mathrm{Pt} / \mathrm{C}$ & $\mathrm{H}_{2} \mathrm{PtCl}_{6}$ in $\mathrm{H}_{2} \mathrm{O}$ or $\mathrm{C}_{2} \mathrm{H}_{5} \mathrm{OH}$ & 207 \\
\hline
\end{tabular}


a model support. Owing to the optimum resolution, XPS reveals slight differences in oxidation states between interfacial and thicker vanadium oxide particles, which cannot be obtained on the high surface area catalysts.

A very similar approach was taken by Eshelman et al. [17,183] to study the anchoring of zirconia on silica. Here the active phase was anchored by a reaction between zirconium ethoxide in ethanol and the silanol groups on an $\mathrm{SiO}_{2} / \mathrm{Si}(100)$ model support. Angle-dependent XPS and depth-profiling AES measurements demonstrated the close to monolayer like dispersion of the thus prepared catalyst (see also Fig. 3).

Studies of catalyst preparations involving acid sites of the support and cluster ions in solution have provided interesting information on the type of species present on the support after impregnation, as work on $\mathrm{Rh} / \mathrm{Al}_{2} \mathrm{O}_{3} / \mathrm{Al}$ model catalysts illustrates. Rhodium on alumina catalysts are usually made by impregnating the $\mathrm{Al}_{2} \mathrm{O}_{3}$ support with a solution of rhodium trichloride. In water, $\mathrm{RhCl}_{3} \cdot x \mathrm{H}_{2} \mathrm{O}$ forms a range of ionic and neutral complexes, in which the $\mathrm{Rh}^{3+}$ ion is surrounded by six ligands, which are $\mathrm{Cl}^{-}, \mathrm{OH}^{-}$, and $\mathrm{H}_{2} \mathrm{O}$. Negatively charged complexes of the form $\left[\mathrm{RhCl}_{x}\left(\mathrm{H}_{2} \mathrm{O}\right)_{y}(\mathrm{OH})_{z}\right]^{n x-}$ adsorb as the result of an electrostatic interaction on the positively charged sites of the alumina surface, whereas the neutral complexes may attach to the support through a reaction with surface $\mathrm{OH}$ groups.

Static SIMS spectra of the freshly impregnated $\mathrm{Rh} / \mathrm{Al}_{2} \mathrm{O}_{3} / \mathrm{Al}$ catalyst (Fig. 33) give a clear indication of the $\mathrm{Rh}$ ligands present after adsorption. The
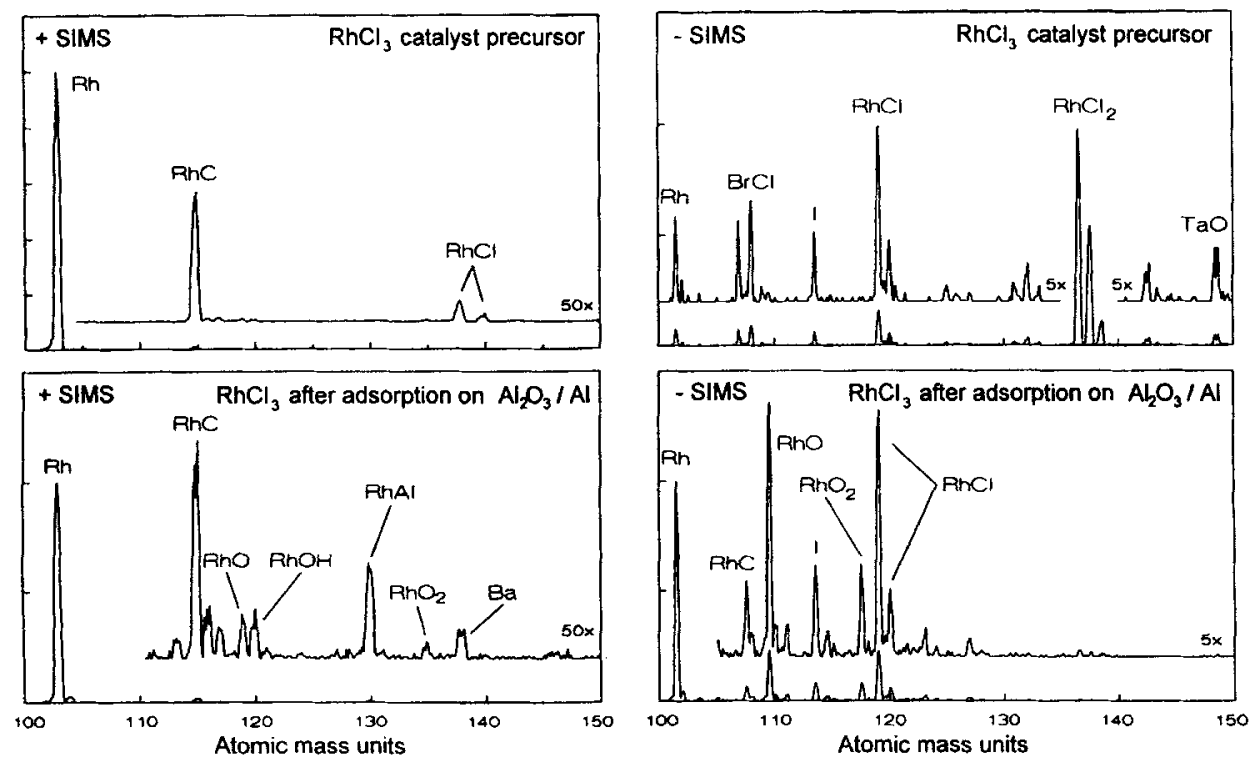

FIG. 33. Positive (left) and negative (right) static SIMS spectra of $\mathrm{RhCl}_{3}$. $x \mathrm{H}_{2} \mathrm{O}$ on a tantalum sample holder (top) and of a model catalyst prepared by adsorbing $\mathrm{Rh}$ complexes derived from $\mathrm{RhCl}_{3} \cdot x \mathrm{H}_{2} \mathrm{O}$ in water on an $\mathrm{Al}_{2} \mathrm{O}_{3} / \mathrm{Al}$ model support (from Borg et al. [50]). 
reference spectrum of the $\mathrm{RhCl}_{3}$ salt shows several molecular peaks characteristic of rhodium coordinated by chlorine. In particular the $\mathrm{RhCl}_{2}^{-}$signal is very intense. As molecular cluster ions from compounds other than alloys are in general the result of a direct emission process [5], the spectrum of Fig. 33 implies that if a sample contains rhodium atoms with more than one chlorine ligand, SIMS is capable of detecting this combination with high sensitivity. The spectrum of the model catalyst, however, shows no peak of $\mathrm{RhCl}_{2}^{-}$, suggesting that $\mathrm{Rh}$ species with more than one $\mathrm{Cl}$ ligand are absent. XPS spectra indicate that rhodium and chlorine are present as $\mathrm{Rh}^{3+}$ and $\mathrm{Cl}^{-}$, respectively, and that the atomic $\mathrm{Cl} / \mathrm{Rh}$ ratio is about 1.4. As SIMS demonstrates $\mathrm{Rh}-\mathrm{Cl}$ contact, whereas $\mathrm{RhCl}_{2}$ and $\mathrm{RhCl}_{3}$ species (for which SIMS is particularly sensitive through the $\mathrm{RhCl}_{2}^{-}$signal) do not appear to be present, XPS and SIMS together indicate that the majority of the Cl-containing $\mathrm{Rh}$ complexes on the catalyst contains one $\mathrm{Cl}^{-}$ion only, and is thus most likely of the form $\left[\mathrm{RhCl}(\mathrm{OH})_{3}\left(\mathrm{H}_{2} \mathrm{O}\right)_{2}\right]^{-}$. Note that this conclusion can not be based on the XPS spectra alone, as alumina is known to strongly bind $\mathrm{Cl}^{-}$ions. The SIMS spectra are of great value here because they confirm that at least a part of the $\mathrm{Cl}^{-}$is coordinated to rhodium.

Supported rhodium catalysts reduce relatively easily. The XPS data in Fig. 34, taken with a monochromated x-ray source, confirm this: Reduction at 470 $\mathrm{K}$ or higher gives rise to a sharp Rh $3 d$ XPS doublet, with a $\mathrm{Rh} 3 d_{5 / 2}$ binding energy of $307.4 \mathrm{eV}$, that is, $0.4 \mathrm{eV}$ higher than the value of the bulk metal, which is a well-known small-particle effect, described in detail by Mason [259]. SIMS reveals that rhodium-chlorine contact disappears during reduction at temperatures between 370 and $470 \mathrm{~K}$, although a significant $\mathrm{ClO}^{-}$ signal demonstrates that chlorine is still present on the support. The $\mathrm{ClO}^{-}$ intensity drops to zero after reduction at $570 \mathrm{~K}$. Hence, reduction of $\mathrm{Rh} / \mathrm{Al}_{2} \mathrm{O}_{3}$ catalysts prepared from $\mathrm{RhCl}_{3}$ proceeds in two steps: First, $\mathrm{Rh}-\mathrm{Cl}$ and $\mathrm{Rh}-\mathrm{O}$ bonds are broken, and $\mathrm{Rh}$ reduces to the metallic state at temperatures below $470 \mathrm{~K}$. The second step involves the removal of residual chlorine from the alumina support, which requires higher temperatures $[18,50]$.

Hydrodesulfurization of heavy oil fractions is carried out with catalysts based on $\mathrm{MoS}_{2}$. These catalysts are made by sulfiding $\mathrm{MoO}_{3} / \mathrm{Al}_{2} \mathrm{O}_{3}$, obtained by impregnation of the support with aqueous solutions of ammonium heptamolybdate, in a mixture of $\mathrm{H}_{2} \mathrm{~S}$ and $\mathrm{H}_{2}$. In order to learn how the sulfidation proceeds in detail, de Jong et al. [45] and Muijsers et al. [260] applied monochromatic XPS, static SIMS, and RBS on a $\mathrm{MoO}_{3} \cdot x \mathrm{H}_{2} \mathrm{O} / \mathrm{SiO}_{2} / \mathrm{Si}(100)$ system. Figure 35 shows the XPS spectra of the model in different stages of sulfidation. The energy resolution is much more favorable than is usually the case for oxide-supported molybdenum samples, and hence XPS of the models yields detailed information on the sulfidation process. For example, the spectra show the presence of bridging disulfide ligands and of substantial amounts of $\mathrm{Mo}^{\mathrm{v}}$ in an early stage of the sulfidation, which suggests that the initial reaction of the $\mathrm{MoO}_{3}$-type precursor with the $\mathrm{H}_{2} \mathrm{~S} / \mathrm{H}_{2}$ atmosphere consists of two elementary steps, namely an exchange of terminal $\mathrm{Mo}^{6+}=\mathrm{O}_{\mathrm{t}}^{2-}$ to 
$\mathrm{Mo}^{6+}=\mathrm{S}^{2-}$, followed by an $\mathrm{Mo}-\mathrm{S}$ redox process in which two adjacent $\mathrm{Mo}=\mathrm{S}$ groups combine to form an $\mathrm{Mo}^{5+}\left(\mathrm{S}_{2}^{2-}\right)_{{ }_{\mathrm{r}}} \mathrm{Mo}^{5+}$ structure at the surface of the particles. Making the XPS peak assignments was greatly facilitated by measuring the XPS spectra of several Mo-S cluster compounds, among which the well-documented thermal decomposition of the triangular Mo(IV) cluster $\left(\mathrm{NH}_{4}\right)_{2}\left(\mathrm{Mo}_{3} \mathrm{~S}_{13}\right) \cdot \mathrm{H}_{2} \mathrm{O}$ to microcrystalline $\mathrm{MoS}_{2}$ [261] yielded the most valuable information on the binding energies of the different sulfur ligands.

Although several authors explored the possibility to prepare molybdenum sulfides on model supports $[16,45,68,260-263]$ all studies so far have concentrated on the chemistry of the $\mathrm{MoO}_{3} \rightarrow \mathrm{MoS}_{2}$ conversion. As the activity of sulfide catalysts is associated with defect sites on the edges of the $\mathrm{MoS}_{2}$ slabs, which are hard to model in a single crystal approach, it should be noted that model catalysts consisting of microcrystalline $\mathrm{MoS}_{2}$ particles offer great potential for studies of adsorption, desorption, and reaction of gases as well.
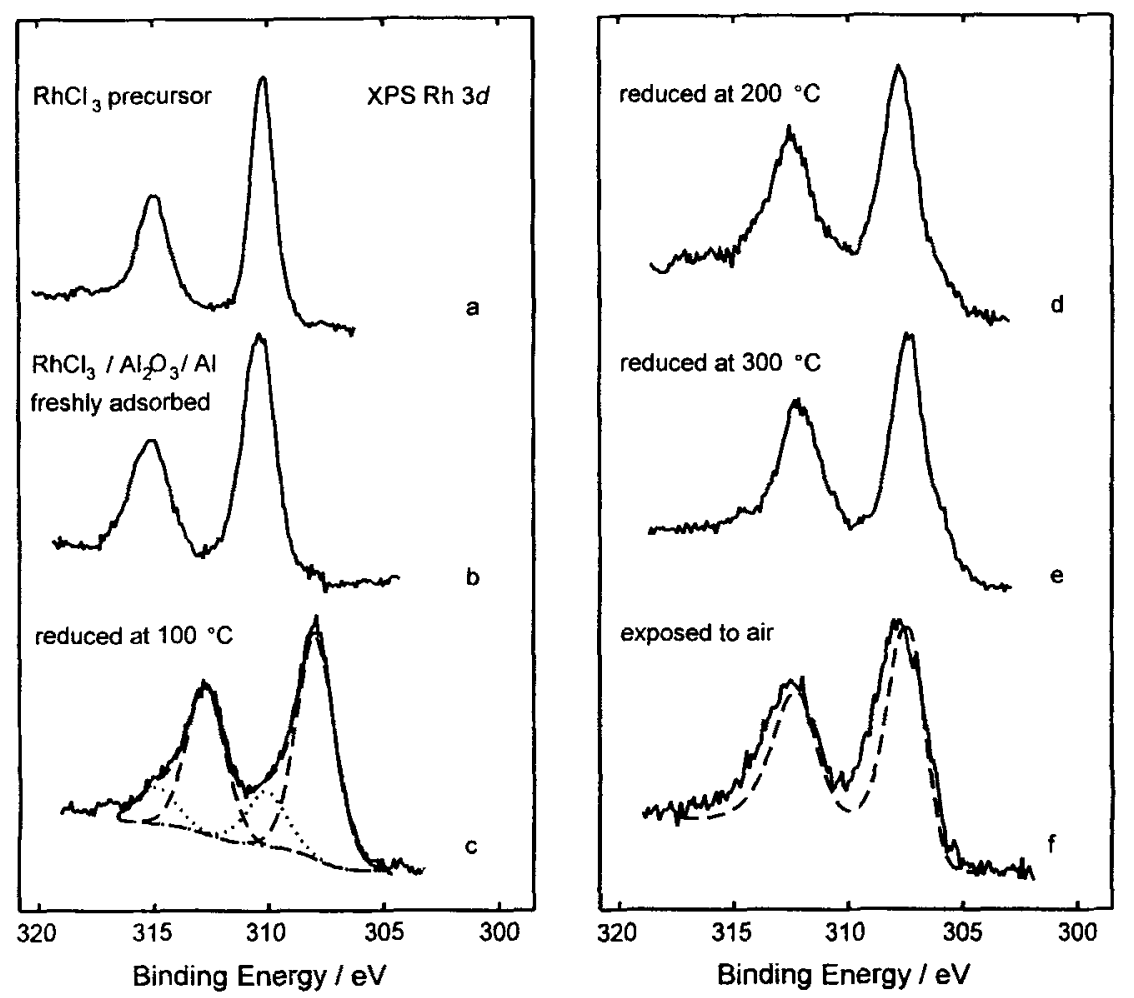

FIG. 34. Rh $3 d X P S$ spectra of (a) $\mathrm{RhCl}_{3} \cdot x \mathrm{H}_{2} \mathrm{O}$ on tantalum, and of a model catalyst prepared by adsorbing $\mathrm{Rh}$ complexes derived from $\mathrm{RhCl}_{3} \cdot x \mathrm{H}_{2} \mathrm{O}$ in water on an $\mathrm{Al}_{2} \mathrm{O}_{3} / \mathrm{Al}$ model support after (b) adsorption and drying, (c)-(e) reduction at the indicated temperatures, and (f) subsequent exposure to air at room temperature. The dashed line represents the $\mathrm{Rh} 3 d$ spectrum of the reduced catalyst (from Borg et al. [50]). 


\section{E. Adsorption and Desorption on Model Metal-Support Systems}

Flat model catalysts offer excellent opportunities for the study of adsorption and desorption on small particles. There are many papers on the subject; see Table 12 for a listing. Thermal desorption is the most often used method to study adsorption; investigations using vibrational spectroscopies and photoemission have been reported as well. Another use of thermal desorption is to measure the total metal surface area. For example, when the metal is deposited by evaporation, some of the deposited clusters may be too small for detection by TEM, AFM, or STM. The small clusters, however, can be easily identified by TPD. The metal area, in conjunction with the total amount of metal deposited, can also be used to calculate the percentage of metal exposed and the particle average diameter.

Model catalysts provide a unique opportunity for the study of spillover from and to the metal cluster. For the oxidation of $\mathrm{CO}$, it has been shown that $\mathrm{CO}$ adsorbs on the support and then diffuses to the metal particles $[135,199,264]$. In fact, $\mathrm{CO}$ molecules arriving at the metal particle by diffusion contribute significantly to the rate at low pressures and have to be taken
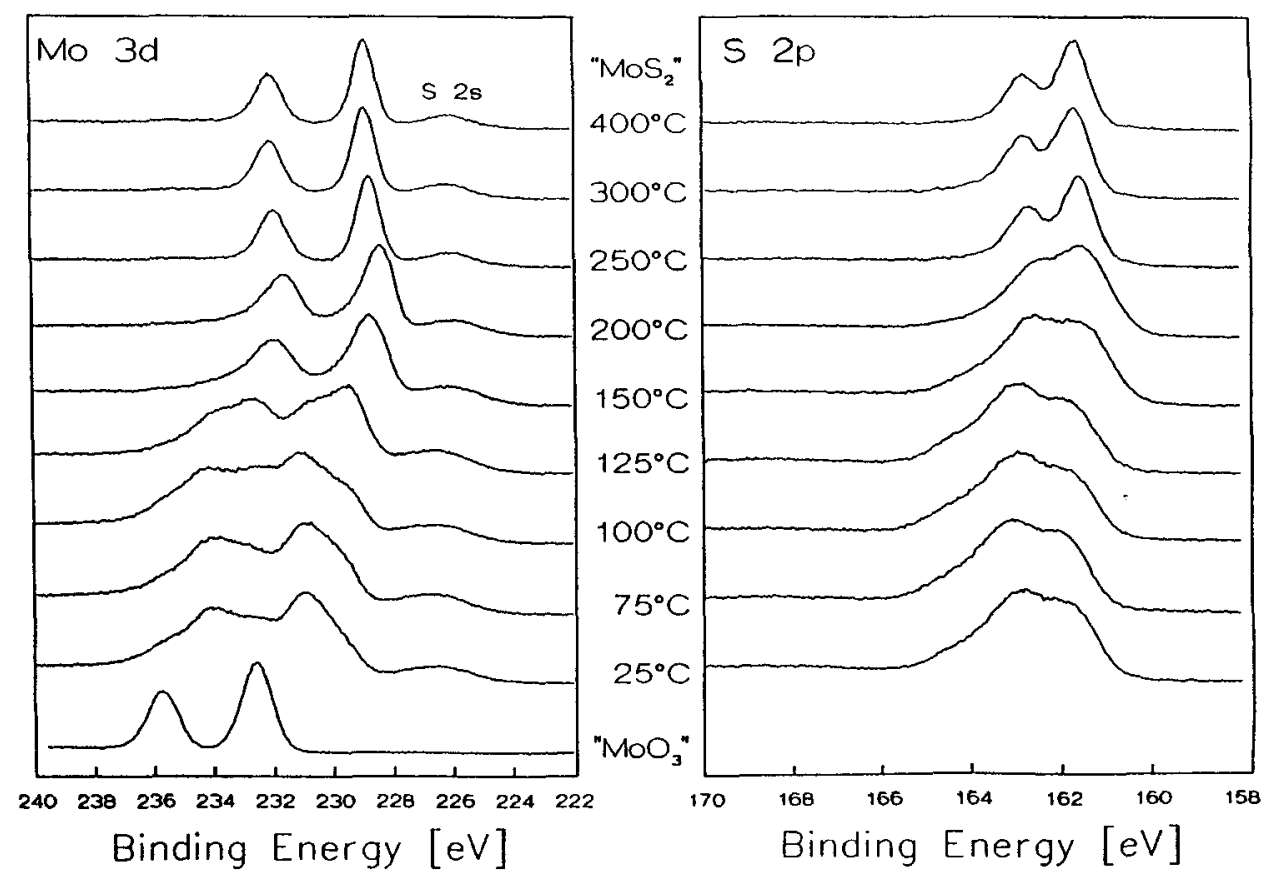

FIG. 35. Mo $3 d$ spectra of a $\mathrm{MoO}_{3} / \mathrm{SiO}_{2} / \mathrm{Si}(100)$ model catalyst sulfided at the indicated temperatures show that $\mathrm{MoO}_{3}$ reacts via $\mathrm{Mo}(\mathrm{V})$ intermediates to $\mathrm{Mo}(\mathrm{IV}) \mathrm{S}_{2}$. The S $2 p$ spectra give clear evidence for the appearance of bridging $\mathrm{S}_{2}^{2-}$ ligands in the early stages of sulfidation, while the $\mathrm{S}^{2-}$ ligand as present in $\mathrm{MoS}_{2}$ emerges at sulfidation temperatures above $420 \mathrm{~K}$ (from Muijsers et al. [260]). 
TABLE 12

Adsorption Studies Employing Particles on Model Supports

\begin{tabular}{|c|c|c|c|c|}
\hline Metal & Support & Gas & Tools & Ref. \\
\hline $\mathrm{Ni}$ & $\mathrm{TiO}_{2} / \mathrm{Ti}$ & $\mathrm{CO}$ & EELS & 384 \\
\hline $\mathrm{Ni}$ & $\mathrm{Al}_{2} \mathrm{O}_{3} / \mathrm{Al}(111)$ & $\mathrm{CO}$ & EELS, TPD & 357 \\
\hline $\mathrm{Ni}$ & Mica & $\mathrm{CO}$ & TDS & 193 \\
\hline $\mathrm{Cu}$ & $\mathrm{ZnO}$ & $\mathrm{CO}$ & XPS, UPS & 26 \\
\hline $\mathrm{Cu}$ & $\mathrm{SiO}_{2}$ & $\mathrm{CO}$ & RAIRS, TPD & $72,277,337$ \\
\hline $\mathrm{Cu}$ & $\mathrm{ZnO}$ & $\mathrm{CH}_{3} \mathrm{OH}$ & TPD & 176 \\
\hline $\mathbf{R u}$ & Mica & $\mathrm{CO}$ & TPD & 196 \\
\hline $\mathbf{R h}$ & $\mathrm{Al}_{2} \mathrm{O}_{3}$ & $\mathrm{CO}$ & IETS & 361 \\
\hline Rh & $\mathrm{Al}_{2} \mathrm{O}_{3}$ & $\mathrm{CO}$ & IETS & 363 \\
\hline Rh & $\mathrm{Al}_{2} \mathrm{O}_{3} / \mathrm{Al}$ & $\mathrm{CO}$ & EELS & 360 \\
\hline Rh & $\mathrm{SiO}_{2} / \mathrm{Ti}$ & $\mathrm{CO}$ & TPD & 272 \\
\hline Rh & $\mathrm{TiO}_{2}(110)$ & $\mathrm{CO}$ & UPS, XPS & 29 \\
\hline $\mathrm{Rh}$ & $\mathrm{Al}_{2} \mathrm{O}_{3}$ & $\mathrm{CO}$ & IETS & 362 \\
\hline Rh & $\mathrm{Al}_{2} \mathrm{O}_{3} / \mathrm{Al}(111)$ & $\mathrm{CO}$ & TPD & $154,215,217$ \\
\hline Rh & $\mathrm{Al}_{2} \mathrm{O}_{3}(0001)$ & $\mathrm{CO}, \mathrm{NO}$ & TPD & 20,271 \\
\hline Rh & $\mathrm{Al}_{2} \mathrm{O}_{3} / \mathrm{Mo}(110)$ & $\mathrm{CO}$ & EELS, TPD & 151 \\
\hline Rh & $\mathrm{Al}_{2} \mathrm{O}_{3}$ & $\mathrm{CO}$ & TPD, SSIMS & 392 \\
\hline Rh & $\mathrm{ZrO}_{2}(100)$ & $\mathrm{NO}, \mathrm{CO}$ & TPD & 181 \\
\hline Rh & $\mathrm{MgO}$ & $\mathrm{CO}$ & TPD, SSIMS & 392 \\
\hline Rh & $\mathrm{CeO}_{2}$ & $\mathrm{CO}$ & TPD & 186,187 \\
\hline Rh & $\mathrm{TiO}_{2} / \mathrm{Ti}(0001)$ & $\mathrm{NO}, \mathrm{CO}, \mathrm{H}_{2}$ & TPD & 254,258 \\
\hline $\mathrm{Rh}$ & $\mathrm{TiO}_{2} / \mathrm{Re}$ & $\mathrm{CO}$ & TPD & 386,387 \\
\hline Rh & $\mathrm{TiO}_{2}(110)$ & $\mathrm{CO}$ & RAIRS & 213,214 \\
\hline Pd & Mica & $\mathrm{CO}$ & TEM, TDS & 193 \\
\hline Pd & Graphite & Co & UPS & 31 \\
\hline Pd & Mica & $\mathrm{CO}$ & TDS & 199 \\
\hline Pd & Mica & $\mathrm{CO}$ & SSIMS & 202 \\
\hline $\mathrm{Pd}$ & $\mathrm{MgO}$ & $\mathrm{CO}$ & TDS, EELS & 165 \\
\hline $\mathbf{P d}$ & $\mathrm{MgO}, \mathrm{Al}_{2} \mathrm{O}_{3}$ & $\mathrm{CO}$ & TPD, SSIMS & 273 \\
\hline Pd & $\mathrm{MgO}$ & $\mathrm{CO}$ & Mol. beam & 275 \\
\hline Pd & $\mathrm{Al}_{2} \mathrm{O}_{3} / \mathrm{Al}$ & $\mathrm{CO}$ & TPD & 359 \\
\hline $\mathbf{P d}$ & Mica & $\mathrm{C}_{2} \mathrm{H}_{4}$ & TPD & 195 \\
\hline Pd & $\mathrm{SiO}_{2} / \mathrm{Mo}(110)$ & $\mathrm{CO}, \mathrm{O}_{2}, \mathrm{NO}$ & TPD, RAIRS & 276,338 \\
\hline Pd & $\mathrm{SiO}_{2} / \mathrm{Si}$ & $\mathrm{H}_{2}, \mathrm{O}_{2}, \mathrm{CO}$ & TPD & 78 \\
\hline Pd & $\mathrm{Al}_{2} \mathrm{O}_{3} /$ metal & $\mathrm{CO}$ & TPD & 358 \\
\hline Pd & $\alpha-\mathrm{Al}_{2} \mathrm{O}_{3}$ & $\mathrm{CO}$ & TPD, SSIMS & 355 \\
\hline $\mathrm{Pd}$ & $\alpha-\mathrm{Al}_{2} \mathrm{O}_{3}(1012)$ & $\mathrm{CO}$ & TPD & 101,351 \\
\hline $\mathrm{Ag}$ & $\mathrm{Al}_{2} \mathrm{O}_{3}$ & $\mathrm{EtOH}$ & IETS & 421 \\
\hline $\mathbf{P t}$ & $\mathrm{SiO}_{2} / \mathrm{Ti}$ & $\mathrm{CO}$ & TPD & 272 \\
\hline $\mathrm{Pt}$ & $\mathrm{TiO}_{2} / \mathrm{Ti}$ & $\mathrm{CO}$ & XPS & 160,383 \\
\hline $\mathrm{Pt}$ & $\mathrm{Al}_{2} \widetilde{\mathrm{O}}_{3} / \mathrm{Ta}$ & $\mathrm{CO}$ & TPD & 367 \\
\hline $\mathrm{Pt}$ & $\mathrm{Al}_{2} \mathrm{O}_{3} / \mathrm{Ta}$ & $\mathrm{CO}, \mathrm{H}_{2}$ & TPD & 352 \\
\hline Pt & $\mathrm{Al}_{2} \mathrm{O}_{3}(0001)$ & $\mathrm{CO}, \mathrm{H}_{2}$ & TPD & 352 \\
\hline Pt & $\mathrm{Al}_{2} \mathrm{O}_{3}(0001)$ & $\mathrm{CO}$ & TPD, UPS & $20,353,335$ \\
\hline $\mathbf{P t}$ & $\mathrm{Al}_{2} \mathrm{O}_{3}$ & $\mathrm{C}_{2} \mathrm{H}_{4}$ & HREELS & 53,54 \\
\hline $\mathbf{P t}$ & $\mathrm{Al}_{2} \mathrm{O}_{3}$ & $\mathrm{CO}$ & HREELS & 55,54 \\
\hline
\end{tabular}


TABLE 12. Continued

\begin{tabular}{lllll}
\hline Metal & \multicolumn{1}{c}{ Support } & \multicolumn{1}{c}{ Gas } & \multicolumn{1}{c}{ Tools } & \multicolumn{1}{c}{ Ref. } \\
\hline $\mathrm{Pt}$ & $\mathrm{TiO}_{2}$ & $\mathrm{C}_{2} \mathrm{H}_{4}$ & HREELS & 53 \\
$\mathrm{Pt}$ & $\mathrm{CeO}_{2}$ & $\mathrm{CO}, \mathrm{NO}, \mathrm{H}_{2}$ & TPD & 185 \\
$\mathrm{Pt}$ & $\mathrm{ZrO}_{2}(100)$ & $\mathrm{CO}$ & TPD & 180 \\
$\mathrm{Pt}$ & $\mathrm{TiO}_{2} / \mathrm{Ti}(0001)$ & $\mathrm{CO}, \mathrm{H}_{2}, \mathrm{NO}$ & TPD & 254,258 \\
$\mathrm{~V}_{2} \mathrm{O}_{5}$ & $\mathrm{TiO}_{2} / \mathrm{Au} / \mathrm{AlN}$ & $\mathrm{O}_{2}, \mathrm{CO}_{2}$ & TPD & 15 \\
$\mathrm{Pt}-\mathrm{Rh}$ & $\mathrm{SiO}_{2} / \mathrm{Ti}$ & $\mathrm{CO}$ & TPD & 272 \\
\hline
\end{tabular}

into account when comparing rates on model catalysts. In the same way, Eriksson and Petersson [78] have shown that spillover species play a role on $\mathrm{CO}$ and $\mathrm{H}_{2}$ oxidation over $\mathrm{Pd}$ supported on $\mathrm{SiO}_{2}$. One important consideration is that high exposures may be necessary to observe spillover. For example, Jacobs et al. [265] observed that about $1 \times 10^{4}$ Langmuir is necessary to observe deuterium spillover on $\mathrm{Pt} / \mathrm{SiO}_{2}$ model catalysts.

A general difficulty in adsorption and reaction studies on supported model catalysts is to ensure that the particles are "clean." Verification of surface cleanliness and definition has become standard practice in surface science of single crystals but is fundamentally more difficult for supported particles. For example, removing impurities from the coordinatively most unsaturated sites may require conditions that affect particle size or morphology. Moreover, certain particle morphologies may only be stable in the presence of adsorbates, which may play a role similar to stabilizing ligands in organometallic cluster chemistry. In other words, definition and cleanliness are by no means trivial in the case of small particles.

Studies of the adsorption states of gases such as $\mathrm{CO}$ and NO have revealed that the desorption states are a function of particle size in a similar way, as the desorption states depend on the particular plane exposed on a single crystal. Particle size effects can largely be understood in terms of distributions of exposed crystal planes and the low coordination sites that are present at boundaries between facets [266]. Effects attributable to modified electronic structure of small particles do not usually have to be invoked and are actually only expected for particles with less than about 20 atoms [267,268].

Interesting results on low coordination sites on small Pd particles in $\mathrm{Pd} / \mathrm{\alpha}-$ $\mathrm{Al}_{2} \mathrm{O}_{3}(1012)$ model catalysts were reported by Ladas et al. [101] (see Fig. 36). TPD spectra of $\mathrm{CO}$ exhibit two states, one desorbing around $450 \mathrm{~K}$, attributed to $\mathrm{CO}$ on crystalline facets of $\mathrm{Pd}$, corresponding to a coverage of $1 \mathrm{CO}$ on $2 \mathrm{Pd}$ atoms; and a more weakly bound state, filled at higher exposures and desorbing around $375 \mathrm{~K}$. The maximum $\mathrm{CO}$ coverage in the latter state increases considerably for smaller particles and is attributed to multiple $\mathrm{CO}$ adsorption on highly unsaturated Pd atoms. The multiple adsorption of $\mathrm{CO}$ in this state is reminiscent of the bonding of $\mathrm{CO}$ ligands in carbonyl complexes [269]. 
Gorte and coworkers made extensive TPD studies of $\mathrm{CO}, \mathrm{NO}$, and $\mathrm{H}_{2}$ on $\mathrm{Pt}$ and $\mathrm{Rh}$ particles evaporated onto supports such as amorphous alumina films, for example, $\alpha-\mathrm{Al}_{2} \mathrm{O}_{3}(0001), \mathrm{ArO}_{2}$, and $\mathrm{CeO}_{2}$ [185,270,271]. Average particle sizes were derived from the uptake of $\mathrm{CO}$ as measured in a desorption experiment and the amount of metal deposited [20]. A comparing study of $\mathrm{CO}$ adsorption on $\alpha-\mathrm{Al}_{2} \mathrm{O}_{3}(0001)$-supported model catalysts and single crystals of $\mathrm{Pt}$ and $\mathrm{Rh}$ nicely illustrates that with respect to $\mathrm{CO}$ adsorption particles behave predominantly as a collection of facets of different surface orientation. Comparison of $\mathrm{Rh}$ and $\mathrm{Pt}$ is particularly interesting because CO TPD spectra from platinum single crystals profoundly depend on the crystallographic plane exposed [e.g., (111) or (110) give strikingly different desorption spectra], whereas CO TPD from $\mathrm{Rh}(111)$, (100), and (110) are very similar. These differences are also observed on the supported particles. The work thus shows that similar $\mathrm{CO}$ desorption states are observed for small particles and for bulk metals, and that the metals, at least in the particle range (ca. $2 \mathrm{~nm}$ average diameter and higher), are not noticeably influenced by the alumina support.

These results are in good qualitative agreement with an earlier study by Zhu and Schmidt [272]. These authors found that the sticking coefficient for $\mathrm{CO}$ of small particles is larger than that of large particles, while the coverage dependence of the sticking coefficient points to adsorption through precursor mechanisms. The measurement of sticking coefficients should be interpreted

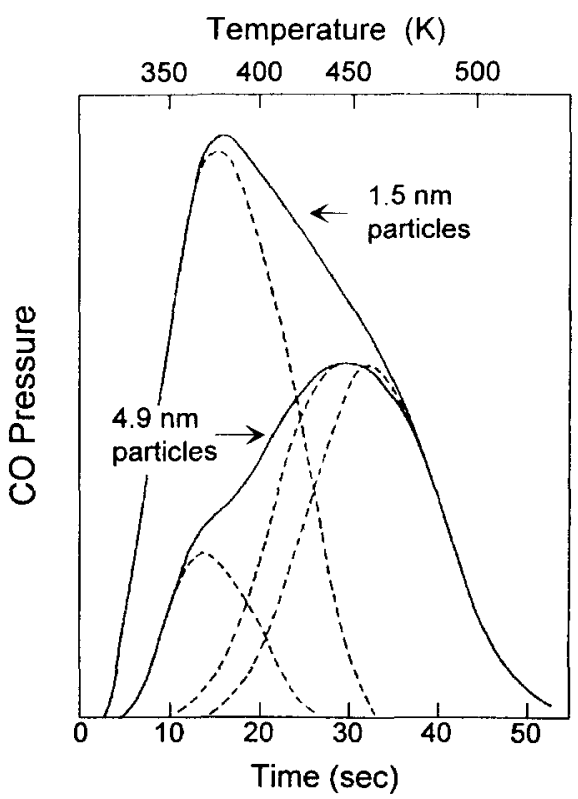

FIG. 36. Comparison of TPD spectra of CO desorbing from Pd: E, for 4.9$\mathrm{nm}$ particles; $\mathrm{F}$, for $1.5-\mathrm{nm}$ particles; subscripts 1 and 2 pertain to states 1 and 2 respectively. Spectra normalized with respect to state 1 (see Ladas et al. [101] for details). 
with care. There are reports in the literature [135,202] which show that CO will adsorb on the support and then diffuse to the metal particle, increasing the apparent sticking probability.

The presence of highly unsaturated adsorption sites makes small particles intrinsically more reactive, which may give rise to dissociative adsorption of molecules that adsorb molecularly on the low index planes of a single crystal of the same metal. For example, $\mathrm{CO}$ adsorbs molecularly on the low index planes of palladium but has been found to dissociate on small particles $[193,199,200,273,274]$. However, later work on well equilibrated Pd particles did not give rise to $\mathrm{CO}$ dissociation, suggesting that dissociation is associated with defects on relatively rough surfaces $[198,275]$.

Particle size effects that can be traced down to the probability of finding adsorption sites of a certain geometry have been found in the adsorption of $\mathrm{CO}$ on $\mathrm{Cu}$ and Pd [276,277], and of ethylene on Pt [53,54] model catalysts. Vibrational spectroscopies have been instrumental in these studies. For example, Goodman and coworkers found that $\mathrm{CO}$ adsorption on relatively large Pd particles resembles that of adsorption on the (111) and (100) faces of palladium. Figure 37 shows the reflection-adsorption IR spectra of $\mathrm{CO}$ on Pd overlayers on thin $\mathrm{SiO}_{2}$ films which had been heated to produce particles in the 3-50 $\mathrm{nm}$ size range, depending on nominal Pd coverage. The three distinct absorption features correspond to $\mathrm{CO}$ adsorbed on 3-fold hollow (1880 $\left.\mathrm{cm}^{-1}\right)$, bridging $\left(1990 \mathrm{~cm}^{-1}\right)$, and on top $\left(2110 \mathrm{~cm}^{-1}\right)$ configurations. The linear CO feature predominates on the smallest particles (1 ML Pd coverage), while the bridged bonding mode is the major one on large particles. Note that the absorption peaks sharpen with increasing particle size and that $\mathrm{CO}$ adsorption on the largest particles can be conceived as adsorption on essentially (111) and (100) surfaces, suggesting that the particles contain mainly facets of these orientations [12].

Although $\mathrm{CO}$ is again the most frequently studied molecule in these vibrational studies, other gases such as NO and ethylene have been investigated as well; see Table 12 . Hensley and Kesmodel $[53,54]$ found with EELS that ethylene converts to ethylidyne only on the larger particles (average size > $1.4 \mathrm{~nm}$ ) of a $\mathrm{Pt} / \mathrm{Al}_{2} \mathrm{O}_{3}$ model catalyst, which they attribute to the need of threefold $\mathrm{Pt}$ sites. The room temperature state of $\mathrm{C}_{2} \mathrm{H}_{4}$ on the smaller particles remained unclear. In the future, combining vibrational techniques such as RAIRS and EELS with tools that determine the structure, such as STM and HRTEM, should give highly interesting information on the adsorption sites on supported particles.

\section{F. Catalytic Reactions on Model Metal-Support Systems}

A list of catalytic studies with model systems is given in Table 13. The most thoroughly studied reaction is $\mathrm{CO}+1 / 2 \mathrm{O}_{2} \rightarrow \mathrm{CO}_{2}$ on $\mathrm{Pd}$ catalysts. There is a large body of literature for this reaction over supported catalysts, 
model systems, and large single crystals. Reviewing the results obtained with model catalysts and comparing them with the ones from supported catalysts and single crystals is useful to illustrate the advantages of using model catalysts.

The oxidation of $\mathrm{CO}$ over $\mathrm{Pd}$ supported on alumina single crystals and amorphous alumina and silica $[101,135,276,278,279]$ was found to be structure insensitive on Pd single crystals [280]. To confirm that the reaction was structure insensitive on supported model catalysts, the mean particle diameter was varied between 2 and $8 \mathrm{~nm}$, as measured by TEM [101]. The total surface area of Pd was measured directly by the TPD of CO to confirm that Pd particles with a diameter smaller than $1 \mathrm{~nm}$, and thus not visible by TEM, would not be present. The reaction was run at a $\mathrm{CO}$ pressure of $1 \times 10^{-4}$ $\mathrm{Pa}, P_{\mathrm{O} 2} / P_{\mathrm{CO}}=1.1$ with the total amount of $\mathrm{CO}_{2}$ measured continuously by a mass spectrometer. Figure 38 shows the variation of turnover rate as a func-

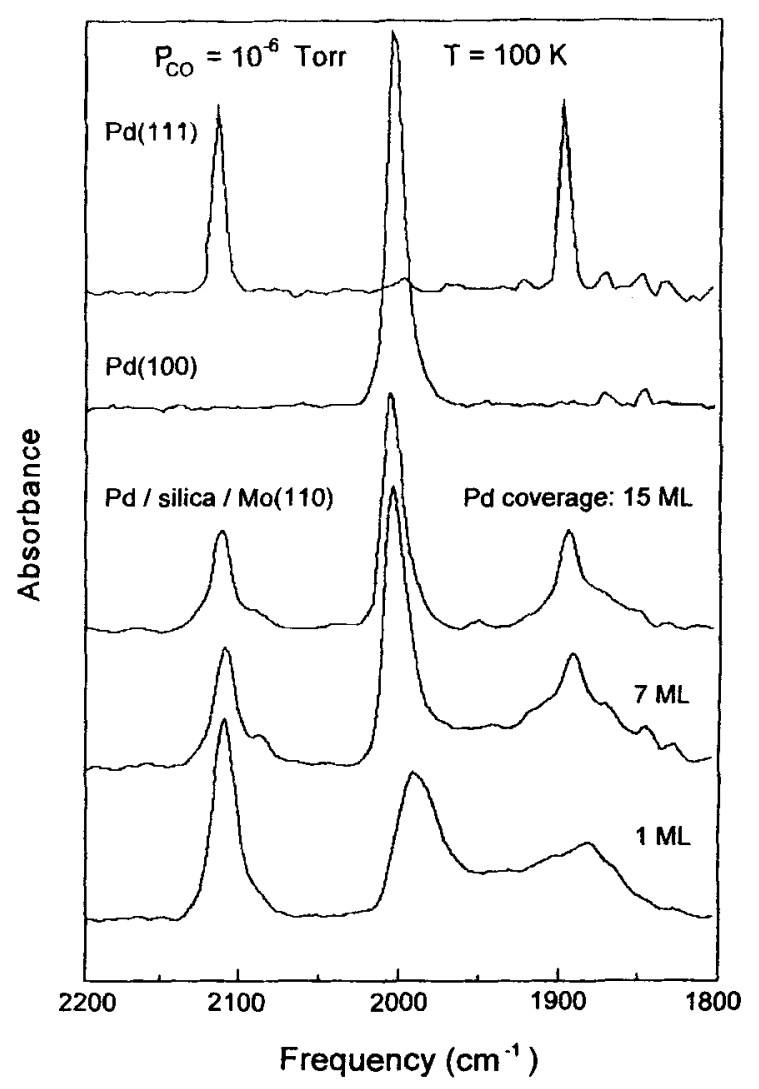

FIG. 37. A comparison of infrared reflection-adsorption spectra of $\mathrm{CO}$ on Pd(111), Pd(100), and model silica supported Pd surfaces. The spectra were collected at $100 \mathrm{~K}$ with a $\mathrm{CO}$ pressure of $10^{-6}$ torr. These spectra demonstrate that the larger particles have well-defined crystal orientations, whereas the smaller particles have a wide distribution of adsorption sites (from Goodman [12]). 
tion of particle size. The result at $445 \mathrm{~K}$ suggests that the reaction is structure insensitive but the result at $518 \mathrm{~K}$ shows that the rate increases as the particle size decreases. To understand the cause for this variation, it is necessary to first discuss the reaction kinetics, which will depend on the temperature and on the reactant partial pressure. At a fixed $P_{\mathrm{O} 2} / P_{\mathrm{CO}}$ ratio, the rate goes through a maximum at $T_{\max }$ as the temperature is increased. Below $T_{\max }$ the rate is roughly proportional to the ratio $P_{\mathrm{O} 2} / P_{\mathrm{CO}}$ and the rate increases with temperature. Above $T_{\max }$ the rate becomes proportional to $P_{\mathrm{CO}}$ and it decreases with temperature due to the decreasing equilibrium constant for $\mathrm{CO}$ adsorption [281]. At $P_{\mathrm{O} 2} / P_{\mathrm{CO}}=1.1$ (Fig. 38) the $T_{\max }$ is around $510 \mathrm{~K}$. The cause for the variation of rates with particle size at $518 \mathrm{~K}$ (where the rate is proportional to $\left.P_{\mathrm{CO}}\right)$ is not due to differences in the reactivity of the particles but to an increased supply of $\mathrm{O}_{2}$ and $\mathrm{CO}$ to the $\mathrm{Pd}$ particles through diffusion from the alumina support (reverse spillover) as the size of the particles decrease. In fact, the rate for $\mathrm{CO}$ oxidation for the smallest particle size at $518 \mathrm{~K}$ is higher

TABLE 13

Reaction Studies Employing Particles on Model Supports

\begin{tabular}{|c|c|c|c|}
\hline Metal & Support & Reaction & Ref. \\
\hline $\mathrm{Cu}$ & $\mathrm{ZnO}(000 \overline{1})$ & $2 \mathrm{H}_{2}+\mathrm{CO} \rightarrow \mathrm{H}_{3} \mathrm{COH}$ & 175 \\
\hline $\mathrm{Ni}$ & $\mathrm{SiO}_{2}$ & $\mathrm{C}_{2} \mathrm{H}_{6} / \mathrm{H}_{2}$ & 233 \\
\hline $\mathrm{Ni}$ & $\mathrm{SiO}_{2}$ & $\mathrm{CO} / \mathrm{H}_{2}$ & 339 \\
\hline $\mathrm{Ni}$ & $\mathrm{Al}_{2} \mathrm{O}_{3} / \mathrm{W}$ & Methanation & 366 \\
\hline Rh & $\mathrm{Al}_{2} \mathrm{O}_{3}$ & $\mathrm{CO} / \mathrm{H}_{2}$ & 364 \\
\hline $\mathrm{Rh} / \mathrm{Pt}$ & $\mathrm{CeO}_{x}+\mathrm{SiO}_{2}$ & $\mathrm{CO} / \mathrm{H}_{2}$ & 35 \\
\hline $\mathrm{Rh} / \mathrm{Pt}$ & $\mathrm{CeO}_{x}+\mathrm{SiO}_{2}$ & $\mathrm{C}_{2} \mathrm{H}_{6} / \mathrm{H}_{2}$ & 35,36 \\
\hline $\mathrm{Rh}$ & $\mathrm{CeO}_{2}$ & $\mathrm{CO} / \mathrm{O}_{2}$ & 187 \\
\hline $\mathrm{Rh}$ & $\mathrm{MgO}, \mathrm{Al}_{2} \mathrm{O}_{3}$ & $\mathrm{CO} / \mathrm{O}_{2}$ & 393 \\
\hline $\mathbf{P d}$ & $\alpha-\mathrm{Al}_{2} \mathrm{O}_{3}$ & $\mathrm{CO} / \mathrm{O}_{2}$ & 101 \\
\hline $\mathbf{P d}$ & $\mathrm{ZnO}$ & Ethanol decomposition & 173 \\
\hline $\mathrm{Pd}$ & Mica & $\mathrm{H}_{2} / \mathrm{D}_{2}$ & 203 \\
\hline$P d$ & Mica & $\mathrm{CO} / \mathrm{O}_{2}$ & 202 \\
\hline Pd & $\mathrm{Al}_{2} \mathrm{O}_{3}$ & $\mathrm{CO} / \mathrm{O}_{2}$ & 264 \\
\hline Pd & Mica & $\mathrm{CO} / \mathrm{O}_{2}$ & 52 \\
\hline $\mathbf{P d}$ & $\mathrm{Si}(100) / \mathrm{O}_{2}$ & 1,3-Butadiene/ $\mathrm{H}_{2}$ & 234 \\
\hline Pd & $\mathrm{SiO}_{2}$ & $\mathrm{CO} / \mathrm{O}_{2}$ & 276 \\
\hline $\mathbf{P d}$ & $\mathrm{SiO}_{2}$ & $\mathrm{NO} / \mathrm{CO}$ & 338 \\
\hline$P d$ & $\mathrm{SiO}_{2}$ & $\mathrm{CO} / \mathrm{O}_{2}$ & 78 \\
\hline$P d$ & $\mathrm{SiO}_{2}$ & $\mathrm{H}_{2} / \mathrm{O}_{2}$ & 78 \\
\hline $\mathbf{P t}$ & $\mathrm{Al}_{2} \mathrm{O}_{3} / \mathrm{Al}$ & Methyl cyclopentane hydrogenolysis & 370 \\
\hline Pt & $\mathrm{SiO}_{2} / \mathrm{Al}$ & Methyl cyclopentane hydrogenolysis & 341 \\
\hline $\mathbf{P t}$ & $\alpha-\mathrm{Al}_{2} \mathrm{O}_{3}(0001)$ & $\mathrm{CO} / \mathrm{O}_{2}$ & 335 \\
\hline $\mathrm{Pt}$ & Pirex, $\mathrm{SiO}_{2}$ & Hydrocarbon reactions & 422 \\
\hline Pt & $\mathrm{Si}(100) / \mathrm{O}_{2}$ & $\mathrm{C}_{2} \mathrm{H}_{4} / \mathrm{H}_{2}$ & 265 \\
\hline
\end{tabular}




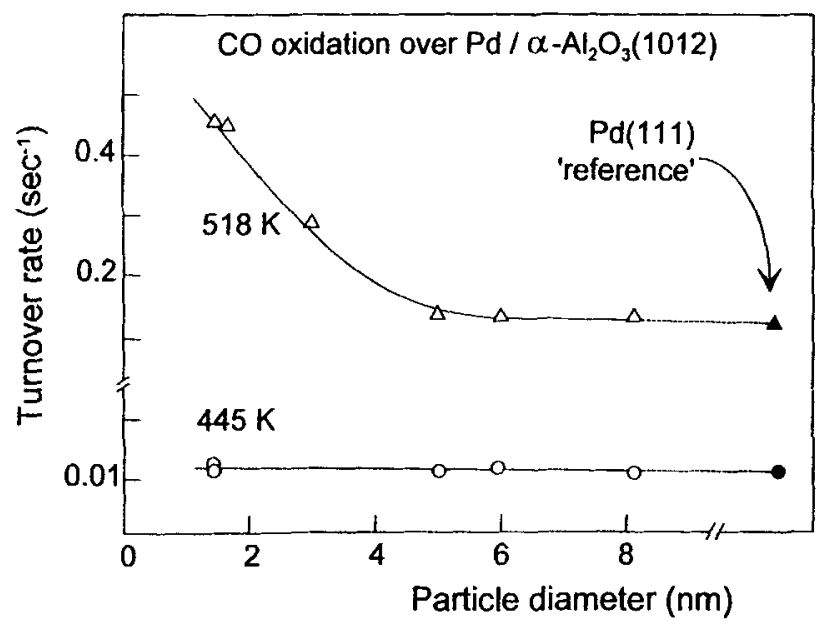

FIG. 38. Turnover rate versus particle size for the oxidation of $\mathrm{CO}$ over $\mathrm{Pd}$ model catalysts at $P_{\mathrm{O} 2} / P_{\mathrm{CO}}=1.1$ (from Ladas et al. [101]).

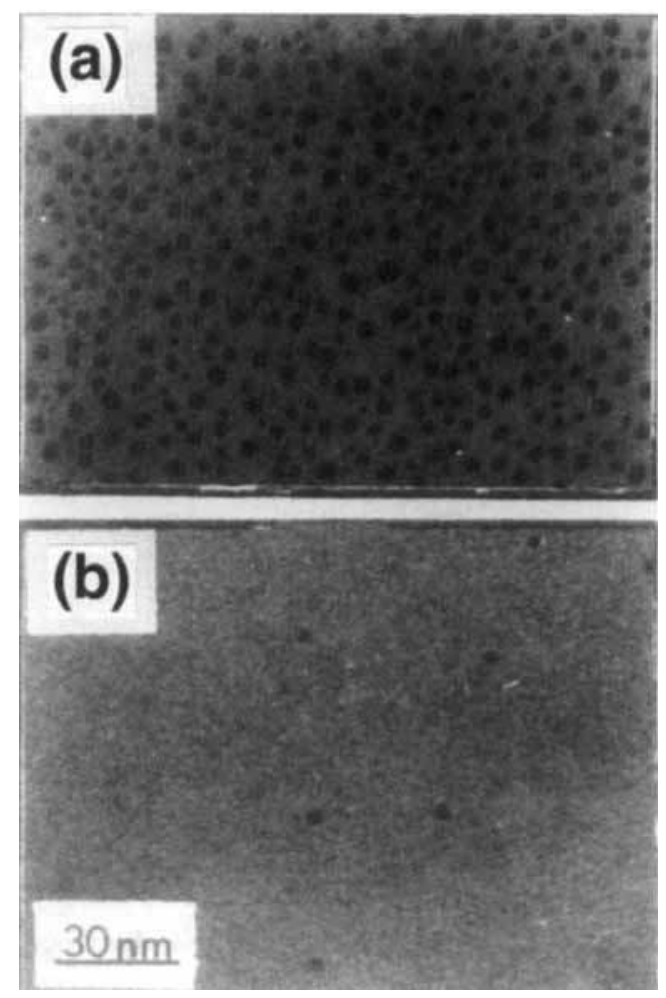

FIG. 39. TEM of Pd on $\alpha-\mathrm{Al}_{2} \mathrm{O}_{3}(1012)$ showing the difference in Pd particle number density between (A) and (B): (a) $d=3.7 \mathrm{~nm}, n=1.3 \times 10^{12} \mathrm{~cm}^{-2}$, (b) $d=$ $3.9 \mathrm{~nm}, n=1.6 \times 10^{10} \mathrm{~cm}^{-2}$ (from Rumpf et al. [135]). 
than the rate of impingement of $\mathrm{CO}$ on the $\mathrm{Pd}$ particles. To prove that reverse spillover was the cause of the rate increase, model catalysts with the same particle size but with a different particle density were prepared (Fig. 39). The sample with the lower Pd particle density has a higher turnover rate because it has a larger collection zone for $\mathrm{CO}$ diffusing from the alumina to the $\mathrm{Pd}$ particles, which shows that the increase in the rate is due to reverse spillover. Note that the reverse spillover effect is not observed at the lower temperature because in this regime the rate is proportional to the ratio $P_{\mathrm{O} 2} / P_{\mathrm{CO}}$, and the reverse spillover of $\mathrm{CO}$ is probably canceled by the reverse spillover of $P_{\mathrm{O} 2}$. Thus, the use of model catalysts provided clear evidence of the reverse spillover effect. Although this effect is probably not important at high pressures, in low-pressure studies on model catalysts it will affect the rates and its effect has to be taken into account when reporting and comparing turnover rates.

Temperature-programmed SIMS studies of the CO oxidation under UHV conditions by Matolín et al. [52,282] and by Kruse and Gillet [283] show that dissociation of $\mathrm{CO}$ and subsequent oxidation of carbon atoms at higher temperatures becomes an additional route to $\mathrm{CO}_{2}$ for small palladium particles on $\mathrm{MgO}$ model supports. This reaction channel via dissociated $\mathrm{CO}$ did not occur on $\operatorname{Pd}(111)$ single crystals $[284,285]$.

The rates for $\mathrm{CO}$ oxidation were also measured at higher pressures (up to $2 \mathrm{kPa}$ ) by Goodman and coworkers on model Pd catalysts [276,279]. These authors were able to measure the enthalpy and entropy of activation for the surface reaction $\mathrm{CO}+\mathrm{O} \rightarrow \mathrm{CO}_{2}$ in situ by RAIRS. This is the first study that monitors the surface of the model catalyst under reaction conditions, showing the feasibility of monitoring the reaction on model catalysts.

The above results for the oxidation of $\mathrm{CO}$ nicely illustrate the wide range of techniques that can be used for model studies in catalysis. However, many of the studies mentioned in Table 13 did not take advantage of the array of characterization techniques available for model catalysts, but relied on TEM only. It is good to point out that if TEM is the main characterization technique, the approach pioneered by Datye and coworkers, viz. use of spherical supports [13], may be better than using flat model catalysts since the catalysts can be prepared with a high surface area and offer better opportunities for reaction studies.

An important point in a study of model catalysts is the eventual comparison of turnover rates between the model and the actual catalysts. Agreement of rates on a turnover basis among model, single crystals and supported catalysts has been reported for the oxidation of $\mathrm{CO}$ (Table 14). This favorable agreement is the reason why we believe that model catalysts can be used as the standard to industrial catalysts [286]. A similar satisfactory agreement in rate between model catalysts, single crystals, and supported catalysts was found in the hydrogenation of ethylene on the $\mathrm{Pt} / \mathrm{SiO}_{2} /$ silicon model catalyst shown in Fig. 23 [96]. This model contains particles of $30 \mathrm{~nm}$ in size that were deposited over oxidized silicon by e-beam lithography. The surface of the metal particles is cleaned by helium or neon ion bombardment at low ion 
TABLE 14

Turnover Rate $\left(\nu_{t}\right)$ and Apparent Activation Energy $\left(E_{a}\right)$ for the Oxidation of Carbon Monoxide Over Pd Catalysts at $445 \mathrm{~K}, P_{\mathrm{O} 2} / P_{\mathrm{CO}}=1.1$, and Total Pressure 20-3000 $\mathrm{Pa}$

\begin{tabular}{lccc}
\hline \multicolumn{1}{c}{ Sample } & $\nu_{t}\left(\mathrm{~s}^{-1}\right)$ & $E_{a}\left(\mathrm{~kJ} \mathrm{~mol}^{-1}\right)$ & Ref. \\
\hline $\mathrm{Pd}(100)$ & 0.1 & 112 & 423 \\
$\mathrm{Pd}(110)$ & 0.1 & 113 & 315 \\
$\mathrm{Pd} / \mathrm{SiO}_{2}$ (model) & 0.3 & 113 & 276 \\
$\mathrm{Pd} / \gamma-\mathrm{Al}_{2} \mathrm{O}_{3}$ (conv.) & 0.1 & 107 & 424 \\
\hline
\end{tabular}

energies $(400 \mathrm{eV})$, and the metal surface area calibrated by $\mathrm{CO}$ thermal desorption. The reaction turnover rate of ethylene hydrogenation was found to be 30 molecules/Pt site/sec at $300 \mathrm{~K}$; very similar to that reported on high surface area or single-crystal catalyst systems. One can vary the platinum particle size in such a model system from 2.5 to $30 \mathrm{~nm}$, as well as vary the distance between metal particles. The cluster array can be fabricated using more than one metal in alternate rows. The oxidized silicon may be replaced by alumina or titania, and promoters may be added to either the metal or the support as desired. The flexibility of catalyst design provided by such a nanoparticle system permits study of metal surface structure sensitivity, reaction rates, reaction selectivity, and the causes of catalyst deactivation by investigating thermal and chemical stability of the particles during reaction conditions

\section{CONCLUDING REMARKS}

Model catalysts could be and should be designed to possess all the complexity of multicomponent and sophisticated industrial catalysts without the high surface area. Elucidation of the high internal surface area permits the researcher to assert complete control over particle size, surface structure, composition, and oxidation states of the catalyst by employing clever fabrication techniques and characterization methods from the full repertoire of surface science. Microreactors and nanoreactors, with volumes ranging from less than $1 \mathrm{~L}$ to a few microliters, can be constructed for obtaining reaction rates and product distributions on these model low-area catalysts under conditions that are identical to those used by industrial technology. Well-chosen surface science techniques can characterize the surface on a nanometer spatial scale not only before and after the reaction but also during the reaction (using STM and laser sum frequency generation, SFG, for example). Controlled fabrication and molecular-level characterization of model catalyst systems should permit us to develop new "high technology" catalyst systems that exhibit $100 \%$ selectivity for desired reaction products and resistance to deactivation, 
even when employed under extreme conditions of temperature, pressure, and reactant mixture. Studies of model catalysts provide the route to the mastery of catalyst science to create new generations of industrial high surface area catalyst systems that contain all the molecular ingredients uncovered by model catalyst system studies.

The study of model catalyst systems is in its infancy. Integrated studies including preparation, complete surface characterization, adsorption, and catalysis have only sparsely been published while this is where the model approach can give unique information. By imitating the manufacture of proven industrial catalysts with their flat counterparts, we are learning new and important details about the surface chemistry underlying catalyst preparation. We are also learning how to prepare metal catalyst-oxide support systems in such a way that the size, structure, and spatial distribution of metal nanoparticles remain uniform. Wet chemical deposition techniques based on anchoring by ion exchange or on precipitation from spin-coated layers are close to industrial practice. Further away from large-scale application, but capable of rigorous control over particle size and distribution, is electron beam lithography. In all cases the substrate can be an oxide such as silica, alumina, or titania, and its preparation can also be controlled on the nanometer scale. The metal and oxide surfaces can be characterized by electron microscopy, scanning Auger microscopy, and atomic force microscopy. All of these techniques are capable (or will be in the near future) of providing the spatial resolution for particle-by-particle characterization of the model system. The surface orientation and defect structure of the particles will vary with preparation methods, particle size, and as a consequence of metal-oxide support interaction. The thermal and chemical stability of the nanoparticles can be tested, and reaction rate and product distribution measurements can be carried out using micro- and nanoreactors which have already been described in the literature $[230,233,234]$.

Although the majority of the model catalyst literature concerns supported metal catalysts, we stress that particles on flat model supports offer highly attractive opportunities for studies on oxides and sulfides as well. As the reactivity of these materials is associated with defects and edges, the usual single-crystal approach employed in fundamental surface science of metals is less meaningful for perfect oxide and sulfide surfaces. Hence, particles on model supports may become the primary systems for surface science investigations of oxides and sulfides.

The use of model catalysts will eventually provide unprecedented control over variables (size, structure, support, composition, etc.) that should permit the optimization of catalytic reaction rates and selectivity. The fabrication methodology may be further developed to produce three-dimensional nanostructures. In this circumstance, high surface area catalytic systems in the range of $\sim 10^{2} \mathrm{~m}^{2} / \mathrm{g}$ can be fabricated that could be employed in industrial technology, allowing model catalyst studies to open new ways for catalyst fabrication. 


\section{ACKNOWLEDGMENT}

The authors are grateful to many colleagues in the field of model catalysts for stimulating discussions, and for providing preprints of their work. I.W.N. was supported by pioneer Grant PGS 70-154 from the Netherlands Organization for Scientific Research and P.L.I.G. by the Foundation for Technical Sciences. F.H.R. and G.A.S. acknowledge support by the Director, Office of Energy Research, Office of Basic Energy Sciences, Materials Sciences Division, of the U.S. Department of Energy under contract DE-AC03$76 \mathrm{SF} 00098$.

\section{REFERENCES}

1. G. Ertl and J. Küppers, Low Energy Electrons and Surface Chemistry, VCH, Weinheim, 1985.

2. L. C. Feldman and J. W. Mayer, Fundamentals of Surface and Thin Film Analysis, North-Holland, New York, 1986.

3. D. P. Woodruff and T. A. Delchar, Modern Techniques of Surface Science, Cambridge University Press, Cambridge, 1988.

4. G. A. Somorjai, Chemistry in Two Dimensions: Surfaces, Cornell University Press, Ithaca, NY, 1980.

5. J. W. Niemantsverdriet, Spectroscopy in Catalysis, an Introduction, VCH, Weinheim, 1993.

6. G. A. Somorjai, Introduction to Surface Chemistry and Catalysis, Wiley, New York, 1994.

7. J. A. Rodriquez and D. W. Goodman, Surf. Sci. Rep., 14, 1 (1991).

8. H. Poppa, Catal. Rev.-Sci. Eng., 35, 359 (1993).

9. R. M. Kroeker and P. K. Hansma, Catal. Rev. -Sci. Eng., 23, 553 (1981).

10. C. H. Bartholomew, in Catalysis (J. J. Spivey, ed.), Royal Society of Chemistry, London, 1993, p. 41.

11. G. B. Raupp, T. J. Udovic, and J. A. Dumesic, in Contribution of clusters physics to materials science and technology: from isolated clusters to aggregated materials (J. Davenas and P. M. Rabette, eds.), Kluwer, Dordrecht, 1986 , p. 255.

12. D. W. Goodman, Chem. Rev., 95, 523 (1995).

13. A. D. Logan, E. J. Bruanschweig, A. K. Datye, and D. J. Smith, Ultramicroscopy, 31, 132 (1989).

14. G. Fuchs, D. Neiman, and H. Poppa, Langmuir, 7, 2853 (1991).

15. J. Nickl, R. Schlögl, A. Baiker, H. Knözinger, and G. Ertl, Catal. Lett., 3, 379 (1989).

16. A. Jimenéz-Gonzaléz and D. Schmeisser, J. Catal., 130, 332 (1991).

17. L. M. Eshelman, A. M. de Jong, and J. W. Niemantsverdriet, Catal. Lett., 10, 201 (1991).

18. H. J. Borg, L. C. A. van den Oetelaar, L. J. van IJzendoorn, and J. W. Niemantsverdriet, J. Vac. Sci. Technol. A, 10, 2737 (1992).

19. E. W. Kuipers, C. Laszlo, and W. Wieldraaijer, Catal. Lett., 17, 71 (1993).

20. E. I. Altman and R. J. Gorte, Surf. Sci., 195, 392 (1988). 
21. W. N. Delgass, G. L. Haller, R. Kellerman, and J. H. Lunsford, Spectroscopy in Heterogeneous Catalysis, Academic Press, New York, 1979.

22. B. Imelik and J. C. Vedrine, Catalyst Characterization: Physical Techniques for Solid Materials, Plenum, New York, 1994.

23. P. L. J. Gunter and J. W. Niemantsverdriet, Appl. Surf. Sci., 89, 69 (1994).

24. U. Bardi, K. Tamura, and Y. Nihei, Catal. Lett., 3, 117 (1989).

25. V. Di Castro, G. Polzonetti, and R. Zanoni, Surf. Sci., 162, 348 (1985).

26. S. V. Didziulis, K. D. Butcher, S. L. Cohen, and E. I. Solomon, J. Am. Chem. Soc., 111, 7110 (1989).

27. C. C. Kao, S. C. Tsai, M. K. Bahl, and Y. W. Chung, Surf. Sci., 95, 1 (1980).

28. C. Kuhrt and M. Harsdorff, Surf. Sci., 245, 173 (1991).

29. H. R. Sadeghi and V. E. Henrich, Appl. Surf. Sci., 19, 330 (1984).

30. Y. Takasu, R. Unwin, B. Tesche, A. M. Bradshaw, and M. Grunze, Surf. Sci., 77, 219 (1978).

31. Y. Takasu, T. Sakuma, Y. Matsuda, and I. Toyoshima, Surf. Sci., 152/153, 479 (1985).

32. J. Liu, G. G. Hembree, G. E. Spinnler, and J. A. Venables, Surf. Sci., 262, L111 (1992).

33. M. José-Yacamán and M. Avalos-Borja, Catal. Rev. Sci. Eng., 34, 55 (1992).

34. T. P. Chojnacki and L. D. Schmidt, J. Catal., 115, 473 (1989).

35. T. Chojnacki, K. Krause, and L. D. Schmidt, J. Catal., 128, 161 (1991).

36. T. P. Chojnacki and L. D. Schmidt, J. Catal., 129, 473 (1991).

37. K. R. Krause and L. D. Schmidt, Catal. Lett., 14, 141 (1992).

38. K. R. Krause and L. D. Schmidt, J. Catal, 140, 424 (1993).

39. T. Wang and L. D. Schmidt, J. Catal., 70, 187 (1981).

40. J. G. Weissman, E. I. Ko, and P. Wynblatt, J. Catal., 108, 383 (1987).

41. M. Chen, T. Wang, and L. D. Schmidt, J. Catal, 60, 356 (1979).

42. F. Enquist and A. Spetz, Thin Solid Films, 145, 99 (1987).

43. A. K. Datye and N. J. Long, Ultramicroscopy, 25, 203 (1988).

44. A. K. Datye and D. J. Smith, Catal. Rev -Sci. Eng., 34, 129 (1992).

45. A. M. de Jong, H. J. Borg, L. J. van IJzendoorn, V. G. F. M. Soudant, V. H. J. de Beer, J. A. R. van Veen, and J. W. Niemantsverdriet, J. Phys. Chem., 97, 6477 (1993).

46. L. J. van IJzendoorn, M. J. A. de Voigt, and J. W. Niemantsverdriet, React. Kinet. Catal. Lett., 50, 131 (1993).

47. P. H. Bolt, S. F. Lobner, T. P. van den Bout, J. W. Geus, and F. H. P. M. Habraken, Appl. Surf. Sci., 70/71, 196 (1993).

48. A. Partridge, S. L. G. Toussaint, C. F. J. Flipse, L. J. IJzendoorn, and L. C. A. van den Oetelaar, J. Vac. Sci. Technol. B14, 585 (1996).

49. H. H. Brongersma, P. A. C. Groenen, and J.-P. Jacobs, in Science of Ceramic Interfaces II (J. Nowotny, ed.), Elsevier, Amsterdam, 1994, p. 113.

50. H. J. Borg, L. C. A. van den Oetelaar, and J. W. Niemantsverdriet, Catal. Lett., 17, 81 (1993).

51. H. J. Borg and J. W. Niemantsverdriet, in Catalysis: A Specialist Periodical Report, Vol. 11 (J. J. Spivey, and A. K. Agarwal, eds.), Royal Society of Chemistry, Cambridge, 1994, p. 1.

52. V. Matolín, E. Gillet, and N. Kruse, Surf. Sci., 186, L541 (1987).

53. D. A. Hensley and L. L. Kesmodel, Surf. Sci., 231, 361 (1990). 
54. D. A. Hensley and L. L. Kesmodel, J. Phys. Chem., 95, 1368 (1991).

55. D. Venus, D. A. Hensley, and L. L. Kesmodel, Surf. Sci., 199, 391 (1988).

56. T. N. Rhodin, B. G. Frederick, and G. Apai, Surf. Sci., 287, 638 (1993).

57. B. G. Frederick, G. Apai, and T. N. Rhodin, Surf. Sci., 244, 67 (1991).

58. B. G. Frederick, G. Apai, and T. N. Rhodin, Phys. Rev. B, 44, 1880 (1991).

59. K. L. Yeung and E. E. Wolf, J. Vac. Sci. Technol. B, 9, 798 (1991).

60. A. Humbert, M. Dayez, S. Granjeaud, and P. Ricci, J. Vac. Sci. Technol. B, 9, 804 (1991).

61. G. W. Clark and L. L. Kesmodel, J. Vac. Sci. Technol. B, 11, 131 (1993).

62. F. J. Cadete Santos Aires, P. Sautet, G. Fuchs, J.-L. Rousset, and P. Mélinon, Microsc. Microanal. Microstruct., 4, 441 (1993).

63. W. Hanrieder, A. Scholz, and H. Meixner, Surf. Sci., 243, 166 (1991).

64. M. Komiyama, S. Morita, and N. Mikoshiba, J. Microscopy, 152, 197 (1988).

65. M. Komiyama and M. Kirino, Chem. Lett., 1992, p. 2301.

66. S. Lee, H. Permana, and K. Y. S. Ng, Catal. Lett., 23, 281 (1994).

67. U. Müller, K. Sattler, J. Xhie, N. Venkateswaran, and G. Raina, J. Vac Sci. Technol. B, 9, 829 (1991).

68. H. Permana, S. Lee, and K. Y. S. Ng, Catal. Lett., 24, 363 (1994).

69. G. E. Poirier, B. K. Hance, and J. M. White, J. Phys. Chem., 97, 5965 (1993).

70. C. N. R. Rao, H. K. N. Aiyer, T. Arunarkavalli, and G. U. Kulkarni, Catal. Lett., 23, 37 (1994).

71. J. Xhie, K. Sattler, N. Mueller, N. Venkateswaran, and G. Raina, J. Vac Sci. Technol. B, 9, 833 (1991).

72. X. P. Xu, S. M. Vesecky, and D. W. Goodman, Science, 258, 5083 (1992).

73. K. L. Yeung and E. E. Wolf, Catal. Lett., 12, 213 (1992).

74. K. L. Yeung and E. E. Wolf, J. Catal., 135, 13 (1992).

75. K. L. Yeung and E. E. Wolf, J. Catal., 143, 409 (1993).

76. K. H. Lee and E. E. Wolf, Catal. Lett., 26, 297 (1994).

77. J. Colchero, O. Marti, J. Mlynek, A. Humbert, C. R. Henry, and C. Chapon, J. Vac. Sci. Technol. B, 9, 794 (1991).

78. M. Eriksson and L.-G. Petersson, Surf. Sci., 311, 139 (1994).

79. R. Erlandsson, M. Eriksson, L. Olsson, U. Helmersson, I. Lundstroem, and L. G. Petersson, J. Vac. Sci. Technol. B, 9, 825 (1991).

80. C. Schild, J. Engweiler, J. Nickl, A. Baiker, M. Hund, M. Kilo, and A. Wokaun, Catal. Lett., 25, 179 (1994).

81. A. Schumacher, L. Scandella, N. Kruse, and R. Prins, Surf. Sci., 289, L595 (1993).

82. R. P. van Duyne, J. C. Hulteen, and D. A. Treichel, J. Chem. Phys., 99, 2101 (1993).

83. A. Partridge, S. L. G. Toussaint, and C. F. J. Flipse, submitted for publication.

84. A. Partridge, S. L. G. Toussaint, C. J. F. Flipse, and E. W. Kuipers, in Forces in Scanning Probe Methods (H.-J. Guntherodt, D. Anselmetti, and E. Meyer, eds.) Kluwer, Schluchsee, 1994, p. 531

85. R. van Wijk, O. L. J. Gijzeman, J. W. Geus, E. ten Grotenhuis, and J. C. van Miltenburg, Catal. Lett., 24, 171 (1994).

86. J. L. Falconer and J. A. Schwarz, Catal. Rev. $\rightarrow$ Sci. Eng., 25, 141 (1983).

87. A. M. de Jong and J. W. Niemantsverdriet, Surf. Sci., 233, 355 (1990).

88. M. Shirai, K. Asakura, and Y. Iwasawa, Catal. Lett., 15, 247 (1992). 
89. M. Shirai, T. Inoue, H. Onishi, K. Asakura, and Y. Iwasawa, J. Catal, 145, 159 (1994).

90. M. Shirai, K. Asakura, and Y. Iwasawa, Catal. Lett., 26, 229 (1994).

91. B. J. Tatarchuk and J. A. Dumesic, J. Catal., 70, 308 (1981).

92. B. J. Tatarchuk, J. J. Chludzinski, R. D. Sherwood, J. A. Dumesic, and R. T. K. Baker, J. Catal., 70, 433 (1981).

93. B. J. Tatarchuk and J. A. Dumesic, J. Catal, 70, 323 (1981).

94. B. J. Tatarchuk and J. A. Dumesic, J. Catal., 70, 335 (1981).

95. O. R. Kahn, E. E. Petersen, and G. A. Somorjai, J. Catal., 34, 294 (1974).

96. P. W. Jacobs, F. H. Ribeiro, G. A. Somorjai, and S. J. Wind, Catal. Lett., 37, 131 (1996).

97. C. T. Campbell, Adv. Catal., 36, 1 (1989).

98. E. W. Kuipers, I. H. Vinkenburg, and H. Oosterbeek, J. Catal., 152, 137 (1995).

99. E. W. Kuipers, W. Wieldraaijer, and G.-J. Kramer, personal communication.

100. X. Xu and D. W. Goodman, Appl. Phys. Lett., 61, 774 (1992).

101. S. Ladas, H. Poppa, and M. Boudart, Surf. Sci., 102, 151 (1981).

102. A. Boffa, C. Lin, A. T. Bell, and G. A. Somorjai, J. Catal., 149, 149 (1994).

103. A. Burneau, B. Humbert, O. Barrès, J. P. Gallas, and J. C. Lavalley, in The Colloid Chemistry of Silica (H. E. Bergna, ed.), American Chemical Society, Washington, DC, 1990, p. 199.

104. L. T. Zhuravlev, Langmuir, 1987, 316 (1987).

105. C. J. Brinker, R. K. Brow, D. R. Tallant, and R. J. Kirkpatrick, J. Non-Cryst. Solids, 120, 26 (1990).

106. F. J. Grunthaner, P. J. Grunthaner, R. P. Vasquez, B. F. Lewis, J. Maserjian, and A. Madhukar, J. Vac. Sci. Technol., 16, 1443 (1979).

107. P. J. Grunthaner, M. H. Hecht, F. J. Grunthaner, and N. M. Johnson, J. Appl. Phys., 61, 629 (1987).

108. J. Finster, D. Schulze, F. Bechstedt, and A. Meisel, Surface Sci., 152/153, 1063 (1985).

109. A. Ourmazd, D. W. Taylor, J. A. Rentschler, and J. Bevk, Phys. Rev. Lett., 59, 213 (1987).

110. F. J. Himpsel, F. R. McFreely, A. Taleb-Ibrahimi, J. A. Yarmoff, and G. Hollinger, Phys. Rev. B, 38, 6084 (1988).

111. M. Niwano, H. Katakura, Y. Takeda, Y. Takakuwa, N. Miyamoto, and M. Maki, J. Vac. Sci. Technol. A, 10, 339 (1992).

112. R. J. Bell and P. Dean, Philos. Mag., 25, 1381 (1972).

113. K. Hubner, Phys. Status Solidi A, 40, 487 (1977).

114. R. N. Nucho and A. Madhukar, in The Physics of $\mathrm{SiO}_{2}$ and Its Interfaces (S.

T. Pantelides, ed.), Pergamon, New York, 1978, p. 60.

115. R. A. Devine, J. Appl. Phys., 60, 86 (1968).

116. A. M. de Jong, PhD thesis, Eindhoven University of Technology, 1994.

117. N. F. Mott, Phil. Mag. B, 55, 117 (1987).

118. F. Rochet, S. Rigo, M. Froment, C. d'Anterroches, C. Maillot, H. Roulet, and G. Dufour, Adv. Phys., 35, 237 (1986).

119. X. P. Xu and D. W. Goodman, Surf. Sci., 282, 323 (1993).

120. W. Stöber, A. Fink, and E. Bohn, J. Colloid Interface Sci., 26, 62 (1968).

121. D. G. Huizenga and D. M. Smith, AIChE J., 32, 1 (1986). 
122. R. K. Iler, The Chemistry of Silica, Wiley, New York, 1979.

123. S. Srinivasan, A. K. Datye, M. Hampden-Smith, I. E. Wachs, G. Deo, J. M. Jehng, A. M. Turek, and C. H. F. Peden, J. Catal., 131, 260 (1991).

124. A. van Blaaderen and A. Vrij, in The Colloid Chemistry of Silica (H. E. Bergna, ed.), American Chemical Society, Washington, DC, 1990, p. 83.

125. H. E. Bergna, in The Colloid Chemistry of Silica (H. E. Bergna, ed.), American Chemical Society, Washington, DC, 1990, p. 1.

126. S. Srinivasan, A. K. Datye, M. H. Smith, and C. H. F. Peden, J. Catal., 145, 565 (1994).

127. B. C. Lippens and J. J. Steggarda, in Physical and Chemical Aspects of Absorbents and Catalysts (B. G. Linsen, ed.), Academic Press, New York, 1970, p. 171.

128. H. Knözinger and P. Ratnasamy, Catal. Rev. -Sci. Eng., 17, 31 (1978).

129. H. Poppa, E. H. Lee, and R. D. Moorhead, J. Vac. Sci. Technol., 15, 1100 (1978).

130. H. Poppa, C. A. Papageorgopoulos, F. Marks, and E. Bauer, Z. Phys. D, 3, 279 (1986).

131. K. Tamura and Y. Nihei, J. Catal., 115, 273 (1989).

132. V. Coustet and J. Jupille, Surf. Sci., 307-309, 1161 (1994).

133. J. M. Rickard, L. Genovese, A. Moata, and S. Nitsche, J. Catal., 121, 141 (1990).

134. H. Poppa, D. Fargues, L. Kieken, D. Neiman, and R. Savoy, Vacuum, 41, 485 (1990).

135. F. Rumpf, H. Poppa, and M. Boudart, Langmuir, 4, 722 (1988).

136. D. L. Cocke, E. D. Johnson, and R. P. Merrill, Catal. Rev.-Sci. Eng., 26, 163 (1984).

137. J. E. Crowell, J. G. Chen, and J. T. Yates, Jr., Surf. Sci., 165, 37 (1986).

138. E. Johnson, Ph.D. thesis, Cornell University, 1985.

139. A. Jimenéz-Gonzaléz and D. Schmeisser, Surf. Sci., 250, 59 (1991).

140. N. Cabrera and N. F. Mott, Rept. Progr. Phys., 12, 163 (1948-49).

141. C. T. Kirk, Jr. and E. E. Hubner, Surf. Sci., 11, 443 (1968).

142. F. P. Fehlner and N. F. Mott, Oxid. Met., 2, 59 (1970).

143. A. F. Beck, M. A. Heine, E. J. Caule, and M. J. Pryor, Corros. Sci., 7, 1 (1967).

144. J. I. Eldridge, R. J. Hussy, D. F. Mitchell, and M. J. Graham, Oxid. Met., 30, 301 (1988).

145. K. Shimizu, R. C. Furneaux, G. E. Thompson, G. C. Wood, A. Gotoh, and K. Kobayashi, Oxid. Met., 35, 427 (1991).

146. M. J. Dignam and W. R. Fawcett, J. Electrochem. Soc., 113, 163 (1966).

147. P. Brüesch, R. Kötz, H. Neff, and L. Pietronero, Phys. Rev. B, 29, 4691 (1984).

148. H. Glassl, R. Kramer, and K. Hayek, J. Catal., 68, 388 (1981).

149. H. H. Madden and D. W. Goodman, Surf. Sci., 150, 39 (1985).

150. P. J. Chen, M. L. Colaianni, and J. T. Yates, Jr., Phys. Rev. B, 41, 8025 (1990).

151. J. G. Chen, M. L. Colaianni, P. Chen, J. T. Yates, and G. B. Fisher, J. Phys. Chem., 94, 5059 (1990).

152. J. G. Chen, J. E. Crowell, and J. T. Yates, Jr., Surf. Sci., 185, 373 (1987).

153. B. G. Frederick, G. Apai, and T. N. Rhodin, J. Am. Chem. Soc., 109, 4797 (1987). 
154. D. N. Belton and S. J. Schmieg, Surf. Sci., 202, 238 (1988).

155. L. J. van IJzendoorn, J. W. Niemantsverdriet, R. J. Severens, P. W. L. van Dijk, and M. J. A. de Voigt, Nucl. Instr. and Meth. B, 89, 114 (1994).

156. P. J. Chen and D. W. Goodman, Surf. Sci., 312, L767 (1994).

157. E. Ruckenstein and M. L. Malhotra, J. Catal., 41, 303 (1976).

158. R. A. van Santen, Theoretical Heterogeneous Catalysis, World Scientific, Singapore, 1991.

159. V. E. Henrich and P. A. Cox, The Surface Science of Metal Oxides, Cambridge University Press, Cambridge, 1994.

160. C. Ocal and S. Ferrer, Surf. Sci., 178, 850 (1986).

161. Z. M. Zhang and V. E. Henrich, Surf. Sci., 277, 263 (1992).

162. J. A. R. van Veen, Z. Phys. Chem. NF, 162, 215 (1989).

163. C. Chapon, C. R. Henry, and A. Chemam, Surf. Sci., 162, 747 (1985).

164. J. J. Metois, K. Heinemann, and H. Poppa, Thin Solid Films, 41, 197 (1977).

165. C. R. Henry and H. Poppa, J. Vac. Sci. Technol. A, 6, 1113 (1988).

166. C. R. Henry and H. Poppa, Thin Solid Films, 189, 303 (1990).

167. M.-C. Wu, J. S. Corneille, C. A. Estrada, J.-W. He, and D. W. Goodman, Chem. Phys. Lett., 182, 472 (1991).

168. S. K. Purnell, X. Xu, D. W. Goodman, and B. C. Gates, J. Phys. Chem., 98, 4076 (1994).

169. P. J. Anderson, R. F. Horlock, and J. F. Oliver, Trans. Faraday Soc., 61, 2754 (1965).

170. Y. Uchida, G. Lehmpfuhl, K. Weiss, and F. Zemlin, Ultramicroscopy, 9, 325 (1982).

171. S. Giorgio, G. S. Henry, C. Chapon, and G. Nihoul, in EUREM 92, Granada, Spain, 1992, p. 645.

172. K. Klier, Adv. Catal., 31, 243 (1982).

173. H. Jacobs, W. Mokwa, D. Kohl, and G. Heiland, Surf. Sci., 126, 368 (1983).

174. H. Jacobs, W. Mokwa, D. Kohl, and G. Heiland, Surf. Sci., 160, 217 (1985).

175. C. T. Campbell, K. A. Daube, and J. M. White, Surf. Sci., 182, 458 (1987).

176. R. Zhang, A. Ludviksson, and C. T. Campbell, Catal. Lett., 25, 277 (1994).

177. S. Roberts and R. J. Gorte, J. Chem. Phys., 93, 5337 (1990).

178. C. A. Leighton, A. J. Swift, and J. C. Vickerman, Surf. Sci., 253, 220 (1991).

179. H. H. Kung, Transition Metal Oxides: Surface Chemistry and Catalysis, Elsevier, Amsterdam, 1989.

180. S. Roberts and R. J. Gorte, J. Phys. Chem., 95, 5600 (1991).

181. G. S. Zafiris and R. J. Gorte, J. Catal., 132, 275 (1991).

182. A. C. Q. M. Meijers, A. M. de Jong, L. M. P. van Gruijthuijsen, and J. W. Niemantsverdriet, Appl. Catal., 70, 53 (1991).

183. A. M. de Jong, L. M. Eshelman, L. J. van IJzendoorn, and J. W. Niemantsverdriet, Surf. Interface Anal., 18, 412 (1992).

184. P. D. L. Mercera, PhD thesis, Twente University of Technology, 1991.

185. G. S. Zafiris and R. J. Gorte, Surf. Sci., 276, 86 (1992).

186. G. S. Zafiris and R. J. Gorte, J. Catal., 139, 561 (1993).

187. G. S. Zafiris and R. J. Gorte, J. Catal., 143, 86 (1993).

188. R. J. Gorte and H. Cordatos, Appl. Catal., B7, 33 (1995).

189. R. J. Gorte, H. Cordatos, and T. Bunluesin, Surf. Sci., 323, 219 (1995). 
190. L. Bragg and G. F. Clarinbull, Crystal Structures of Minerals, Bell, London, 1965.

191. H. Poppa and E. H. Lee, Thin Solid Films, 32, 223 (1976).

192. M. Thomas, J. T. Dickinson, H. Poppa and G. M. Pound, J. Vac. Sci. Technol, 15,568 (1978).

193. D. L. Doering, H. Poppa, and J. T. Dickinson, J. Catal., 73, 104 (1982).

194. D. L. Doering, J. T. Dickinson, and H. Poppa, J. Catal., 73, 91 (1982).

195. W. G. Durrer, H. Poppa, J. T. Dickinson, and C. Park, J. Vac. Sci. Technol. A, 3, 1545 (1985).

196. C. Park, W. G. Durrer, H. Poppa, and J. T. Dickinson, J. Catal., 95, 361 (1985).

197. R. Koch and H. Poppa, Thin Solid Films, 151, 367 (1987).

198. R. Koch and H. Poppa, J. Vac. Sci. Technol. A, 5, 1845 (1987).

199. E. Gillet, S. Channakhone, and V. Matolin, J. Catal., 97, 437 (1986).

200. M. F. Gillet and S. Channakone, J. Catal., 97, 427 (1986).

201. V. Matolín, E. Gillet, and S. Channakhone, J. Catal., 97, 448 (1986).

202. V. Matolin and E. Gillet, Surf. Sci., 166, L115 (1986).

203. Y. Takasu, K. Kasahara, and Y. Matsuda, Bull. Chem. Soc. Ipn., 57, 2313 (1984).

204. A. B. Stiles, Catalyst Supports and Supported Catalysts: Theoretical and Applied Concepts, Butterworths, London, 1987.

205. J. F. Hamilton and P. C. Logel, Thin Solid Films, 16, 49 (1973).

206. J. F. Hamilton and P. C. Logel, Thin Solid Films, 23, 89 (1974).

207. H. Poppa and R. D. Moorhead, Surf. Sci., 106, 478 (1981).

208. J. J. Metois, J. C. Heyraud, and Y. Takeda, Thin Solid Films, 51, 105 (1978).

209. P. Fayet, F. Patthey, H. V. Roy, T. Detzel, and W.-D. Schneider, Surf. Sci., 269/270, 1101 (1992).

210. L. C. Chao and R. P. Andres, J. Colloid Interface Sci., 165, 290 (1994).

211. T. Chang, S. L. Bernasek, and J. Schwartz, J. Am. Chem. Soc., 111, 758 (1989).

212. J. Evans, B. E. Hayden, J. F. W. Mosselmans, and A. J. Murray, J. Am. Chem. Soc., 114, 6912 (1992).

213. J. Evans, B. E. Hayden, J. F. W. Mosselmans, and A. J. Murray, in Elementary Reaction Steps in Heterogeneous Catalysis (R. W. Joyner and R. A. van Santen, eds.) Kluwer Academic Publishers, Dordrecht, 1993, p. 179.

214. J. Evans, B. E. Hayden, J. F. W. Mosselmans, and A. J. Murray, Surf. Sci., 301, 61 (1994).

215. D. N. Belton and S. J. Schmieg, Appl. Surf. Sci., 32, 173 (1988).

216. D. N. Belton and S. J. Schmieg, J. Vac. Sci. Technol. A, 6, 859 (1988).

217. D. N. Belton and S. J. Schmieg, Surf. Sci., 199, 518 (1988).

218. Metal Clusters in Catalysis (B. C. Gates, L. Guczl, and H. Knözinger, eds.), Elsevier, Amsterdam, 1986.

219. T. Suntola, Mater. Sci. Rep., 4, 216 (1989).

220. T. Suntola, Finnish patent FI 87892B 910716, 1992.

221. J. Nickl, C. Schild, A. Baiker, M. Hund, and A. Wokaun, Fresenius J. Anal. Chem., 346, 79 (1993).

222. K. Josek, C. Linsmeier, H. Knözinger, and E. Taglauer, Nucl. Instr. Meth. B, 64, 596 (1992). 
223. B. Tesche, E. Alizo-Delgado, and H. Knözinger, Catal. Lett., 10, 171 (1991).

224. E. W. Kuipers, C. Doornkamp, W. Wieldraaijer, and R. E. van den Berg, Chem. Mater., 5, 1367 (1993).

225. R. M. van Hardeveld, P. L. J. Gunter, L. J. van IJzendoorn, W. Wieldraaijer, E. W. Kuipers, and J. W. Niemantsverdriet, Appl. Surf. Sci., 84, 339 (1995).

226. C. Doornkamp, C. Laszlo, W. Wieldraaijer, and E. W. Kuipers, J. Mater. Res., 10, 411 (1995).

227. F. J. E. Handels, Masters thesis, Eindhoven University of Technology, 1995.

228. M. F. Crommie, C. P. Lutz, and D. M. Eigler, Science, 262, 218 (1993).

229. I. Brodie and J. J. Muray, in The Physics of Micro/Nanofabrication, Plenum, New York, 1992.

230. F. H. Ribeiro and G. A. Somorjai, Rec. Trav. Chim. Pays-Bas, 113, 419 (1994).

231. Specification of Leica e-beam tools, Leica, 1993.

232. L. P. Muray, personal communication.

233. I. Zuburtikudis and H. Saltsburg, Science, 258, 1337 (1992).

234. A. C. Krauth, K. H. Lee, G. H. Bernstein, and E. E. Wolf, Catal. Lett., 27, 43 (1994).

235. L. D. Marks, Ultramicroscopy, 18, 445 (1985).

236. M. Flüeli, R. Spycher, P. A. Stadelmann, P. A. Buffat, and J.-P. Borel, Europhys. Lett., 6, 329 (1988).

237. M. José-Yacamán, R. Herrera, A. Gómez, S. Tehuacanero, and P. SchabesRetchkiman, Surf. Sci., 237, 248 (1990).

238. M. José-Yacamán and A. Gomez, Appl. Surf. Sci., 19, 348 (1984).

239. W. L. Winterbottom, Acta Met., 15, 303 (1967).

240. W. H. Lee, K. R. Vanloon, V. Petrova, J. B. Woodhouse, C. M. Loxton, and R. I. Masel, J. Catal., 126, 658 (1990).

241. A.-C. Shi, K. K. Fung, J. F. Welch, M. Wortis, and R. I. Masel, in Microstructure and Properties of Catalysts (M. M. J. Treacy, J. M. Thomas, and J. M. White, eds.), Materials Research Society, Pittsburgh, 1988, p. 59.

242. J. Dundurs, L. D. Marks, and P. M. Ajayan, Phil. Mag. A, 57, 605 (1988).

243. D. J. Smith, A. K. Petford-Long, L. R. Wallenberg, and J.-O. Bovin, Science, 233, 872 (1986).

244. S. Iijima and T. Ichihashi, Phys. Rev. Lett., 56, 616 (1986).

245. P. M. Ajayan and L. D. Marks, Phys. Rev. Lett., 63, 279 (1989).

246. J.-O. Bovin, R. Wallenberg, and D. J. Smith, Nature, 317, 47 (1985).

247. S. Iijima and T. Ichihashi, Jpn. J. Appl. Phys., 24, L125 (1985).

248. E. Ruckenstein and S. H. Lee, J. Catal., 86, 457 (1984).

249. G. B. McVicker, R. L. Garten, and R. T. K. Baker, J. Catal., 54, 129 (1978).

250. S. J. Tauster, S. C. Fung, and R. L. Garten, J. Am. Chem. Soc., 100, 170 (1978).

251. J. A. Horsley, J. Am. Chem. Soc., 101, 2870 (1979).

252. M. K. Bahl, S. C. Tsai, and Y. W. Chung, Phys. Rev. B, 21, 1344 (1980).

253. T. Huizinga and R. Prins, J. Phys. Chem., 85, 2156 (1981).

254. D. N. Belton, Y.-M. Sun, and J. M. White, J. Phys. Chem., 88, 5172 (1984).

255. D. N. Belton, Y.-M. Sun, and J. M. White, 88, 1690 (1984).

256. A. D. Logan, E. J. Braunschweig, A. K. Datye, and D. J. Smith, Langmuir, 4, 827 (1988).

257. J. Santos, J. Phillips, and J. A. Dumesic, J. Catal., 81, 147 (1983). 
258. D. N. Belton, Y. M. Sun, and J. M. White, J. Catal, 102, 338 (1986).

259. M. G. Mason, Phys. Rev. B, 27, 748 (1983).

260. J. C. Muijsers, T. Weber, R. M. van Hardeveld, H. W. Zandbergen, and J. W. Niemantsverdriet, J. Catal., 157, 698 (1995).

261. E. Diemann, T. Weber, and A. Müller, J. Catal., 148, 288 (1994).

262. P. A. Spevack and N. S. McIntyre, Appl. Catal., 64, 191 (1990).

263. P. A. Spevack and N. S. Mcintyre, J. Phys. Chem., 97, 11031 (1993).

264. C. R. Henry, Surf. Sci., 223, 519 (1989).

265. P. W. Jacobs, S. J. Wind, F. H. Ribeiro, and G. A. Somorjai, submitted for publication (1996).

266. R. van Hardeveld and F. Hartog, Surf. Sci., 15, 189 (1966).

267. R. L. Whetten, D. M. Cox, D. J. Trevor, and A. Kaldor, Phys. Rev. Lett., 54, 1494 (1985).

268. C. S. Richtsmeyer, E. K. Parks, K. Liu, G. Pobo, and S. J. Riley, J. Chem. Phys., 82, 3659 (1985).

269. G. Ertl, J. Vac. Sci. Technol., 435 (1977).

270. H. Cordatos, T. Bunluesin, and R. J. Gorte, Surf. Sci., 323, 219 (1995).

271. E. I. Altman and R. J. Gorte, J. Catal., 113, 185 (1988).

272. Y. Zhu and L. D. Schmidt, Surf. Sci., 129, 107 (1983).

273. V. Matolín and E. Gillet, Surf. Sci., 238, 83 (1990).

274. S. Ichikawa, H. Poppa, and M. Boudart, J. Catal., 91, 1 (1985).

275. C. R. Henry, C. Chapon, and C. Goyhenex, Surf. Sci., 272, 283 (1992).

276. X. Xu and D. W. Goodman, J. Phys. Chem., 97, 7711 (1993).

277. X. P. Xu, S. M. Vesecky, J. W. He, and D. W. Goodman, J. Vac. Sci. Technol. A, 11, 1930 (1993).

278. L. Kieken and M. Boudart, in New Frontiers in Catalysis (L. Guczi, F. Solymosi, and P. Tétényi, eds.), Elsevier, New York, 1993, p. 1313.

279. X. Xu and D. W. Goodman, Catal. Today, 21, 57 (1994).

280. T. Engel and G. Ertl, Adv. Catal., 28, 1 (1979).

281. R. A. van Santen and J. W. Niemantsverdriet, Chemical Kinetics and Catalysis, Plenum, New York, 1995.

282. V. Matolín, E. Gillet, N. M. Reed, and J. C. Vickerman, J. Chem. Soc. Faraday Trans., 86, 2749 (1990).

283. N. Kruse and E. Gillet, Z. Phys. (D), 12, 575 (1989).

284. V. Matolín, E. Gillet, and M. Gillet, Surf. Sci., 162, 354 (1985).

285. V. Matolín, S. Channakhone, and E. Gillet, Surf. Sci., 164, 209 (1985).

286. M. Boudart, Chemtech, 1986, p. 688.

287. N. D. Spencer, R. C. Schoonmaker, and G. A. Somorjai, J. Catal., 74, 129 (1982).

288. D. R. Strongin, J. Carrazza, S. R. Bare, and G. A. Somorjai, J. Catal, 103, 213 (1987).

289. S. R. Bare, D. R. Strongin, and G. A. Somorjai, J. Phys. Chem., 90, 4726 (1986).

290. D. R. Strongin and G. A. Somorjai, J. Catal., 109, 51 (1988).

291. D. R. Strongin and G. A. Somorjai, Catal. Lett., 1, 61 (1988).

292. D. J. Dwyer, K. Yoshida, and G. A. Somorjai, Adv. Chem. Ser, 178, 65 (1979).

293. J. J. C. Geerlings, M. C. Zonnevylle, and C. P. M. De Groot, Surf. Sci,, 241, 315 (1991). 
294. J. J. C. Geerlings, M. C. Zonnevylle, and C. P. M. De Groot, Surf. Sci., 241, 302 (1991).

295. R. D. Kelley and D. W. Goodman, Surf. Sci., 123, L743 (1982).

296. D. W. Goodman, Appl. Surf. Sci., 19, 1 (1984).

297. C. T. Campbell and D. W. Goodman, Surf. Sci., 123, 413 (1982).

298. D. W. Goodman, Surf. Sci., 123, L679 (1982).

299. C. T. Campbell and K. A. Daube, J. Catal., 104, 109 (1987).

300. J. Nakamura, J. M. Campbell, and C. T. Campbell, Shokubai, 32, 336 (1990).

301. C. T. Campbell and B. E. Koel, Surf. Sci., 183, 100 (1987).

302. J. Szanyi and D. W. Goodman, Catal. Lett., 10, 383 (1991).

303. A. J. Gellman, D. Neiman, and G. A. Somorjai, J. Catal., 107, 92 (1987).

304. A. J. Gellman, M. E. Bussell, and G. A. Somorjai, J. Catal., 107, 103 (1987).

305. C. C. Knight and G. A. Somorjai, Surf. Sci., 240, 101 (1990).

306. G. H. Vurens, V. Maurice, M. Salmeron, and G. A. Somorjai, Surf. Sci., 268, 270 (1992).

307. M. E. Bussell and G. A. Somorjai, J. Catal., 106, 93 (1987).

308. M. E. Bussell, A. J. Gellman, and G. A. Somorjai, Catal. Lett., 1, 195 (1988).

309. M. Logan, A. J. Gellman, and G. A. Somorjai, J. Catal., 94, 60 (1985).

310. C. H. F. Peden and D. W. Goodman, J. Phys. Chem., 90, 1360 (1986).

311. C. H. F. Peden and D. W. Goodman, ACS Symp. Series, Vol. 288, American Chemical Society, 1985, p. 185.

312. D. G. Castner, R. L. Blackadar, and G. A. Somorjai, J. Catal., 66, 257 (1980).

313. S. H. Oh, G. B. Fisher, J. E. Carpenter, and D. W. Goodman, J. Catal., 100, 360 (1986).

314. A. K. Datye, B. F. Hegarty, and D. W. Goodman, Faraday Discuss. Chem. Soc., 87, 337 (1989).

315. P. J. Berlowitz, C. H. F. Peden, and D. W. Goodman, J. Phys. Chem., 92, 5213 (1988).

316. P. J. Berlowitz and D. W. Goodman, J. Catal., 108, 364 (1987).

317. C. T. Campbell and M. T. Paffett, Surf. Sci., 139, 396 (1984).

318. C. T. Campbell, J. Catal., 99, 28 (1986).

319. C. T. Campbell, J. Phys. Chem., 89, 5789 (1985).

320. M. J. Wax, R. D. Kelley, and T. E. Madey, J. Catal., 98, 487 (1986).

321. T. J. Udovic, R. D. Kelley, and T. E. Madey, Surf. Sci., 150, L71 (1985).

322. D. J. Godbey, F. Garin, and G. A. Somorjai, J. Catal., 117, 144 (1989).

323. C. Kim and G. A. Somorjai, J. Catal., 134, 179 (1992).

324. M. Asscher, J. Carrazza, M. Khan, K. Lewis, and G. A. Somorjai, J. Catal,, 98, 277 (1986).

325. M. E. Bussell, A. J. Gellman, and G. A. Somorjai, J. Catal., 110, 423 (1988).

326. M. E. Bussell and G. A. Somorjai, J. Phys. Chem., 93, 2009 (1989).

327. J. R. Engstrom, D. W. Goodman, and W. H. Weinberg, J. Am. Chem. Soc., 110,8305 (1988).

328. W. D. Gillespie, R. K. Herz, E. E. Petersen, and G. A. Somorjai, J. Catal., 70, 147 (1981).

329. S. M. Davis, F. Zaera, and G. A. Somorjai, J. Am. Chem. Soc., 104, 7453 (1982).

330. S. M. Davis, F. Zaera, and G. A. Somorjai, J. Catal., 85, 206 (1984).

331. E. L. Garfunkel and G. A. Somorjai, Surf. Sci., 115, 441 (1982). 
332. F. Zaera and G. A. Somorjai, J. Catal., 84, 375 (1983).

333. J. W. A. Sachtler and G. A. Somorjai, J. Catal., 81, 77 (1983).

334. R. C. Yeates and G. A. Somorjai, Surf. Sci., 134, 729 (1983).

335. G. S. Zafiris and R. J. Gorte, J. Catal., 140, 418 (1993).

336. X. P. Xu, J. W. He, and D. W. Goodman, Surf. Sci., 284, 103 (1993).

337. X. Xu and D. W. Goodman, J. Phys. Chem., 97, 683 (1993).

338. X. P. Xu and D. W. Goodman, Catal. Lett., 24, 31 (1994).

339. K. Coulter, X. Xu, and D. W. Goodman, J. Phys. Chem., 98, 1245 (1994).

340. J. W. He, X. Xu, J. S. Corneille, and D. W. Goodman, Surf. Sci., 279, 119 (1992).

341. R. Kramer and H. Zuegg, J. Catal., 85, 530 (1984).

342. M. Chen and L. D. Schmidt, J. Catal., 55, 348 (1978).

343. T. Wang and L. D. Schmidt, J. Catal., 71, 411 (1981).

344. J. Burkhardt and L. D. Schmidt, J. Catal., 116, 240 (1989).

345. J. G. Weissman, E. I. Ko, and P. Wynblatt, J. Catal., 125, 9 (1990).

346. D. J. Smith, M. H. Yao, L. F. Allard, and A. K. Datye, Catal. Lett., 31, 57 (1995).

347. P. Légaré and A. Fritsch, Surf. Interface Anal., 15, 698 (1990).

348. H. Poppa, C. A. Papageorgopoulos, and E. Bauer, Ultramicroscopy, 20, 145 (1986).

349. H. Poppa, F. Rumpf, R. D. Moorhead, and C. Henry, in Microstructure and Properties of Catalysts (M. M. J. Treacy, J. M. Thomas, and J. M. White, eds.) Materials Research Society, Pittsburgh, 1988, p. 1.

350. H. Poppa, Ultramicroscopy, 11, 105 (1983).

351. S. Ichikawa, H. Poppa, and M. Boudart, in Catalytic Materials: Relationship between Structure and Reactivity (T. E. Whyte, Jr., R. A. Dalla Betta, E. G. Derouane, and R. T. K. Baker, eds.), American Chemical Society, Washington, DC, 1984, p. 439.

352. E. I. Altman and R. J. Gorte, J. Catal., 110, 191 (1988).

353. E. I. Altman and R. J. Gorte, Surf. Sci., 216, 386 (1989).

354. S. Roberts and R. J. Gorte, Appl. Surf. Sci., 55, 135 (1992).

355. M. H. El-yakhloufi and E. Gillet, Catal. Lett., 17, 11 (1993).

356. K. Asakura, M. Shirai, and Y. Iwasawa, Catal. Lett., 20, 117 (1993).

357. J. G. Chen, J. E. Crowell, and J. T. Yates, Jr., Surf. Sci., 187, 243 (1987).

358. M. Valden, J. Aaltonen, E. Kuusisto, M. Pessa, and C. J. Barnes, Surf. Sci., 307-309, 193 (1994).

359. I. Stará and V. Matolín, Surf. Sci., 313, 99 (1994).

360. L. H. Dubois, P. K. Hansma, and G. A. Somorjai, Appl. Surf. Sci., 6, 173 (1980).

361. R. M. Kroeker, W. C. Kaska, and P. K. Hansma, J. Catal., 57, 72 (1979).

362. R. C. Jaklevic, L. Elie, and H. C. Yao, Surf. Sci., 171, 279 (1986).

363. J. Klein, A. Léger, S. D. Cheveigné, C. Guinet, M. Belin, and D. Defourneau, Surf. Sci., 82, L288 (1979).

364. R. M. Kroeker, W. C. Kaska, and P. K. Hansma, J. Catal., 61, 87 (1980).

365. J. Sotola and Z. Knor, J. Catal., 145, 501 (1994).

366. S. D. Bischke, D. W. Goodman, and J. L. Falconer, Surf. Sci., 150, 351 (1985).

367. E. I. Altman and R. J. Gorte, Surf. Sci., 172, 71 (1986).

368. B. G. Frederick, G. Apai, and T. N. Rhodin, Surf. Sci., 277, 337 (1992). 
369. H. Glassl, R. Kramer, and K. Hayek, J. Catal., 68, 397 (1981).

370. R. Kramer and H. Zuegg, J. Catal., 80, 446 (1983).

371. T. Wang, C. Lee, and L. D. Schmidt, Surf. Sci., 163, 181 (1985).

372. T. F. Hayden and J. A. Dumesic, J. Catal., 103, 366 (1987).

373. Y. F. Chu and E. Ruckenstein, J. Catal., 55, 281 (1978).

374. J. J. Chen and E. Ruckenstein, J. Catal., 69, 254 (1981).

375. K.-T. Kim and S.-K. Ihm, J. Catal., 96, 12 (1985).

376. H. Glass1, R. Kramer, and K. Hayek, J. Catal., 63, 167 (1980).

377. C. Linsmeier, H. Knoezinger, and E. Taglauer, Surf. Sci., 275, 101 (1992).

378. P. K. Hansma, D. A. Hickson, and J. A. Schwartz, J. Catal., 48, 237 (1977).

379. G. Fuchs, D. Neiman, and H. Poppa, Thin Solid Films, 207, 65 (1992).

380. S. Bourgeois, F. Jomard, and M. Perdereau, Surf. Sci., 249, 194 (1991).

381. J.-M. Pan and T. E. Madey, Catal. Lett., 20, 269 (1993).

382. H. R. Sadeghi and V. E. Henrich, J. Catal., 87, 279 (1984).

383. C. Ocal and S. Ferrer, J. Chem. Phys., 84, 6474 (1986).

384. S. Takatani and Y.-W. Chung, J. Catal, , 90, 75 (1984).

385. V. Andera, Appl. Surf. Sci., 51, 1 (1991).

386. A. V. Kalinkin and A. V. Pashis, React. Kinet. Catal. Lett., 46, 33 (1992).

387. A. V. Kalinkin and A. V. Pashis, React. Kinet. Catal. Lett., 46, 39 (1992).

388. S. Roberts and R. J. Gorte, J. Catal., 124, 553 (1990).

389. A. K. Datye, A. D. Logan, and K. J. Blankenburg, Ultramicroscopy, 34, 47 (1990).

390. K. Heinemann, T. Osaka, and H. Poppa, Ultramicroscopy, 12, 9 (1983).

391. R. A. Hubert and J. M. Gilles, Appl. Surf. Sci., 22/23, 631 (1985).

392. V. Matolín, K. Masek, M. H. Elyakhloufi, and E. Gillet, J. Catal., 143, 492 (1993).

393. V. Matolín, M. H. Elyakhloufi, K. Masek, and E. Gillet, Catal. Lett., 21, 175 (1993).

394. C. Goyhenex and C. R. Henry, J. Electr. Spectrosc. Rel. Phenom., 61, 65 (1992).

395. G. Apai and B. G. Frederick, Langmuir, 3, 395 (1987).

396. B. E. Handy, J. A. Dumesic, R. D. Sherwood, and R. T. K. Baker, J. Catal., 124, 160 (1990).

397. H. N. Aiyer, V. Vijayakrishnan, G. N. Subbanna, and C. N. R. Rao, Surf. Sci., 313, 392 (1994).

398. P. B. Smith, S. L. Bernasek, J. Schwartz, and G. S. McNulty, J. Am. Chem. Soc., 108, 5654 (1986).

399. M. Arai, T. Ishikawa, T. Nakayama, and Y. Nishiyama, J. Colloid Interf. Sci., 97, 254 (1984).

400. E. Ruckenstein and S. H. Lee, J. Catal., 109, 100 (1988).

401. E. Ruckenstein and X. D. Hu, J. Catal., 100, 1 (1986).

402. S. H. Lee and E. Ruckenstein, J. Catal., 107, 23 (1987).

403. D. Potoczna-Petru and L. Kepinski, Catal. Lett., 9, 355 (1991).

404. I. Sushumna and E. Ruckenstein, J. Catal., 94, 239 (1985).

405. E. G. Derouane, R. T. K. Baker, J. A. Dumesic, and R. D. Sherwood, J. Catal., 69,101 (1981).

406. T. Wang and L. D. Schmidt, J. Catal., 66, 301 (1980).

407. R. Lamber and G. Schulz-Ekloff, Surf. Sci., 258, 107 (1991). 
408. E. Ruckenstein and J. J. Chen, J. Colloid Interf. Sci., 86, 1 (1982).

409. R. T. K. Baker, E. B. Prestridge, and G. B. McVicker, J. Catal., 89, 422 (1984).

410. R. T. K. Baker and J. A. France, J. Catal., 39, 481 (1975).

411. R. T. K. Baker, E. B. Prestridge, and R. L. Garten, J. Catal., 56, 390 (1979).

412. K. N. Rai, in Sintered Metal-Ceramic Composites (G. S. Upadhyaya, ed.), Elsevier, Amsterdam, 1984, p. 145.

413. R. T. K. Baker, C. Thomas, and R. B. Thomas, J. Catal., 38, 510 (1975).

414. E. Ruckenstein and Y. F. Chu, J. Catal., 59, 109 (1979).

415. I. Sushumna and E. Ruckenstein, J. Catal., 109, 433 (1988).

416. I. Sushumna and E. Ruckenstein, J. Catal., 108, 77 (1987).

417. P. Wynblatt and N. A. Gjostein, Scripta Metall., 7, 969 (1973).

418. J. E. Stulga, P. Wynblatt, and J. K. Tien, J. Catal., 62, 59 (1980).

419. R. Gollob and D. B. Dadyburjor, J. Catal., 68, 473 (1981).

420. Y. F. Chu and E. Ruckenstein, Surf. Sci., 67, 517 (1977).

421. H. E. Evans, W. M. Bowser, and W. H. Weinberg, Surf. Sci., 85, L497 (1979).

422. J. R. Andersen, R. J. MacDonald, and Y. J. Shimoyama, J. Catal., 20, 147 (1971).

423. A. D. Logan and M. T. Paffett, J. Catal., 133, 179 (1992).

424. L. Kieken and M. Boudart, Catal. Lett., 17, 1 (1993). 